NBER WORKING PAPER SERIES

\title{
LOCATION AS AN ASSET
}

\author{
Adrien Bilal \\ Esteban Rossi-Hansberg \\ Working Paper 24867 \\ http://www.nber.org/papers/w24867
}

\author{
NATIONAL BUREAU OF ECONOMIC RESEARCH \\ 1050 Massachusetts Avenue \\ Cambridge, MA 02138 \\ July 2018
}

We thank Pablo Fajgelbaum, Eduardo Morales, Yasusada Murata, Diego Puga, Steve Redding, Matt Turner and numerous seminar participants for useful comments. None of the authors had any financial relationship that affected the work or conclusions of this paper. The views expressed herein are those of the authors and do not necessarily reflect the views of the National Bureau of Economic Research.

NBER working papers are circulated for discussion and comment purposes. They have not been peer-reviewed or been subject to the review by the NBER Board of Directors that accompanies official NBER publications.

(C) 2018 by Adrien Bilal and Esteban Rossi-Hansberg. All rights reserved. Short sections of text, not to exceed two paragraphs, may be quoted without explicit permission provided that full credit, including $\odot$ notice, is given to the source. 
Location as an Asset

Adrien Bilal and Esteban Rossi-Hansberg

NBER Working Paper No. 24867

July 2018

JEL No. D14,E21,J61,J62,R13,R23,R30

\begin{abstract}
The location of individuals determines their job opportunities, living amenities, and housing costs. We argue that it is useful to conceptualize the location choice of individuals as a decision to invest in a 'location asset.' This asset has a cost equal to the location's rent, and a payoff through better job opportunities and, potentially, more human capital for the individual and her children. As with any asset, savers in the location asset transfer resources into the future by going to expensive locations with good future opportunities. In contrast, borrowers transfer resources to the present by going to cheap locations that offer few other advantages. As in a standard portfolio problem, holdings of this asset depend on the comparison of its rate of return with that of other assets. Differently from other assets, the location asset is not subject to borrowing constraints, so it is used by individuals with little or no wealth that want to borrow. We provide an analytical model to make this idea precise and to derive a number of related implications, including an agent's mobility choices after experiencing negative income shocks. The model can rationalize why low wealth individuals locate in low income regions with low opportunities even in the absence of mobility costs. We document the investment dimension of location, and confirm the core predictions of our theory with French individual panel data from tax returns.
\end{abstract}

\author{
Adrien Bilal \\ Princeton University \\ abilal@princeton.edu \\ Esteban Rossi-Hansberg \\ Princeton University \\ Department of Economics \\ 289 Julis Romo Rabinowitz Building \\ Princeton, NJ 08544-1021 \\ and NBER \\ erossi@princeton.edu
}




\title{
Location as an Asset*
}

\author{
Adrien Bilal \\ Princeton University
}

\author{
Esteban Rossi-Hansberg \\ Princeton University
}

July 19, 2018

\begin{abstract}
The location of individuals determines their job opportunities, living amenities, and housing costs. We argue that it is useful to conceptualize the location choice of individuals as a decision to invest in a 'location asset'. This asset has a cost equal to the location's rent, and a payoff through better job opportunities and, potentially, more human capital for the individual and her children. As with any asset, savers in the location asset transfer resources into the future by going to expensive locations with good future opportunities. In contrast, borrowers transfer resources to the present by going to cheap locations that offer few other advantages. As in a standard portfolio problem, holdings of this asset depend on the comparison of its rate of return with that of other assets. Differently from other assets, the location asset is not subject to borrowing constraints, so it is used by individuals with little or no wealth that want to borrow. We provide an analytical model to make this idea precise and to derive a number of related implications, including an agent's mobility choices after experiencing negative income shocks. The model can rationalize why low wealth individuals locate in low income regions with low opportunities even in the absence of mobility costs. We document the investment dimension of location, and confirm the core predictions of our theory with French individual panel data from tax returns.
\end{abstract}

\section{Introduction}

Few decisions shape an individual's life more than the location decision. It determines job opportunities, social interactions, schooling and entertainment options, as well as a number of other less central characteristics of someone's life. The location decision is essential particularly because of the large heterogeneity in location characteristics, even within a country, a state, a region, or a city. Living in Soho in Manhattan is quite different than living in Queens, and a world apart from living in parts of Newark or Camden, New Jersey. These spatial differences are enormous. Life prospects for a kid growing in Palo Alto are staggeringly different than those for someone growing in central Detroit, even if they come from similar backgrounds and

*Bilal: abilal@princeton.edu Rossi-Hansberg: erossi@princeton.edu. We thank Pablo Fajgelbaum, Eduardo Morales, Yasusada Murata, Diego Puga, Steve Redding, Matt Turner and numerous seminar participants for useful comments. 
both go to local public schools. The obvious question that arises is then, why do people remain in some of these locations? Why do we fail to see people go to the locations that offer the best prospects for them and for their families?

Three main answers have been offered to these questions in the economics literature. The first one relies on the presence of large migration costs that make moving to better locations not worth the cost.1 The second one argues that local living costs, as reflected in housing and other local prices, compensate for other local benefits over the residency period. The third one simply argues that agents 'cannot afford' to live in some places perhaps due to indivisibilities in housing. The problem with the first explanation is that it is hard to imagine that moving costs are sufficient to bridge the gap between the best and worse neighborhoods in virtually all regions of the world. These largely unobserved costs seem to be just a stand-in for another mechanism. As for the other two explanations, although housing and other local costs can differ substantially across regions, adjusting the size of one's apartment, commuting from cheaper locations, and buying in big-boxed stores and other national retailers are effective strategies to deal with local prices $2^{2}$ Something is missing from this basic notion of static spatial equilibrium where similar marginal movers equalize utility across locations adjusted for moving costs.

In this paper we propose a different way of conceptualizing the location decision of agents. We argue that the location decision can be understood as an asset investment decision. Buying more of the asset involves moving to better locations that cost more today but give better returns tomorrow, while selling the asset implies moving to cheaper locations with little opportunities. The 'location as an asset' view can explain why agents prefer locations that seem undesirable from a static spatial equilibrium perspective even in the absence of moving costs. It can also explain why local living costs compensate the benefits from desirable locations for some agents but not for others, even in the absence of non-homotheticities or differences in preferences. The 'location asset' should not be confused with 'an asset at a location', like a house. The location asset is used by all agents, including renters and owners, when they make location choices 3

The location asset has some specific features that make it different than other assets and determine their use. As any other asset, unconstrained agents own it only to the extent that the return from doing so dominates that of other assets, in particular risk free bonds. The unique characteristic of the location asset is that it is not subject to borrowing constraints. Agents can always borrow, namely, transfer resources from the future to the present, by going to cheaper location with worse opportunities. If an agent is not in the worst possible location already, she can keep transferring resources from the future to the present by 'selling' the location asset. The other unique characteristic of this asset is that the amount of the asset that

\footnotetext{
${ }^{1}$ Kennan and Walker (2011) estimate that moving costs as large as $\$ 380$ thousand 2010 dollars (for young movers, 312 thousand for average ones) are needed to account for observed migration flows using a state-of-the-art model of location decisions. Diamond, McQuade, and Qian (2017) using a policy that implements rent-controls in the San Francisco area find a smaller but still large fixed cost of around $\$ 40$ thousand.

${ }^{2}$ Another potential reason for these location choices are non-homotheticities in preferences: the less wealthy simply like certain amenities better and the locations that have them are the ones with worse opportunities.

${ }^{3}$ We view housing wealth as financial wealth that is perhaps less liquid. So borrowers will run it down completely before they become financially constrained and start using the location asset to transfer resources intertemporally.
} 
an agent can hold is limited by the housing needs, labor supply, fertility decisions and other choices that determine the current cost and the future benefits of living in a particular location. As such, the asset has heterogenous returns depending on the holder of the asset.

Conceptualizing location decisions as buying and selling a 'location asset' is useful to understand mobility decisions. Consider an agent with little or no wealth that receives a front-loaded income shock. For example, a blue-collar worker in the automobile industry in Detroit that gets fired. Where will she go? A good neighborhood with excellent schools for her children and plenty of job opportunities or a run-down neighborhood in Saint Louis? Think first about the consumption-savings decision of this agent. The frontloaded shock makes her want to transfer consumption from the future to the present. In the absence of accumulated wealth, smoothing consumption requires borrowing. The absence of collateral, however, implies that she will be constrained to borrow using standard financial assets. What is left is to borrow using the location asset and downgrade to a cheaper location with worse opportunities. Hence, constrained agents that receive bad shocks will have a higher demand for locations that offer few opportunities at minimal cost. Similarly, front-loaded positive shocks will make constrained individuals upgrade location so as to save using the location asset.

Multiple implications follow. For example, changes in the rewards for particular occupations will result in front-loaded shocks for dynastic families, since heads-of-households have already invested in an occupation while their descendants have yet to choose. Hence, these changes in rewards will lead to spatial segregation as auto workers who borrow locate in Detroit and computer programmers and Yoga teachers who save locate in Palo Alto. Our view also implies that low rates of return in financial market (e.g. low interest rates) result in low rates of return of the 'location asset' and therefore larger price differentials across locations, reminiscent of the low interest rate period after the 2008 financial crisis where some of the differentials in house prices increased. Finally, our view underscores that place-based policies may hurt the currently poor as they reduce the supply of cheap locations where those individuals may prefer to locate.

To make precise our conceptualization of the location decision as an asset that does not face borrowing constraints, we start by proposing a simple two period economy where agents have heterogenous asset holdings, incomes, and levels of skills. Agents have access to a risk free bond but face a standard borrowing constraint that prevents them from borrowing beyond an exogenous amount. Individuals choose a consumption profile and a location, which in turn determines their current rent and income next period as a function of their skill. There is a continuum of locations that differ in the marginal return of a unit of skill. In equilibrium wealthy agents locate in their ideal city conditional on their skill, while constrained individuals, either because they have low assets levels or back-loaded incomes, locate in cities that pay less but where rents are lower. Namely, they borrow using the location asset. Back and front-loaded shocks have the effects described above.

We then present a fully-fledged infinite horizon dynamic model with similar characteristics in order to generalize our findings and provide a framework that is potentially closer to quantitative analysis. Agents now face an idiosyncratic income process. The main advantage of this framework relative to our simple 
two-period framework is that wealth is now endogenous and we can compute an invariant wealth distribution, and, perhaps more importantly, that we can use it to understand the reaction of constrained and unconstrained dynasties to transitory and permanent income shocks over multiple periods. The drawback of this more complex framework is that our analysis is based on numerical simulations only. As a result of an idiosyncratic temporary income shock, unconstrained individuals first run down their financial assets until they are at the borrowing constraint. Once there, they start borrowing using the location asset and so downgrade their location in order to minimize fluctuations in their level of consumption. This downgrading of location continues until individuals reach the worse location they are willing to go to, or the income shock reverts to the high value. Once the temporary shock has reverted, individuals go back to the initial location progressively:4

The implications of the 'location as an asset' view are sharp. Negative (positive) front-loaded shocks should make constrained individuals downgrade (upgrade) location, while unconstrained agents should not change their location. To contrast these predictions with empirical evidence we use detailed individual panel data from France. We use a longitudinal $4 \%$ panel of workers which allows us to track the same individual over several years. The dataset provides us with the wage of employed individuals together with their location and a number of other characteristics. Consistent with our model, we order locations according to the average income of local residents to obtain a ranking of locations.

We first document that moving to locations with a higher rank pays off gradually over time. We find that the returns to moving to the best location relative to moving to the worst double after 7 years for observationally equivalent individuals. Comparing similar individuals, movers to the best location relative to movers to the worst location receive wages that are $10 \%$ higher upon moving, but that gap widens to $20 \%$ after 7 years. These findings support the view that moving to better locations pays off gradually over time, thus underscoring the importance of the investment aspect of location 5

We then proceed to study empirically the location decisions of individuals that experience unemployment spells. We track how the rank of an individual's location changes when they find a new job. The results are stark, individuals that start at the bottom quintile of the distribution of income in their location (and so are presumably more financially constrained) downgrade their location by about 5 percentile points relative to

\footnotetext{
${ }^{4}$ Our infinite horizon model shares many features with dynamic portfolio problems with investors who face a credit constraint on risk-free bonds. Thus, we build a Huggett (1993) economy with a second asset: the 'location asset'. In particular, our model could be viewed as one in which possibly constrained entrepreneurs choose in which project to invest (the location), subject to a collateral constraint. Related work includes but is not limited to Angeletos (2007) and Moll (2014). Our framework is distinct from those in two dimensions. First, we model both risk-aversion and idiosyncratic additive income shocks on the investor side, leading individuals to use the location asset to smooth consumption when they are close to the constraint. Second, individuals in our model always wish to hold a convex combination of both assets, due to the endogenously nonlinear returns of the 'location asset'.

${ }^{5}$ Glaeser and Mare (2001) find some evidence in the U.S. for dynamic gains from migrating to larger cities. Also in the U.S. Baum-Snow and Pavan (2012) show in a structural model that differences in initial wages are important drivers of pay differentials between small cities, while differences in wage growth explain a large part of pay differentials between larger cities. De La Roca and Puga (2017) use Spanish administrative data to show that the returns to mobility between cities of different sizes accrue partly over time. Although our ranking of locations is different since it relies on income rather than size, they obtain similar magnitudes.
} 
individuals at the top quintile. Conditional on moving, the location rank falls by as much as 15 percentile points. These results are robust to a battery of municipality, occupation, industry, birthplace and age fixed effect. Our theory also predicts that individuals sort positively across places based partly on their income. Therefore, we expect selection to bias our estimates downwards. Consistently, after an unemployment spell, the relative location rank of an individual falls by 35 percentile points when controlling for past wages. Of course, the relative downgrading of an individual's location might potentially be the result of obtaining a job that pays lower wages after their unemployment spells, consuming different amounts of local amenities, or adjusting commuting, and this might be related to their origin wage percentile. However, when we control for post-unemployment wages, commuting distance and local amenities, our results are essentially unchanged. This indicates that the downgrading of location is not simply reflecting the static choice to consume less amenities 6

The empirical analysis described so far uses an individual's location in her municipality's income distribution as a proxy for the likelihood of being financial constrained. Of course, although this proxy is justified by our theory, it is not a direct measure of assets. We do not observe an individual's financial assets, but we can leverage the longitudinal dimension of our data and construct a measure of assets by accumulating savings derived from observed wage profiles and a simple model of intertemporal consumption choices. As with our previous measure, constrained individuals downgrade their location as a result of an unemployment shock. Given its construction, there can be measurement error in this measure of assets, which would bias the relative downgrading effect towards zero. Nevertheless, we estimate that after an unemployment spell individuals at the bottom of the local asset distribution downgrade 8 percentile points relative to agents at the top. As expected, when we allow this effect to vary by a location rank's decile, we find that individuals use the 'location asset' more in poorer places. These facts are, as far we know, unknown to the literature and can be estimated precisely given the large number of observations in our data.

There is a large literature documenting the large variation in income levels and other outcomes across locations 7 Kennan and Walker (2011) argue forcefully that inter-state migration decisions are made based on income prospects, but are also influenced importantly by geographic differences. In fact, Diamond (2016) and Giannone (2017) show that the U.S. has experienced increasing skill segregation, indicating that spatial gaps are not diminishing. Kaplan and Schulholfer-Whol (2017) show that mobility in the U.S. is declining 8 Going one step further, Fogli and Guerrieri (2018) argue that spatial segregation is related to income inequality because it affects the returns to human capital and therefore offspring's education.

Most equilibrium analysis of individual location choices is either cast in partial equilibrium and so does

\footnotetext{
${ }^{6}$ Note that downgrading location due to a simple static choice to consume less urban amenities as a result of the nonemployment spell is not consistent with our results. The reason is that, absent financial constraints, if two individuals live in the same location but have different incomes, the high income individual is the one that loses more at impact from nonemployment and for whom location is more elastic. Hence, if anything, the high income individual necessarily downgrades more. We prove this result formally in Appendix B.2.

${ }^{7}$ See Wilson (1987), Denton and Massey (1993), Cutler and Glaeser (1997), Desmet and Rossi-Hansberg (2013), Altonji and Mansfield (2014), and Hsieh and Moretti (2018) among many other.

${ }^{8}$ Kaplan and Schulhofer-Wohl (2017) link the decline in U.S. mobility to falling wage differentials within occupations.
} 
not consider the valuation side of the 'location as an asset' view (like Kennan and Walker, 2011, or Diamond, 2016) or static and based on a simple spatial equilibrium condition that does not include the investment aspect of location decisions (like Desmet and Rossi-Hansberg, 2013, Allen and Arkolakis, 2014, Redding, 2016, or Caliendo et al., 2018). Giannone (2017) and Desmet, Nagy and Rossi-Hansberg (2018) do provide dynamic general equilibrium setups with costly migration, but migration decisions only provide static gains or losses. In Caliendo, Dvorkin and Parro (2017) agents solve forward looking problems in deciding their location but they simply consume their income and so do not solve a consumption-savings decision or accumulate wealth.

The view of investment as an asset was hinted at initially by Sjaastad (1962). Lucas (2004), Morten (2017) and Calvacanti-Ferreira et al. (2016) also present evidence and arguments to view migration as a stepping-stone or a form of self-insurance 9 Some of the most detailed studies of mobility for low income, and likely constrained individuals, are consistent with the 'location as an asset' view. For example, in the "Moving to Opportunity" randomized experiment, conditioning aid on upgrading location reduced the use of housing vouchers by about a third (21 percentage points). Furthermore, while the literature using this experiment initially found that economic outcomes were not affected by an upgrade in location (Duncan et al., 2013), the most recent studies have found strong evidence that the outcomes for children that moved when young are positive (Chetty, et al., 2016, and Davis et al., 2017), consistent with our emphasis on the investment dimension of location decisions rather than on the current benefits. Using tax records, Chetty and Hendren (2017) found a trade-off between child future earnings and rents. They estimate that a $1 \%$ increase in a child's future earnings can be achieved by moving to a location with a median rent that is $\$ 176$ higher. The 'location as an asset' view argues that constrained agents might not want to take what seems like a good bargain, since they are constrained and want to borrow not invest further.

The rest of the paper is organized as follows. The next section, Section 2, introduces the simplest model necessary to make precise our notion of location decisions as investment decisions. This simple two period model is then extended to an infinite horizon model in Section 3. In that section we present examples of the implied dynamic consumption, asset, and location paths of individuals. Section 4 presents our empirical analysis using the French individual level panel to show that agent's location decision respond to nonemployment spells as our theory predicts. Section 5 concludes. An Appendix includes the technical proofs, additional robustness tests, and detailed data descriptions.

\section{A Simple Model}

We aim to provide the simplest setup in which our 'location as an asset' view can be made precise. Because we need location to be an investment, we need a model with at least two periods. Hence, we model an economy over periods 0 and 1 . The economy consists of a unit mass of individuals that differ in their skill, $s \in[\underline{s}, \bar{s}]$, and their income in period 0 and $1,\left\{y_{t}\right\}_{t=0}^{1} \in\left[\underline{y}_{t}, \bar{y}_{t}\right]$. The income of the individual in

\footnotetext{
${ }^{9}$ Fernandez and Rogerson (1998) and Fogli and Guerreri (2018) discuss the trade-off between location and children education.
} 
period 0 includes her labor income plus any wealth she is initially endowed with. In sum, an individual is characterized by a triplet $\left(y_{0}, y_{1}, s\right)$. We denote the joint probability density function over these outcomes by $f$ and the cumulative distribution by $F$.

There is a continuum of locations or 'cities'. We classified cities according to the complementarity of the returns from living in them with the skills of individuals. We denote locations by an index $z \in[\underline{z}, \bar{z}]$ with $\underline{z} \geq 0$. The density of cities with characteristic $z$ is given by $h$ with cumulative density $H$. The skill of an individual determines the benefits from locating in cities. We assume that the returns for an individual of skill $s$ to living in city $z$ are given by $z s$. Agents can move freely across locations. Hence, the supermodularity of this function will lead to positive assortative matching conditional on other individual characteristics, as we describe below.

The population density, $L(z)$, of individuals living in cities of type $z$, as well as land rents, $q(z)$, in those cities are determined endogenously. We assume that the cost of supplying housing increases with population size due to some form of decreasing returns. Hence,

$$
q(z)=Q(L(z)) \text { for } z \in[\underline{z}, \bar{z}]
$$

where $Q(0)=0$ and $Q$ strictly increasing. That is, housing is free in locations without population and rents are strictly increasing in city size.

Individuals have access to a risk free bond with gross interest $R>1$. We assume that this world interest rate is exogenous and determined in world markets 10 Agents are subject to a standard borrowing constraint that limits their asset holdings between period 0 and $1, a$, to be above some level $\underline{a}$. Hence, if, for example $\underline{a}=0$, agents can only save but not borrow with the financial asset.

\subsection{Asset and Location Choices}

Households maximize lifetime utility with a discount factor given by $\beta \leq 1$. For simplicity we specify the period utility function as $u(c)=\log c$ but virtually all our results go through for any concave utility function that satisfies Inada conditions. The problem of a household is then to choose consumption in each period, purchases of the risk free bond, and location in period 1 , to solve

$$
\begin{array}{ll} 
& V\left(y_{0}, y_{1}, s\right)=\max _{c_{0}, c_{1}, a, z} \log c_{0}+\beta \log c_{1} \\
\text { s.t. } & c_{0}+a+q(z)=y_{0} \\
& c_{1}=z s+y_{1}+R a \\
& a \geq \underline{a} .
\end{array}
$$

That is, individuals maximize utility subject to budget constraints each period, as well as the borrowing

\footnotetext{
${ }^{10}$ Technically, we only need $R>0$, which we can allow without loss of generality. In addition, it would be simple to endogenize the interest rate $R$ through an asset market clearing condition without changing any of our core results.
} 
constraint. In period zero, an agent's income includes anything he earns today and all of his wealth. Note that we have abstracted from any returns from the complementarity between an agent's skill and the city where she starts (say, $z_{0} s$ ). We think of this term as also being embedded in $y_{0}$. Not explicitly recognizing this term explicitly avoids carrying $z_{0}$ as a state variable in the consumer problem. This is without loss of generality given that free mobility implies that current location only affects an agent's decisions through current income.

Note also that we make the agent pay rent one period in advance. So land rent for their chosen $z$ location, $q(z)$, enters the left-hand-side of the period 0 budget constraint only. Rent paid for living in location $z_{0}$ in period 0 is not modeled and would simply be included in the resulting period 0 income. Making household pay rent one period in advance underscores the investment nature of the location choice. Namely, it recognizes that the good jobs, amenities, or education associated with living in a good location are enjoyed over time and not necessarily immediately after arriving there. Furthermore, although we do not incorporate other current urban costs as commuting, congestion, or crime, or urban benefits as amenities, all of them can be thought of as included in the net current price of location $q(z)$.

The problem above abstracts from a flexible housing demand choice since it makes anyone living in location $z$ pay the same cost $q(z)$. We decided not to incorporate this margin explicitly because, absent adjustment costs, the housing demand choice is a static choice that does not eliminate or prevent the use of the location asset (although it can affect its return).11 The problem in (1) also abstracts from income risk. In the next section we write a multi-period extension with uncertainty about the realization of the income process. However, in this simple model without uncertainty, the location asset is used to transfer consumption across time, but not across states of nature or for precautionary purposes. Of course, in a richer environment the location asset could also be used for these alternative purposes.

The first-order conditions of the problem in (1) imply the standard 'Financial Euler equation'

$$
\frac{c_{1}^{*}\left(y_{0}, y_{1}, s\right)}{\beta c_{0}^{*}\left(y_{0}, y_{1}, s\right)} \geq R \text { for all }\left(y_{0}, y_{1}, s\right)
$$

with equality if and only if the borrowing constraint is not binding, namely $a^{*}\left(y_{0}, y_{1}, s\right)>\underline{a}$. We denote all individual optimal choices with an asterisk $\left(^{*}\right)$.

Absent borrowing constraints, the desired asset holdings of an individual $\left(y_{0}, y_{1}, s\right)$, denoted by $\tilde{a}\left(y_{0}, y_{1}, s\right)$, are given by their income net of rents in period zero $\left(y_{0}-q(z)\right)$ minus permanent consumption, which is given by $\left(y_{0}+\frac{y_{1}+z^{*} s}{R}-q\left(z^{*}\right)\right) /(1+\beta) 12$ Namely,

$$
\tilde{a}\left(y_{0}, y_{1}, s\right)=y_{0}-q\left(z^{*}\left(y_{0}, y_{1}, s\right)\right)-\frac{y_{0}+\frac{y_{1}+z^{*}\left(y_{0}, y_{1}, s\right) s}{R}-q\left(z^{*}\left(y_{0}, y_{1}, s\right)\right)}{1+\beta} .
$$

\footnotetext{
${ }^{11}$ In Appendix B.1 we develop an extension where agents can choose the size of their house and pay a prize $q(z)+p \ell$ for renting $\ell$ units of housing in location $z$.

${ }^{12}$ Whenever it is clear by the context we abbreviate optimal choices and do not write the dependence on the agent's type. Namely, we might write $z^{*}$ instead of $z^{*}\left(y_{0}, y_{1}, s\right)$.
} 
Thus, actual savings in the financial asset are given by

$$
a^{*}\left(y_{0}, y_{1}, s\right)=\max \left\{\tilde{a}\left(y_{0}, y_{1}, s\right), \underline{a}\right\} .
$$

Free mobility implies that individuals are never constrained in the 'location asset'. Hence, for all agents, the location decision yields a 'Mobility Euler equation' given by

$$
\frac{c_{1}^{*}\left(y_{0}, y_{1}, s\right)}{\beta c_{0}^{*}\left(y_{0}, y_{1}, s\right)}=\frac{s}{q^{\prime}\left(z^{*}\left(y_{0}, y_{1}, s\right)\right)}
$$

for all $\left(y_{0}, y_{1}, s\right)$.

Hence agents can optimize their intertemporal consumption path by choosing their holdings of financial assets and what we have dubbed the 'location asset'. To make the analogy with a standard asset more precise, we can propose two interpretations. First, one in which each location $z$ constitutes an asset, and agents moving to location $z$ buy the asset, and the ones moving out sell it. How much of it they buy is limited by their housing demand and labor supply. Here, for simplicity, we have limited labor supply and housing demand to be equal to one. The return of the asset depends on the skill of the individual, $s$, and is given by the right-hand-side of equation (3), namely, $s / q^{\prime}\left(z^{*}\right)$.

An alternative interpretation is to consider only a single asset with unit cost. The quantity purchased of the asset is equal to the housing costs, $q$, and returns of the asset depend both on the quantity purchased and the skill of the individual. Again, those returns are given by $s / q^{\prime}\left(z^{*}\right)$. Under both these interpretations, the individual's problem (1) can be seen as a standard portfolio choice problem in which the risk-free bond is subject to a borrowing constraint, and the return to the 'location asset' is endogenously nonlinear and specific the individual's skill.

We are ready to define a competitive equilibrium in our economy.

Definition 1 Given a distribution $F$ of triplets $\left(y_{0}, y_{1}, s\right) \in\left[\underline{y}_{0}, \bar{y}_{0}\right] \times\left[\underline{y}_{1}, \bar{y}_{1}\right] \times[\underline{s}, \bar{s}]$ and an interest rate $R$, an equilibrium is a set of individual decision functions $c_{0}^{*}, c_{1}^{*}, a^{*}:\left[\underline{y}_{0}, \bar{y}_{0}\right] \times\left[\underline{y}_{1}, \bar{y}_{1}\right] \times[\underline{s}, \bar{s}] \rightarrow \mathbb{R}_{+}$and $z^{*}:\left[\underline{y}_{0}, \bar{y}_{0}\right] \times\left[\underline{y}_{1}, \bar{y}_{1}\right] \times[\underline{s}, \bar{s}] \rightarrow[\underline{z}, \bar{z}]$, and rent and population functions $q, L:[\underline{z}, \bar{z}] \rightarrow \mathbb{R}_{+}$such that

- individuals solve the problem in (1) and

- land rents are such that $q(z)=Q(L(z))$ for $z \in[\underline{z}, \bar{z}]$ where city population $L(z)$ satisfies

$$
\int_{\underline{z}}^{z} L(z) H(d z)=\int_{\underline{y}_{0}}^{\bar{y}_{0}} \int_{\underline{y}_{1}}^{\bar{y}_{1}} \int_{\underline{s}}^{\bar{s}} \mathbf{1}\left[z^{*}\left(y_{0}, y_{1}, s\right) \leq z\right] F\left(d y_{0}, d y_{1}, d s\right) \text { for all } z \in[\underline{z}, \bar{z}]
$$

and 1 denotes the indicator function.

Condition (4) guarantees that the number of people in locations worse that $z$ (the left-hand-side of the condition) is equal to the number of people that choose to live in those locations (the right-hand-side of 
the condition). Note that Condition (4) has to hold for all $z \in[\underline{z}, \bar{z}]$ and so it implicitly determines the population density function $L(z)$.

\subsection{Equilibrium Allocation and House Rents}

In order to understand agent's location choices, consider a city $z$ in which an unconstrained individual $\left(y_{0}, y_{1}, s\right)$ lives. Because $a^{*}\left(y_{0}, y_{1}, s\right)>\underline{a}$, equation 2 holds with equality and so the returns she faces on the financial and the location asset need to be equal. That is,

$$
R=\frac{s}{q^{\prime}\left(z^{*}\left(y_{0}, y_{1}, s\right)\right)}
$$

This implies that unconstrained individuals sort into cities on the basis of their skill component $s$ only. Then, if $q(\cdot)$ is a strictly increasing function (something we show below), there exists a matching function $\mathcal{Z}^{U}(s)=z^{*}\left(y_{0}, y_{1}, s\right)$ for unconstrained individuals, such that

$$
R=\frac{s}{q^{\prime}\left(\mathcal{Z}^{U}(s)\right)}
$$

Furthermore, when $q(\cdot)$ is convex (which we also show below), $\mathcal{Z}^{U}(s)$ is strictly increasing. Of course, whether individuals are constrained on the financial asset depends on their income path and skill, and the resulting location choice. For example, a flat income path with $y_{0}$ high relative to the values of future income, $y_{1}$, and skill, $s$, implies that the individual is not constrained.

Now consider an individual with the same $y_{1}$ and $s$ but low enough $y_{0}^{\prime}<y_{0}$ such that she is constrained. This individual has a larger marginal rate of substitution than the interest rate, so the Financial Euler equation (2) holds with strict inequality. Since the agent can still use the location asset, and so (3) holds, this implies that $s / q^{\prime}\left(\mathcal{Z}^{U}(s)\right)=R<s / q^{\prime}\left(\mathcal{Z}^{C}\left(y_{0}^{\prime}, y_{1}, s\right)\right)$ where $\mathcal{Z}^{C}\left(y_{0}^{\prime}, y_{1}, s\right)$ is the constrained agent's location choice. Note that the constrained agent's location choice depends on all the individual characteristics, not just $s$. Hence, for $q(\cdot)$ strictly increasing, $\mathcal{Z}^{U}(s)>\mathcal{Z}^{C}\left(y_{0}^{\prime}, y_{1}, s\right)$. Constrained individuals locate in cities with lower land rents and lower returns to skill than unconstrained individuals with the same skills. The reason is that they use the location asset rather than the financial asset to adjust their intertemporal consumption path. More specifically, they borrow using the location asset to transfer resources to the present, something financial markets do not allow them to do.

$\mathcal{Z}^{C}\left(y_{0}, y_{1}, s\right)$ is increasing in $y_{0}$ and in fact will converge to $\mathcal{Z}^{U}(s)$ as we increase $y_{0}$. In contrast, it is decreasing in $y_{1}$, since larger future income results in larger need to borrow from the future and therefore more use of the location asset to do so. Finally, more skilled individuals locate in better cities, whether constrained or unconstrained, due to the skill complementary we introduce in individual earnings. Note that the reason the individual location choice is always uniquely determined is our setup is the supermodular income in $z$ and $s$. In contrast, if agents had identical skills, they would be indifferent about where to locate when unconstrained, but their use of the location asset to transfer consumption to the present would still 
determine their location choice when constrained. We formalize this discussion in the following lemma that characterizes the location decision of agents.

Lemma 1 There exists a pair of matching functions $\mathcal{Z}^{U} \underset{+}{s} \underset{+}{\text { and }} \underset{\mathcal{Z}^{C}}{\left(y_{0}, y_{1}, s\right)}$ such that individual $\left(y_{0}, y_{1}, s\right)$ chooses city

- $z^{*}\left(y_{0}, y_{1}, s\right)=\mathcal{Z}^{U}(s)$ if $y_{0} \geq Y_{0}\left(y_{1}, s\right)$, so she is unconstrained, and

- $z^{*}\left(y_{0}, y_{1}, s\right)=\mathcal{Z}^{C}\left(y_{0}, y_{1}, s\right)<\mathcal{Z}^{U}(s)$ if $y_{0}<Y_{0}\left(y_{1}, s\right)$, so she is constrained,

where

$$
\begin{aligned}
\underset{+}{Y_{0}\left(y_{1}, s\right)} & =\left\{y_{0} \mid a^{*}\left(y_{0}, y_{1}, s\right)>\underline{a}\right\} \\
& =\left(1+\beta^{-1}\right) \underline{a}+q\left(\mathcal{Z}^{U}(s)\right)+\frac{y_{1}+s \mathcal{Z}^{U}(s)}{\beta R}
\end{aligned}
$$

and $\mathcal{Z}^{U}$ and $\mathcal{Z}^{C}$ are determined by a system of ordinary differential equations described in Appendix A.1.

Proof. See Appendix A.1

Lemma 1 characterizes the threshold for current income $y_{0}$ that determines whether an individual is constrained using the function $Y_{0}\left(y_{1}, s\right)$. Because the rent function is increasing in $z$ as we show below, and since $\mathcal{Z}^{U}(s)$ is increasing in $s$, this threshold is increasing in both arguments. More future income makes unconstrained individuals want to consume more in the present and therefore makes the constraint on borrowing more binding. Similarly, more skilled individuals will earn more in the future and will live in more expensive cities, making the constraint more binding.

Of course, given the monotonicity of $\mathcal{Z}^{U}(s)$ and $\mathcal{Z}^{C}\left(y_{0}, y_{1}, s\right)$ in $s$, we can define the inverse as $\mathcal{S}^{U}(z)=$ $\mathcal{Z}^{U-1}(z)$ and $\mathcal{S}^{C}\left(y_{0}, y_{1}, z\right)=\mathcal{Z}^{C-1}\left(y_{0}, y_{1}, z\right)$. These functions then tell us the skill of the set of constrained and unconstrained individuals that live in a given city $z$. In equilibrium, unconstrained individuals always locate in better cities than constrained ones, hence there exists a threshold $\hat{z}$ such that for $z<\hat{z}$ all individuals in the city are constrained and above that we have a mixed of constrained and unconstrained individuals. The best city, $\bar{z}$, is an exception and has no constrained agents. The following corollary states these results formally.

Corollary 2 There exists a threshold $\hat{z}$ such that individuals in city $z \geq \hat{z}$ are either

- unconstrained with skill $s=\mathcal{S}^{U}(\underset{+}{z})$ and $y_{0} \geq Y_{0}\left(y_{1}, \mathcal{S}^{U}(z)\right)$, or 
- constrained with $s=\mathcal{S}^{C}\left(\underset{-}{\left.y_{0}, y_{1}, z\right)}>\mathcal{S}^{U}(z)\right.$, and

$$
\begin{aligned}
Y_{0}\left(y_{1}, \mathcal{S}^{U}(z)\right) & >y_{0} \\
\mathcal{S}^{C}\left(y_{0}, y_{1}, z\right) & =\frac{\mathcal{S}^{U}(z)\left(y_{1}+R \underline{a}\right)}{\beta R\left(y_{0}-\underline{a}-q(z)\right)-z \mathcal{S}^{U}(z)}
\end{aligned}
$$

In cities $z<\hat{z}$, all individuals are constrained, and $\mathcal{S}^{C}\left(y_{0}, y_{1}, z\right)=\frac{q^{\prime}(z)\left(y_{1}+R \underline{a}\right)}{\beta\left(y_{0}-\underline{a}-q(z)\right)-z q^{\prime}(z)}$.

Proof. Direct corollary of Lemma 1 .

Figure 1 represents these results graphically. We have discussed all the elements in the figure except for $\tilde{z}$ that represents the lowest city that has non-negative housing rents. Namely, $\tilde{z}$ is implicitly defined by $q(\tilde{z})=0$. If $q(z)$ is strictly increasing in $z$, any city with $z<\tilde{z}$ is not feasible. Note that the upper bound of the correspondence of skills that live in the city is given by $\mathcal{S}^{C}\left(y_{0}, y_{1}, z\right)$ evaluated at the lowest current income (denoted by $\underline{y_{0}}$ ) and highest future income $\left(\overline{y_{1}}\right)$. Namely, the most constrained individual in the city, which is the highest skilled individual using the location asset the most. Note that below $\hat{z}$ the city has only constrained individuals, and only the lowest skilled individuals locate in the worst city $\tilde{z}$ (as long as $\underline{z}$ is low enough).

We can also represent graphically the set of current income levels, $y_{0}$, of individuals that locate in a given city. Of course, current income and initial wealth are indistinguishable in our two-period setup. We do so in Figure 2, In city $z$, all individuals with incomes $y_{0} \geq Y_{0}\left(y_{1}, \mathcal{S}^{U}(z)\right)$ are unconstrained and locate according to their skill level only. Other individuals that locate in those cities are constrained and have low income, and either high skills, high future income or both. Because lower current income leads individuals to choose worse cities, it must be that the lowest income present in a given city $z$ is the income of the individual with the highest incentives to save in the location asset. Namely, the highest skill agent with the lowest future income present in the city. This lower bound, denoted by $\underline{Y}_{0}(z)$ in the figure, can be found by evaluating the expression for $\mathcal{S}^{C}$ in equation 6 in Corollary 2 at $\bar{s}$ and the lowest future income $\underline{y}_{1}$.

We finish the discussion of an equilibrium in our simple two-period economy with a characterization of the house rent schedule. As we alluded already above, land rents are increasing in $z$ since higher $z$ cities yield higher income for individuals of all skills. Furthermore, the complementarity between $z$ and $s$ implies that the highest skilled unconstrained individuals locate there, which implies that rents grow more than proportionally with city type, as does the income of its unconstrained residents. Hence, rents are convex. Figure 3 illustrates such a rent function for two values of the interest rate, $R 13$

In cities with unconstrained individuals the slope of the rent function is given by the $\mathcal{S}^{U}(z) / R$. Namely, the slope of the rent function is determined by the skill of unconstrained individuals in the city and is inversely proportional to the interest rate. Thus, a low interest rate implies that the house rent schedule is steeper. Since the return of the location asset for an unconstrained individual with skill $s$ is $s / q^{\prime}\left(\mathcal{Z}^{U}(s)\right)$,

\footnotetext{
${ }^{13}$ The thresholds $\tilde{z}$ and $\hat{z}$ in the figure refer to the high $R$ case.
} 


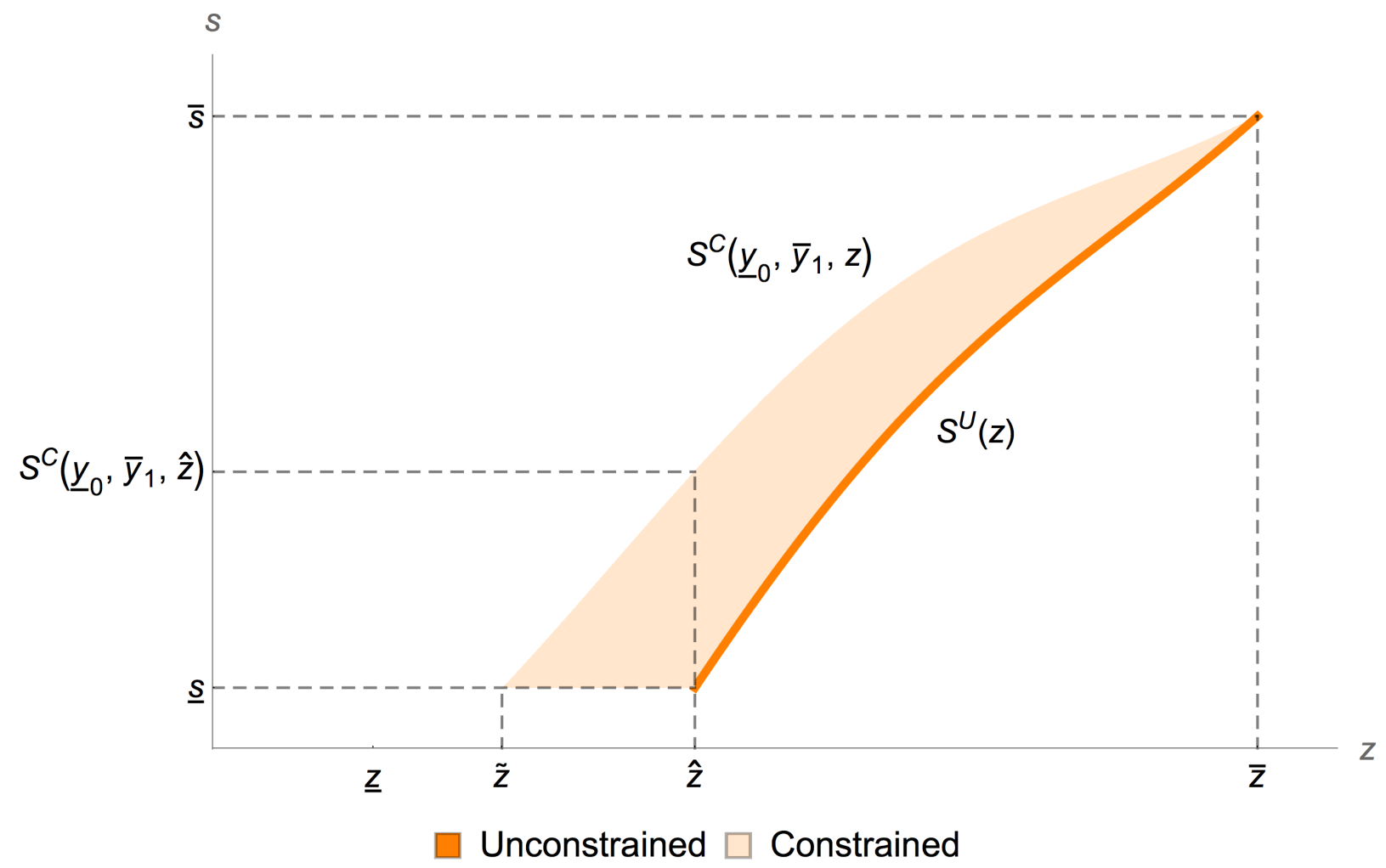

Figure 1: Allocation of skills to cities

this naturally also implies a lower return of the competing location asset by no-arbitrage. That is, lower returns in the financial market result in steeper rents that reduce the return of the location asset (see Figure 3). Furthermore, a lower interest rate $R$ implies that more agents wish to borrow and hence are constrained. This implies more downgrading and segregation. So the model predicts that periods of low interest rates should be periods of increasing rent differentials across cities and more segregation, reminiscent of the pre and post- 2008 crisis housing markets around the world. We formalize these results in the following lemma.

Lemma 3 The equilibrium house rent function has the following properties:

- $q(z)$ is increasing and convex,

- for $z \geq \hat{z}, q^{\prime}(z)=\frac{\mathcal{S}^{U}(z)}{R}$, and

- $\frac{\partial q^{\prime}(z)}{\partial R}<0$ for $z \geq \hat{z}$ if $\bar{s}-\underline{s}$ is sufficiently small.

Proof. See Appendix A.2.

Note that our results on the use of the location asset do not require either skill heterogeneity or the assumed supermodularity between $s$ and $z$. Consider the case in which there is only one skill, say $s_{0}$, and 


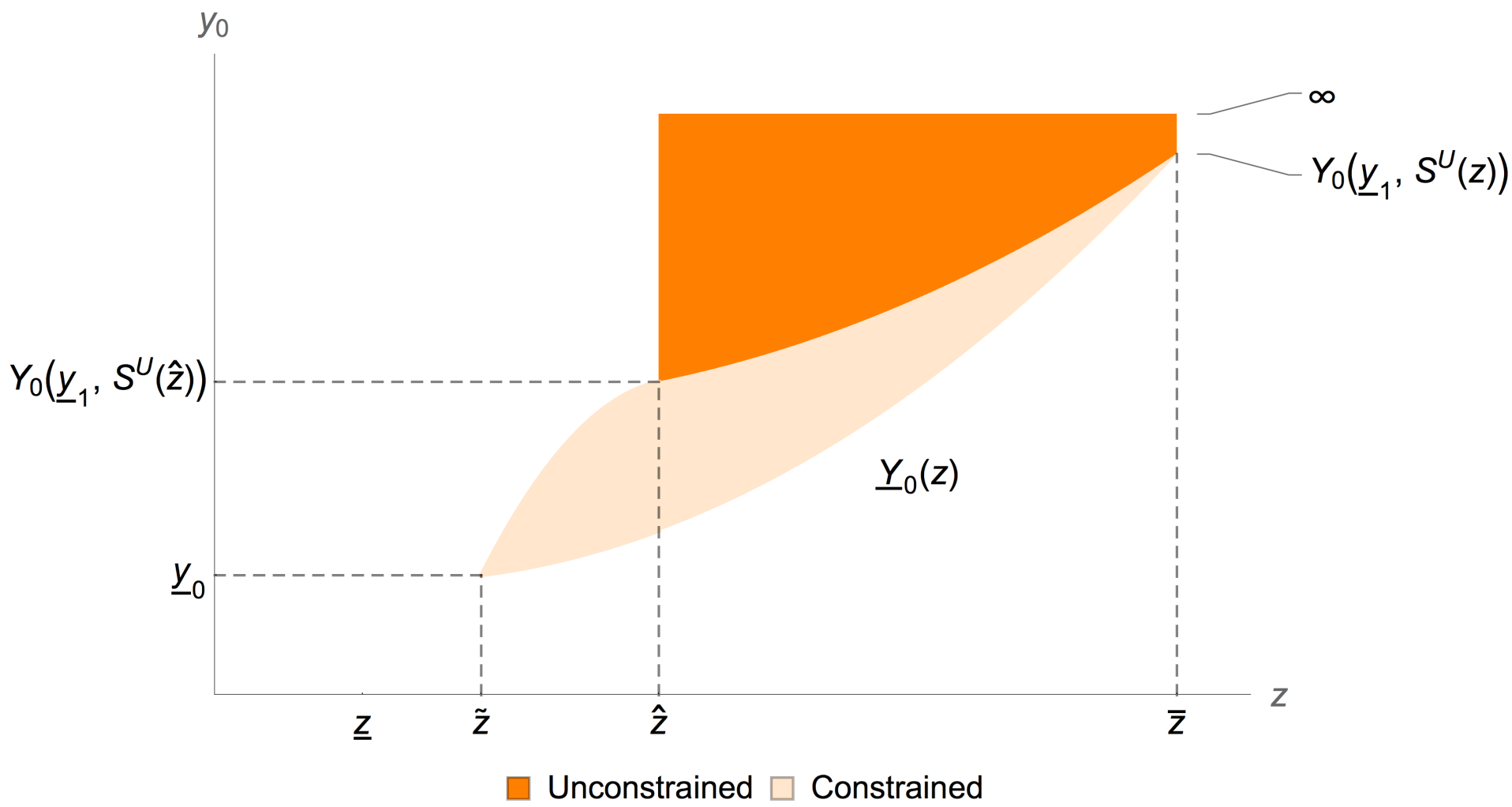

Figure 2: Allocation of income groups to cities

so everyone obtains the same benefit from living in a given city. In this case, there is complete spatial segregation between constrained and unconstrained individuals. Namely, there is a threshold location $\hat{z}$, so that all unconstrained individuals are indifferent between locations $z \geq \hat{z}$, and constrained individuals locate in places $z<\hat{z}$, where the return to the location asset is higher than the interest rate.

\subsection{Optimal Allocation}

The equilibrium allocation of the model described above is inefficient due to the presence of borrowing constraints. The inefficiency is reflected in the use of the location asset by constrained individuals. Their use of the location asset ameliorates the effect of the financial constraint. However, because it reduces total output in the second period by driving agents to locations where they earn less, the resulting allocation is still inefficient relative to an economy without financial constraints.

Finding an efficient allocation can be broken down in two parts. First, the problem of allocating individuals across locations to maximize discounted second period output net of housing costs, and second the allocation of consumption in both periods across individuals of different types. We focus on the solution of the first part of the planner's problem. The second part is a redistribution problem that depends on the 


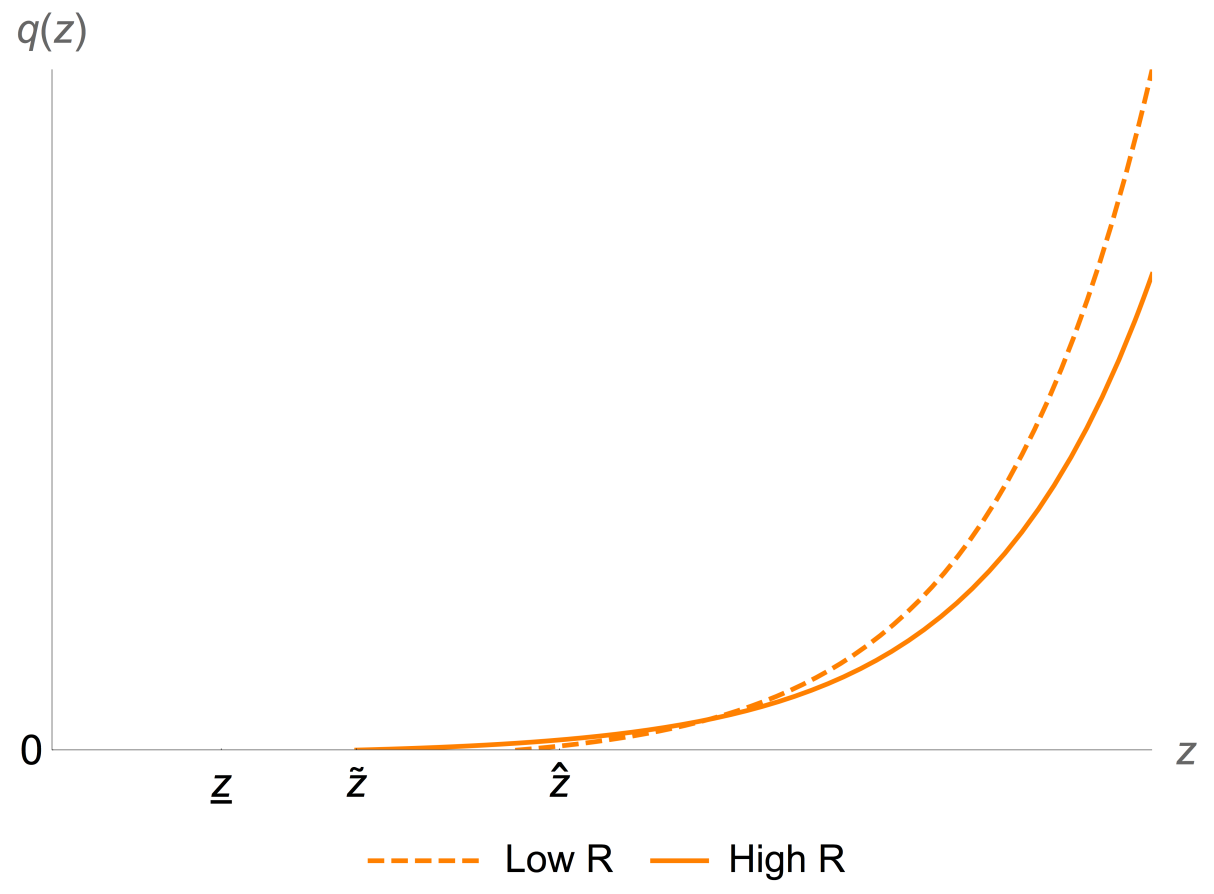

Figure 3: House rents across cities

chosen social welfare function and for any standard welfare function the solution is increasing in the total output generated by the allocation of agents across locations.

Given the assumed supermodularity between $s$ and $z$, the planner allocation necessarily involves a oneto-one increasing matching function. Namely, the solution exhibits positive assortative matching. Hence, in contrast to the equilibrium allocation, only one type of agent locates in a given city. We show this rigorously in the following lemma.

Lemma 4 Consider the problem of a planner in a small open economy that does not face credit constraints and has access to an asset with exogenous return $R$. Then:

- the planner allocates individuals according to an increasing matching function $\mathcal{Z}^{S P}(s)$, and

- the decentralized allocation yield strictly less (i) present value of output, and (ii) present value of output net of housing costs

Proof. See Appendix A.3.

\subsection{Placed-Based Policies}

The equilibrium described above determines the distribution of population across cities, $L(z)$, for all $z \in[\underline{z}, \bar{z}]$ with $L(z)>0$ for $z \in[\tilde{z}, \bar{z}]$. In the equilibrium allocation, agents with low values of $s$ that are constrained 
decide to locate in the lower range of cities because they use the location asset to borrow. We now want to consider the effect that place based-policies might have on welfare for the different types of agents. Placebased policies aim to improve the characteristics of some of the worse locations in the economy. This is naturally costly, and implies taxing other locations. Therefore, as a stylized representation of these policies, consider policies that shrink the range of characteristics of equilibrium cities $[\tilde{z}, \bar{z}]$ to a singleton $\left\{z_{0}\right\}$, keeping the mass of cities constant. We choose $z_{0}$ to guarantee that the average income that individuals derive from cities stays unchanged, namely, $\left.E[s z]=z_{0} E[s]\right]^{14}$ Thus, this policy captures the essential elements of placebased policies if they are implemented without generating any aggregate loss of resources. Note also that positive sorting between skills and city types implies that

$$
z_{0}=E\left[z \times \frac{s}{E[s]}\right]>E[z]
$$

That is, the targeted city type is better than the average.

To explain our general result below it is useful to start with an example where $\underline{s}=0$. Namely, the lowest skilled individuals in the economy have zero skill and, therefore, derive no benefits from living in better cities. These individuals in equilibrium locate in the worst cities in the economy, $\tilde{z}$, and pay zero rent $q(\tilde{z})=0$. Naturally, such individuals will be worse off if we implement our place-based policy. In the equilibrium with place-based policies rents are positive and identical in all cities, but for the lowest skilled individuals the benefits of locating in the improved cities are still zero. Hence, anyone with $\underline{s}=0$ necessary losses from the policy. By continuity, there is a range of individuals with $s>0$ that are also worse off after the policy. If they have some skills, they benefit in terms of future income, but the increase in rents still dominates. Or, in other words, the policy prevents them from borrowing with the location asset. Something they would like to do.

As long as $\underline{s}=0$, the logic above applies for any policy that reduces the range of cities at the bottom of the distribution. Namely, any policy that improves the worst city that agents have access to (and therefore increases its equilibrium rents). Of course, this logic also relies on keeping the mass of cities constant. This is intuitive, place-based policies that improve the worse cities in the equilibrium allocation but that allow for the creation of new low- $z$ cities would achieve little.

The logic described above for the case of $\underline{s}=0$ can be extended to a more general setting with $\underline{s}>0$, when $Q(L(z))=L^{\eta}$ with $\eta<1{ }^{15}$ In this case we can characterize the set of individuals that lose using the matching functions. The individuals that are guaranteed to lose are the ones between the lowest skill, and the skill of the individuals that locate, in the original equilibrium, in the average city. The reason is, again, that up to that point the convexity of housing prices implies that the increase in rents associated with the

\footnotetext{
${ }^{14}$ The expectation on the left-hand-side is taken with respect to the equilibrium allocation in space in the competitive equilibrium with different cities, before the policy change. The expectation on the right-hand-side involves only the exogenous marginal distribution of skill.

${ }^{15}$ This is a natural assumption that holds, for example, in the standard circular monocentric city model with a central business district and commuting (as in Desmet and Rossi-Hansberg, 2013). In that case, $\eta=1 / 2$.
} 
policy does not compensate the future gain in income for these agents. That is, these agents get low returns for the location asset, so they like to use it to borrow, not to save. This is particularly true for constrained individuals, so the set of skills of constrained individuals that lose is larger than the set of unconstrained individuals that lose from the policy. The next lemma presents the formal result.

Lemma 5 Suppose house rents are concave in population, i.e. $Q(L(z))=L^{\eta}$ with $\eta<1$. Then a place-based policy that makes all cities have characteristic $z_{0}$ makes

- all unconstrained agents with $s \in\left[\underline{s}, S^{U}(E[z])\right]$ worse off and

- all constrained agents $\left(y_{0}, y_{1}, s\right)$ with $s \in\left[\underline{s}, S^{C}\left(y_{0}, y_{1}, E[z]\right)\right]$ worse off.

Since $S^{C}\left(y_{0}, y_{1}, E[z]\right)>S^{U}(E[z])$, the set of skills of constrained individuals that are worse off is larger.

Proof. See Appendix A.4.

\subsection{The Location Effect of Front and Back-Loaded Shocks}

The results above can also be used to describe how agents react to shocks of different types. We are particularly interested in income shocks that affect the relative slope of an individual's income path. Namely, shocks that affect income today, $y_{0}$, relative to income tomorrow, $y_{1}+s z$. These shocks will induce agents to adjust their savings using the financial and location assets. In Section 4 we study how workers in France reallocate across regions as a result of an unemployment spell. An unemployment spell is a front-loaded shock for individuals that receive little or no severance pay, since it reduces income today relative to income tomorrow. So we can contrast the model's predictions with our observations for France. Other front-loaded shocks include declines in the compensation of particular occupations or particular industries. The shock is front-loaded because individuals and their descendants can adjust their future occupation and industry, but are stuck in the short run.

Consider an individual $\left(y_{0}, y_{1}, s\right)$ that experiences an idiosyncratic negative front-loaded shock that decreases $y_{0}$ to $y_{0}^{\prime}<y_{0}$ but increases $y_{1}$ to $y_{1}^{\prime} \geq y_{1}$. Because the shock is idiosyncratic, it does not affect the equilibrium matching function or rent schedule. The results in Lemma 1 imply that agents that are constrained will use the location asset more and will downgrade their location, since $\mathcal{Z}^{C}\left(y_{0}^{\prime}, y_{1}^{\prime}, s\right)<\mathcal{Z}^{C}\left(y_{0}, y_{1}, s\right)$. Unconstrained individuals that become constrained due to the shock also downgrade their location, since $\mathcal{Z}^{C}\left(y_{0}^{\prime}, y_{1}^{\prime}, s\right)<\mathcal{Z}^{U}(s)$. In contrast, unconstrained individuals that remain unconstrained (individuals such that $\left.y_{0}>y_{0}^{\prime}>Y_{0}\left(y_{1}^{\prime}, s\right) \geq Y_{0}\left(y_{1}, s\right)\right)$ stay where they are, since $\mathcal{Z}^{U}(s)$ is independent of the income path. Hence, constrained individuals, or those that become constrained, borrow more using the location asset, while unconstrained individuals use the financial asset to transfer consumption to the present. Of course, since what matters for the argument is the slope of the income path, a positive back-loaded shock has a similar effect on location choices and the use of the location asset. 
A positive front-loaded shock or a negative back-loaded shock has exactly the reverse effect. Constrained individuals, or individuals that become unconstrained, save with the location asset and upgrade location. Individuals that were, and remain, unconstrained use the financial market to save and do not change their use of the location asset.

Note that permanent adverse (or positive) shocks can imply a change in the slope of the income profile. For example a permanent adverse shock that increases both $y_{0}$ and $y_{1}$ induces borrowing if $y_{0}^{\prime}-y_{1}^{\prime} / \beta R<$ $y_{0}-y_{1} / \beta R$. Such a shock then generates the same qualitative effects on the use of the location asset as a front-loaded negative shock. In contrast, if $y_{0}^{\prime}-y_{1}^{\prime} / \beta R>y_{0}-y_{1} / \beta R$, the shock induces extra savings and so has a similar qualitative effect than a back-loaded negative shock. Of course, if $y_{0}^{\prime}-y_{1}^{\prime} / \beta R=y_{0}-y_{1} / \beta R$, locations remain unchanged.

As a last possibility consider an individual that acquires more skill, namely, an increase in $s$. Because $s$ increases income in the future, some of the implications of the increase in $s$ are similar to those of a back-loaded positive shock. On top of this, an increase in $s$ increases the return of the location asset relative to the financial asset which implies that agents want to save more using the location asset. Hence, they want to upgrade their city. Lemma 1 tells us that the the second effect always dominates, given that both $\mathcal{Z}^{C}\left(y_{0}, y_{1}, s\right)$ and $\mathcal{Z}^{U}(s)$ are increasing in $s$.

In the context of our simple model and the results described above, we can think of a worker losing her job as changing current income from $y_{0}$ to $y_{0}^{\prime}$. Once the worker find a new job next period she again earns $y_{1}$. If the worker receives unemployment benefits that are, say, a fraction $\kappa<1$ of her last salary, then $y_{0}^{\prime}=y_{0} \kappa$ and the shock is a front-loaded negative shock that makes individuals downgrade if constrained and not relocate if unconstrained. If in contrast the worker receives, say, a severance pay that makes the current payment larger than when employed, $y_{0}^{\prime}=\sigma\left(y_{0}\right) y_{0}>y_{0}$ (perhaps at the cost of a lower $y_{1}$ when she finds a job), then the shock is a front-loaded positive shock that will make constrained individuals upgrade. Now, if the generosity of severance pay depends on the level of income (e.g. $\sigma\left(y_{0}\right)$ is increasing), then high income individuals that are constrained upgrade location when they lose their job while low income ones downgrade. Overall, however, since high income individuals are less constrained than low income ones, we expect the use of the location asset to be more pronounced among people in the latter group. We contrast this exact implications with French data in Section 4.

\section{Infinite Horizon Model}

In this section we extend our model to an infinite horizon economy. The key differences with the model presented in the previous section, is that now agents live forever and receive an idiosyncratic income stream $y_{t}$. Depending on their skill, location, asset holdings, and income, they make consumption and savings decisions. To do so they use the financial market subject to a borrowing constraint and the location asset by choosing where to live. As before, cities differ in their return to skill and their rent. Also as before, one can view individuals as solving a two-asset portfolio choice problem subject to a borrowing constraint on 
the risk-free bond. In contrast to the two period model, the infinite horizon version determines the invariant distribution of wealth in the population and therefore the wealth composition of cities as well.

In any period $t$, infinitely-lived individuals receive an idiosyncratic income shock $y_{t}$, which follows a first-order Markov chain with states $y_{1}, \ldots, y_{N}$ and a given transition matrix, $\Lambda$. Throughout we assume that individuals have a permanent skill $s \sqrt{16}$ In period $t$, an individual in location $z_{t}$ with an asset level $a_{t}$, chooses how much to consume $c_{t}$, how much to save $a_{t+1}$ in a one period risk-free bond with interest rate $R$, and where to live next period, $z_{t+1}$. Agents can move freely across locations. Their income in period $t$ is $y_{t}+s z_{t}$. To go to location $z_{t+1}$, they need to pay the rent $q\left(z_{t+1}\right)$ one period in advance, i.e. in period $t$. Finally, we assume that the risk-free bond is subject to a standard credit constraint $a_{t+1} \geq \underline{a}$.

Given an increasing and concave flow utility function $u$ satisfying Inada conditions, and a discount factor $\beta<1$, individuals maximize

$$
\begin{aligned}
V\left(a_{t}, z_{t}, y_{t}, s\right) & =\max _{\left\{a_{t+1}, z_{t+1}\right\}_{t=0}^{\infty}} E_{0}\left[\sum_{t=0}^{\infty} \beta^{t} u\left(c_{t}\right)\right] \\
\text { s.t. } & c_{t}+a_{t+1}+q\left(z_{t+1}\right)=y_{t}+s z_{t}+R a_{t}, \\
& a_{t+1} \geq \underline{a} .
\end{aligned}
$$

If we denote optimal choices with an asterisk, as in the two period model the solution to this dynamic optimization problem yields a financial Euler equation

$$
\frac{u^{\prime}\left(c_{t}^{*}\left(a_{t}, z_{t}, y_{t}, s\right)\right)}{\beta E_{t}\left[u^{\prime}\left(c_{t+1}^{*}\left(a_{t+1}, z_{t+1}, y_{t+1}, s\right)\right)\right]} \geq R
$$

that holds with equality if and only if $a_{t+1}^{*}\left(a_{t}, z_{t}, y_{t}, s\right)>\underline{a}$. Also similarly, free mobility implies a mobility Euler equation given by

$$
\frac{u^{\prime}\left(c_{t}^{*}\left(a_{t}, z_{t}, y_{t}, s\right)\right)}{\beta E_{t}\left[u^{\prime}\left(c_{t+1}^{*}\left(a_{t+1}, z_{t+1}, y_{t+1}, s\right)\right)\right]}=\frac{s}{q^{\prime}\left(z_{t+1}^{*}\left(a_{t}, z_{t}, y_{t}, s\right)\right)}
$$

which implies that

$$
\frac{s}{q^{\prime}\left(z_{t+1}^{*}\left(a_{t}, z_{t}, y_{t}, s\right)\right)} \geq R
$$

with equality if and only if $a_{t+1}^{*}\left(a_{t}, z_{t}, y_{t}, s\right)>\underline{a}$. Note that, again we have that, for non-constrained individuals, city choice $z_{t+1}^{*}\left(a_{t}, z_{t}, y_{t}, s\right)$ only depends on skill $s$.

Denote by $F_{t}$ the joint distribution of the four-tuple $\left(a_{t}, z_{t}, y_{t}, s\right)$ in period $t$. Then the distribution of

\footnotetext{
${ }^{16}$ It is feasible to relax this restriction and introduce idiosyncratic skill shocks, although at some computational cost.
} 
people across cities, $L_{t}(z)$ is given by

$$
\int_{\underline{z}}^{z} L_{t}(z) H(d z)=\sum_{i=1}^{N} \int_{\underline{a}}^{\infty} \int_{\underline{z}}^{\bar{z}} \int_{\underline{s}}^{\bar{s}} \mathbf{1}\left[z^{*}\left(a, z, y_{i}, s\right) \leq z\right] F_{t}(d a, d z, d s) \text { for all } z \in[\underline{z}, \bar{z}]
$$

and rents are given by $q(z)=Q(L(z))$. This economy converges to a steady state where the distribution $F_{t}$ is constant over time.

An equilibrium of the model above can be computed numerically. We do so for a CRRA utility function, for a uniform distribution of cities, and for a particular house rent schedule ${ }^{17}$ We choose reasonable parameters values that allow us to illustrate the main forces at work. The exact values, specifications, and solution method are described in Appendix C.

Figure 4 presents the results of a simulation of this model. We focus on the reaction of a particular individual to a transitory income shock. The figure presents five panels, each of them displaying a different variable. For comparison purposes we present the behavior of an individual that can move (solid dark lines), and therefore use the location asset, and the behavior of an individual that cannot move from her preferred location when unconstrained, $\mathcal{Z}^{U}(s)$ (dashed light lines). The difference between these two cases represents the way in which the location asset helps the individual deal with the transitory income shock. We plot the effects for a particular individual with a fixed skill level.

The first panel in Figure 4 simply plots the income shock over time. The agent can be in two income states: high, $y_{H}=0.2$, and low, $y_{L}=0.0518$ In period zero, the agent transitions from the high to the low income level. It stays there until the eighth period when he transitions back to the high income. This income process is identical for both scenarios, with and without mobility.

The second panel plots the level of financial assets. We start the individual at assets that are $150 \%$ of the transitory income level in the high state (also equal to $60 \%$ of the level of the maximum accumulated financial assets for the agent that cannot move). The individual also receives an income proportional to her skill and the city where she lived, $z_{t} s$. This additional income represents most of the individual's income. The transitory path represents between 15 and $30 \%$ of the agent's total income. As a result of the shock, the agent consumes part of her financial assets and therefore the asset balance declines until it hits zero, which is the level of the financial constraint. That is, individuals cannot borrow at all in financial markets. This decline in financial assets happens a bit faster when individuals can use the location asset, since in that case they know that when they hit the financial constraint they will be able to smooth consumption by moving. In period 4, the agent that cannot move hits the borrowing constraint and stays there for several periods. The agent that can use the location asset hits the borrowing constraint one period earlier. When

\footnotetext{
${ }^{17}$ In principle, specifying a given house rent schedule is without loss of generality, because we can find a skill distribution that would lead to this particular house rent schedule as an equilibrium outcome. Of course, endogenizing the house rent schedule is essential to perform aggregate counterfactual simulations. In the exercises below, we only consider counterfactuals that change the state of a particular individual and therefore do not affect the aggregate equilibrium allocation and prices.

${ }^{18} \mathrm{We}$ could think of the low state as unemployment, and the high state as employment. Our calibration of the transition matrix $\Lambda$ then implies a steady-state unemployment rate of about $14 \%$.
} 


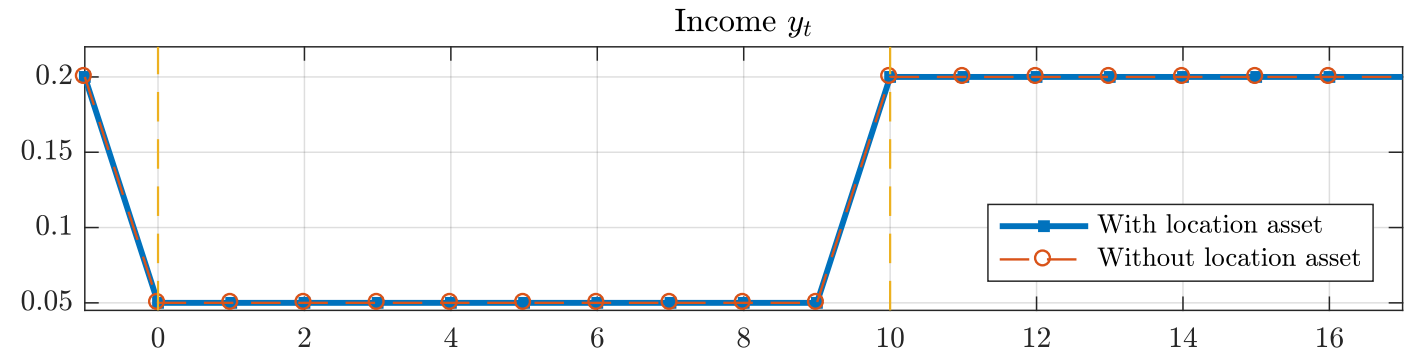

Financial assets $a_{t}$

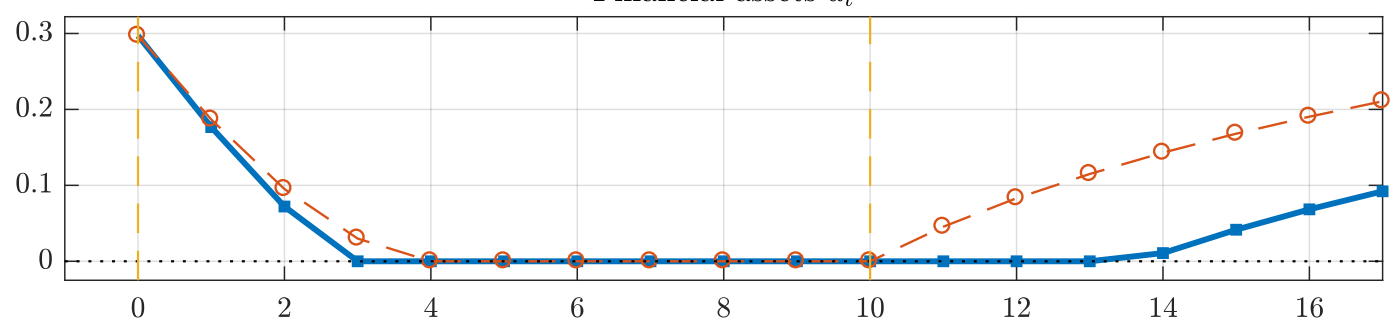

Location $z_{t}$

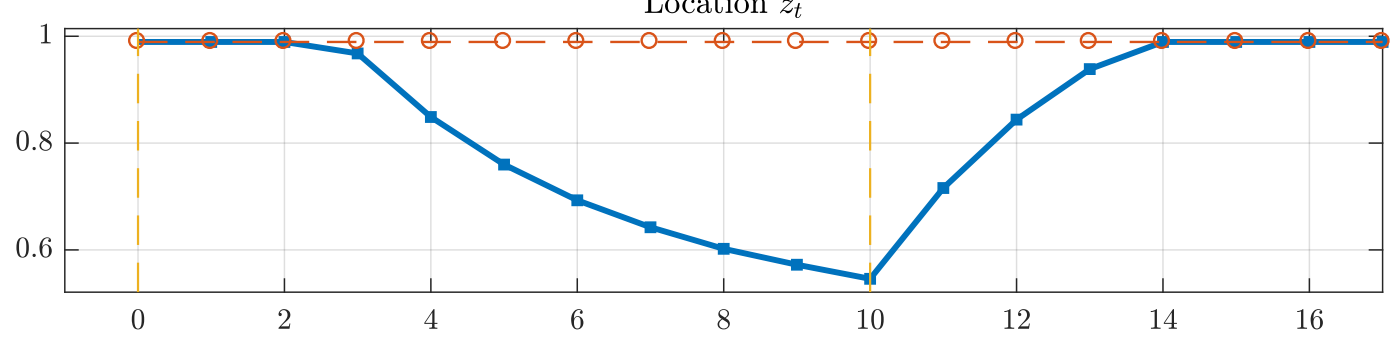

House rents $q\left(z_{t+1}\right) /$ Total income $y_{t}+s z_{t}$

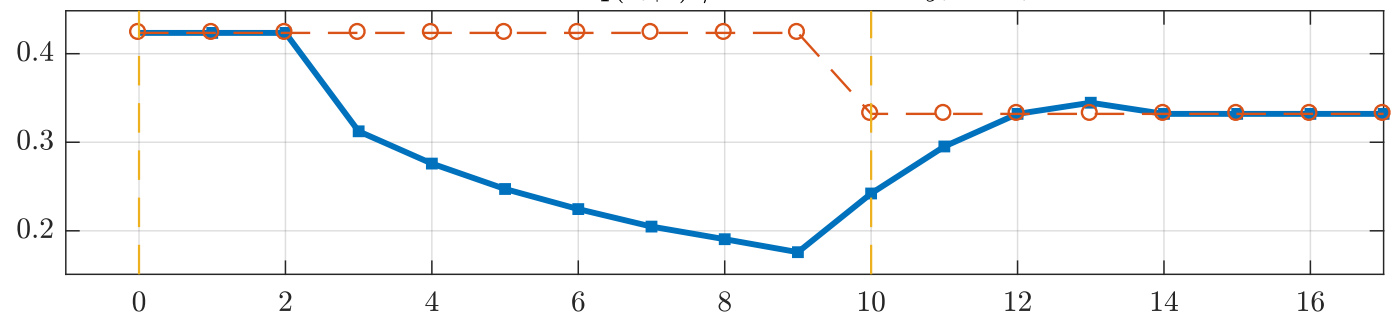

Consumption $c_{t}$

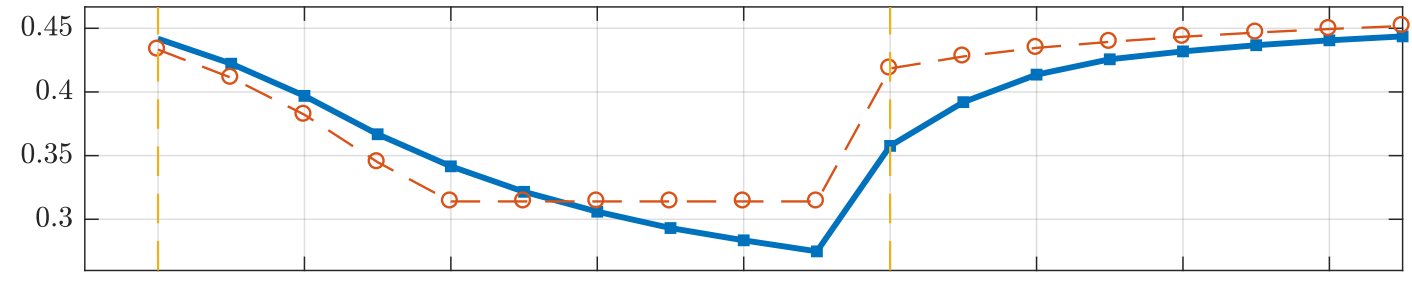

Figure 4: Dynamic reaction to a temporary income shock 
the income shock reverses in period 10, without the location asset, the agent immediately starts saving and building a financial asset stock. In contrast, because at that point the location asset pays a higher return than the financial asset, the individual that can use the location asset, uses it to save. Such an individual stays stuck at the constraint for an extra two periods while it moves to better locations. Eventually, she reaches her desired location, the return she perceives on the location asset goes down, and she starts saving with the financial asset. Note that the presence of the location makes the individual stay longer at the financial constraint!

The third panel plots the location of the agent over time. The ideal unconstrained location of the agent is at city $\mathcal{Z}^{U}(s)=0.99$. The agent that cannot move simply stays there throughout. The one that can stays there until financial assets hit the financial constraint. Once she runs down financial assets to zero, she starts borrowing using the location asset. That is, she starts downgrading her location progressively. In this case the total downgrade is about $40 \%$, similar in magnitude to the largest effects we calculate for France in the next section. This downgrading continues until the agent either reaches the minimum location she is willing to live in, or the shock reverses. In the plot it continues throughout the 10 periods where the agent obtains a low income. After the shock reverses to the high income state, the agent starts upgrading her location progressively. The last period where she is financially constrained, she reaches her unconstrained preferred city and starts saving with the financial asset only. Throughout the transition, the change in the city component of income due to the use of the location asset reaches 0.28 , which is of the same order of magnitude than the high idiosyncratic income state.

The fourth panel in Figure 4 shows the share of housing expenditure in total income. The average share lies between $20 \%$ and 40\%, similar to the data (Davis and Ortalo-Magne, 2011). At impact, the share of housing expenditure jumps up due to the fall in income. It starts falling from that peak since agents pay rents one period in advance. It keeps falling as the agents borrow with the location asset and downgrade their location. It falls even more as the income shock reverts to the high state and then starts increasing when the agent starts saving with the location asset. It overshoots the desired unconstrained level with high income due to the need to pay rents in advance, but eventually stabilizes at the same level as the immobile agent.

The bottom panel in the figure shows the agent consumption path with and without mobility. As we have underscored, the use of the location asset allows the agent to smooth consumption better since it can borrow even when she is at the financial constraint. The result is a consumption path that declines more slowly than without the location asset. Because borrowing with the location asset involves sacrificing future income, the total fall in consumption is also eventually somewhat larger. Once the shock reverses, the path out of the consumption slump is also smoother for agents that can use the location asset. Overall, these dynamic patterns of behavior vary substantially with and without the location asset.

The ability to use the location asset results in expected welfare gains for the agent 19 The presence of

\footnotetext{
${ }^{19}$ The gains from using the location asset for one particular path of realizations can be either negative or positive. For example, in Figure 4 the negative shock lasts for several periods. This increases the set of periods where agents that use the
} 
some gains is obvious given that the location asset provides a way of relaxing the friction imposed by the financial constraint and the agent can always decide not to move. In Figure 5 we present the percentage gain in consumption, and in consumption equivalent welfare from using the location asset. The values are calculated starting from the ideal city for unconstrained individuals, $\mathcal{Z}^{U}(s)$, and we keep the skill of the individual fixed, as in Figure 4. Figure 5 then plots the relative consumption and welfare from using the location asset as a function of the starting asset level. It presents the gains for agents with a current high or low income realization. Clearly, because we are not estimating the parameters of the model for a particular circumstance, the level of the gains provides only a rough indication of what is at stake from using the location asset. In contrast, the qualitative patterns are more interesting. Most consumption gains happen close to the constraint for low-income individuals who are dissaving. These consumption gains quickly fade away as we consider individuals with higher levels of assets. However, because those consumption gains occur precisely in the high marginal utility states, they translate into welfare gains of almost $2 \%$ close to the constraint 20 The figure also shows that agents in the low income state benefit more than agents in the high income state, as they are the most likely to use the 'location asset'.
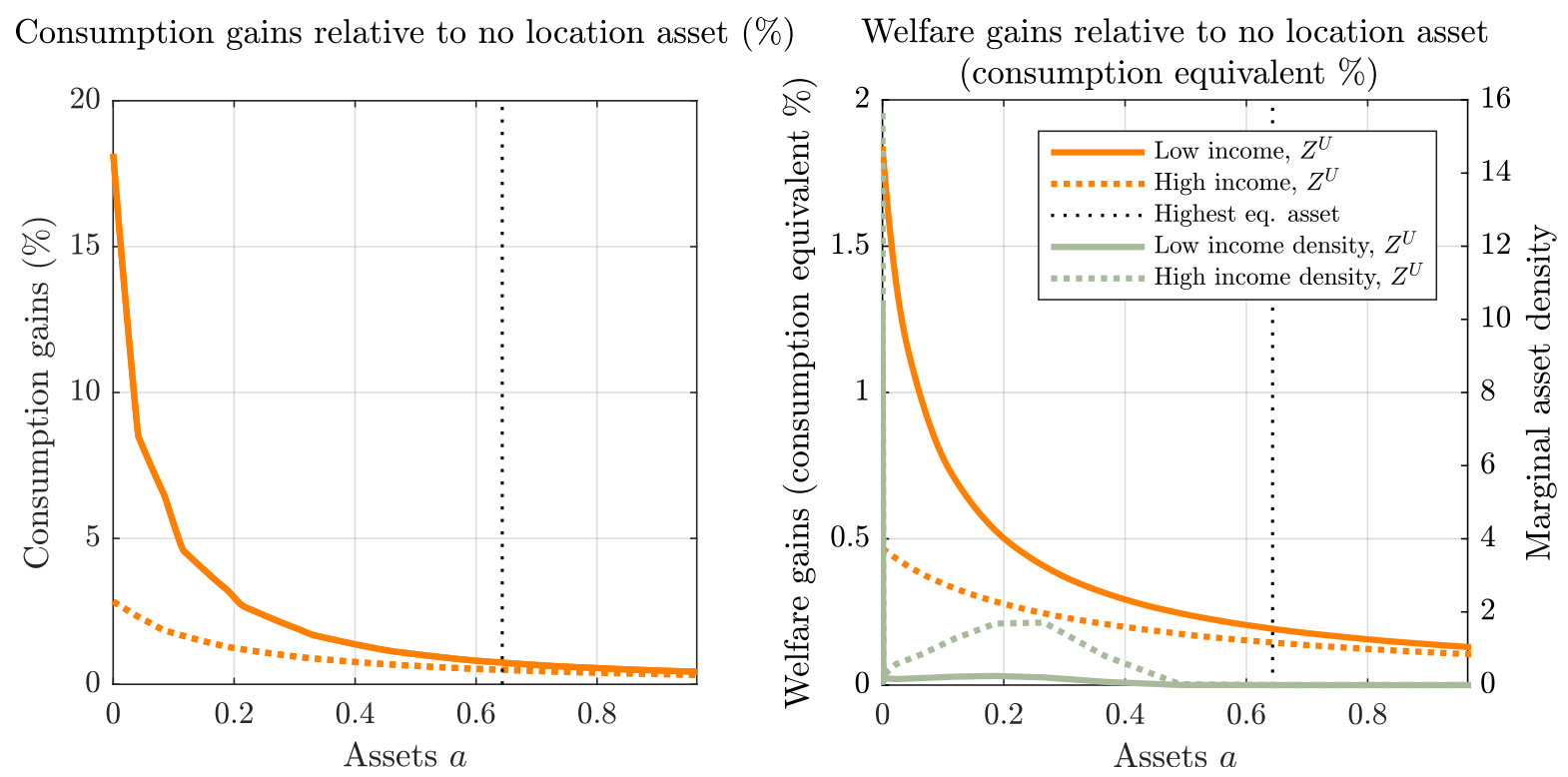

Figure 5: Consumption and welfare gains from the use of the Location Asset

Of course, because we have assumed that there is no cost of mobility at all, in our model agents optimize

location asset obtain less consumption. However, this particular path is relatively unlikely. Other paths with shorter duration of the negative transitory shock yield larger benefits from the use of the location asset, and are more likely. In expectation, there are gains since the agent has a larger more flexible choice set.

${ }^{20}$ Gains in flow consumption can be as high as $18 \%$ for low-income individuals close to the constraint that live in their unconstrained preferred location. These gains are larger than the ones depicted in Figure 4 . This is the case because individuals usually start downgrading location one period before they hit the constraint. Note also that the small kinks in the consumption gains are due to kinks in the consumption policy functions, when individuals hit the constraint next period. 
their location every period. Small moving costs would make adjustments to the agents' location, and therefore borrowing and saving with the location asset, more infrequent (although still beneficial). In addition, because the borrowing constraint generates a concave value function in wealth, small moving costs would reduce the frequency of moves more for low-wealth individuals relative to high-wealth individuals. Together with shocks to skill this would help explain jointly the sorting patterns across space and mobility patterns across income groups. We now explore some of the implications of our view of location choices using French individual location histories.

\section{Location Choices in France}

We have discussed in detail several implications of our view of location decisions as investing in a location asset. The main one of them is that constrained individuals will downgrade their location as a result of a negative front-loaded income shock. In contrast, unconstrained individuals will not react to these shocks. In this section we want to contrast this prediction with individual level data. We do so using data for France for the period 1994-2007. We use employer tax return data from a $4 \%$ longitudinal panel representative of all workers in the French economy from 1994 to 2007. We observe a worker identifier, the worker's wages, the start and end dates of all her employment spells, residence and workplace municipality, as well as a number of worker characteristics like age, gender, occupation and birthplace. There are 36569 municipalities in France, with an average area of 15 squared kilometers and 435 inhabitants.

Our data is very detailed, however, contrasting it with our theoretical predictions involves several choices. First, since the data does not have direct information on assets or the extent to which workers are "constrained' to borrow in financial markets, we need to take a stand on what are the worker's characteristics that make them more likely to be constrained. Furthermore, we do not have the worker's skill or her level of education.

Finally, we do not have a location characteristics that tells us which locations are more complementary with skill, or more attractive. To address these challenges we use our theoretical model. First, the positive assortative matching implication links a worker's skill with her earnings which we observe. Furthermore, as implied by the model in Section 2, residents of cities with higher $z$ will have higher average incomes. Hence, we can determine the $z$-rank of cities using the rank of their average income ${ }^{21}$ (see Figure 1). Finally, the model tells us that the highest income individuals in any city are the ones that are not constrained. Hence we can look at the percentile of an individual in the income distribution of her residence municipality to obtain an index of the likelihood that the individual is constrained (see Figure 2). In a second exercise, we go further and compute a local asset rank from wage data using a perpetual inventory method that leverages the longitudinal dimension of our data. Armed with these choices we are ready to explore the mobility choices of individuals and contrast them with the implications of our 'location as an asset' view.

\footnotetext{
${ }^{21}$ In the main text, we present results when we use the rank of every municipality it the 2002 distribution. In the Appendix, we show that our results are virtually unchanged when we use the rank in the current year's distribution instead.
} 


\subsection{The Impact of Location on Wages}

We start by verifying that our measure of $z$ is robust to controlling for house prices and selection. Figure 11in Appendix D.2 displays mean log daily real wages 22 across deciles of $z$-rank. It also plots the average residual wages from a standard Mincer regression with a full set of gender, age, occupation and industry fixed effects. In both cases, real wages are increasing in $z$. Observed real wages are $40 \%$ higher in the best municipality in France, relative to the worst. Residual real wages are only $20 \%$ higher. Hence, while important, selection on observables explains only half of pay differential across locations indexed by our measure $z$. To control for selection on unobservables, we also include worker fixed effects in our Mincer regression, and plot mean residual wages from the fixed-effect regression. Residual wages remain monotonically and significantly increasing with our measure of $z$, although differences between the bottom and top location decile reduce to about $2.5 \%$.

In order for location to resemble an investment decision, it is essential that some of the benefits (or costs) of living in a given location accrue over time. The ideal experiment to test if the returns of moving to a better municipality increase over time would randomly allocate identical workers across different locations, and would compare wages over time of workers who were allocated to good locations relative to those who were allocated to bad locations. In practice, however, finding instruments that achieve such a random spatial allocation is difficult. Therefore, we turn to a difference-in-difference specification in which we control for as many observable characteristics as possible. We isolate movers and estimate

$$
\log \frac{w_{i t}}{w_{i,-1}}=\alpha_{i t}+\gamma_{t} \log w_{i,-1}+\beta_{t} P\left(z_{i 0}\right)+\varepsilon_{i t}
$$

where $P\left(z_{i 0}\right)$ is the percentile of the municipality where individuals migrated in $t=0$. The dependent variable $\log \frac{w_{i t}}{w_{i,-1}}$ denotes wage growth between the period just before the move (period -1 ) and period $t$. The difference specification controls for any time-invariant worker characteristic (a worker fixed effect). $\alpha_{i t}$ controls non-parametrically for age, gender, year, 2-digit origin occupation, 2-digit origin industry, and origin municipality fixed effects interacted with the year since the move $t$. Occupation, industry, and municipality are measured before the move at $t=-1$. We also control for the wage before the move $\log w_{i,-1}$ to control for individual-specific trends in wage growth ${ }^{23}$ Finally, estimating this equation on movers only avoids picking up unobserved heterogeneity between movers and stayers.

The investment dimension of mobility is captured by the difference $\beta_{t}-\beta_{0}{ }^{24}$ The identifying assumption that lends a causal interpretation to this estimate is that there are no unobserved shocks that are systematically correlated with mobility decisions and wage growth between 0 and $t$ and orthogonal to our

\footnotetext{
${ }^{22}$ We deflate wages using a house price index at the département-year level, to control for differences in local prices. There are 96 départements in mainland France.

${ }^{23}$ If wage growth has a systematic individual component, then the pre-move wage must partly reflect it. Thus, controlling for the pre-move wage nets out any individual-specific wage growth rates and so it plays a similar role than individual fixed effects in the wage growth regression.

${ }^{24}$ The initial effect, $\beta_{0}-\beta_{-1}$, could capture, on top of the immediate effect from moving, a short term investment component that is not realized immediately but takes less than 2 years to be reflected in wages.
} 
controls. Hence, if individuals receive an idiosyncratic worker-level shock at $t-1$ that makes their wage grow systematically faster in better municipalities, in a way that is orthogonal to worker fixed effects, the non-parametric trends, and pre-move wages, then we would not be able to interpret $\beta_{t}-\beta_{0}$ in a causal way ${ }^{25}$

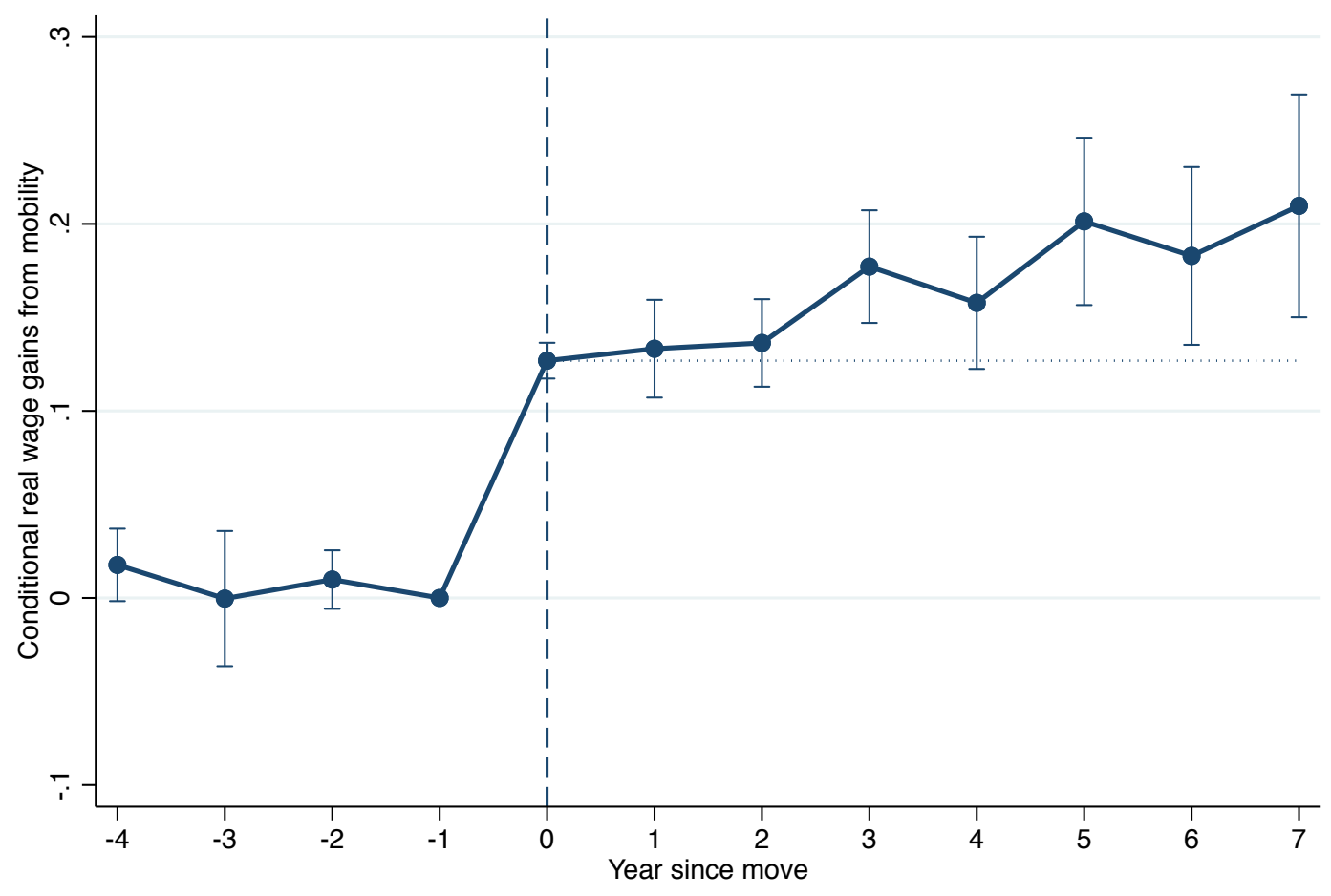

Figure 6: Plot of the $\beta_{t}-\beta_{-1}$ coefficients, for $t=-4 \ldots 7$, and observed daily real wages. $t=0$ is the first move of a worker and is the instantaneous effect of location. Standard errors clustered at the origin municipality level. Using the $4 \%$ long panel. The dots show the point estimate, and vertical bars are the $90 \%$ confidence intervals.

Figure 6 shows the estimation results. It displays the point estimates relative to period -1 , together with $90 \%$ confidence intervals. The estimate for $t=0$ reveals that moving to the best location in France conditional on our controls leads to about $12 \%$ higher wages than moving to the worst location. Comparing the estimate at $t=7$ to the estimate at $t=0$ shows that the return to migration almost doubles after 7 years: wages are then $21 \%$ higher. The Appendix shows that our result that the incremental gains from mobility accrue partly over time, and reach about $10 \%$ after 7 years, is robust to dropping all our controls or

\footnotetext{
${ }^{25}$ One way to alleviate this concern would be to include worker-specific trends in the estimation. The drawback is that it would probably absorb too much of the effect of mobility. For instance, Postel-Vinay and Robin (2002) show that structural estimates of worker and firm heterogeneity in wage determination attribute much less variation to worker characteristics than typical fixed effects estimates as in Abowd et al. (1999) (40\% instead of 80\%). Bonhomme et al. (2018) show that one way to get around this issue is to cluster observations in broader categories before estimating the fixed effects. This is akin to our approach that bins wage growth at the worker level in 2-digit occupation $\mathrm{x}$ industry $\mathrm{x}$ municipality categories and adds the pre-move wage control.
} 
the non-parametric trends $\alpha_{i t}{ }^{26}$ We conclude that location in fact has a payment structure that resembles an intertemporal asset.

\subsection{Moving Decisions after Non-Employment Shocks}

The previous subsection showed that location can be viewed as an asset. We now turn to explore if agents actively use this asset. We study the changes in residential locations as a result of an unemployment spell. We see the location of an individual in a particular job. As a result of job termination the individual disappears from the dataset and we see the individual appear again when she find another job. We select individuals that have at least one unemployment spell of at least 40 days, that had employment before and after for at least 90 days, and that switch employer after the unemployment spell. This selection guarantees that the shock is significant in magnitude and avoids people that have unstable temporary employment. After an individual find a new job, we can look at the average income rank of the new residential location and compare it with the original rank. ${ }^{27}$

Figure 7 provides some basic statistics for our dataset. The top panel plots the number of labor market transitions involving unemployment spells. Our data includes more than two hundred thousand transitions with one and two quarter long unemployment, and about hundred thousand where unemployment lasts three quarters. For comparison purposes, there are about seventy five thousand transitions in which individuals change jobs without an unemployment spell in between. So there is plenty of data to study the type of transitions we are interested in. The bottom panel presents the fraction of agents that change location as a function of the length of the unemployment spell. It distinguishes between agents in the bottom quintiles of the income distribution, top quintile, and all agents. The fraction of movers that are unemployed for one quarter or change jobs without going through unemployment is above $20 \%$. The fraction increases with the length of the unemployment spell, and between the top and bottom income quintile, although it is not monotone in income for all unemployment spell lengths. Thus, the number of agents that see a change in employment and move is substantial, particularly if they go through a long unemployment spell ${ }^{28}$

The main implication of our model is that individuals with a low income rank in their original location (and therefore presumably financially constrained according to our theory) should downgrade their location relative to individuals in the same location who are at the top of the location's income distribution 29

\footnotetext{
${ }^{26}$ In Appendix D.3 Figure 12 presents a simple comparison of observed wages for movers, binned into quintiles of their destination. Figure 13 shows the results for a version of regression (9) without the fixed effects $\alpha_{i t}$. In both cases the results are similar.

${ }^{27}$ Section D.1 contains a thorough description of the data and the construction of the sample.

${ }^{28}$ Long unemployment spells are also less likely to reflect voluntary vacation periods between jobs.

${ }^{29}$ Figure 7 reveals that there is not much mobility differences across income groups. Note that the mobility implications of our view depend on the types of shocks individuals experience. When income declines as the result of a regional shock that affects an entire municipality, and local rents decline, borrowing using the 'location asset' may imply staying in the declining region rather than moving away.
} 

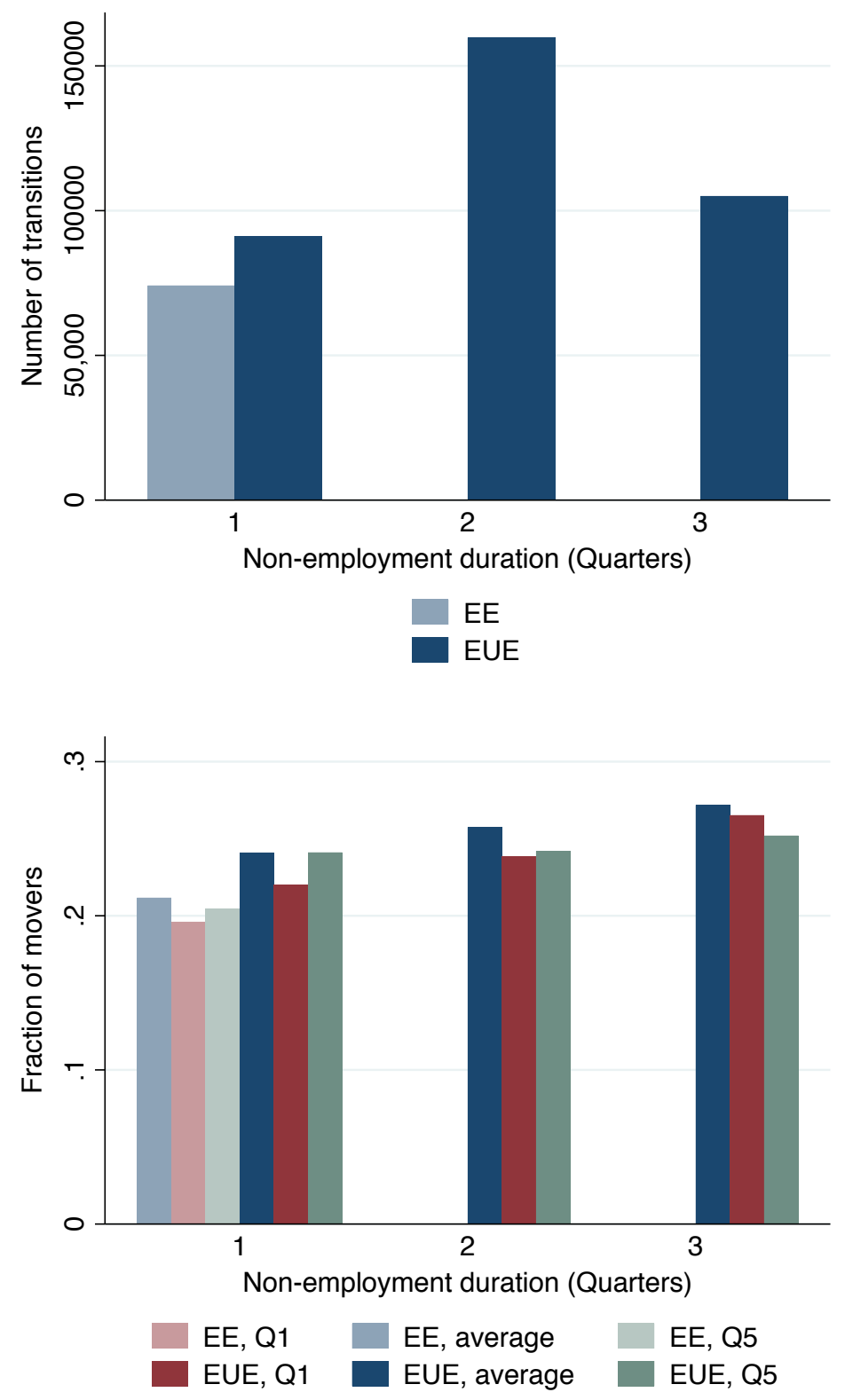

Figure 7: Total number of transitions (top panel) and fraction of movers (bottom panel)

Therefore we first estimate the following regression,

$$
P\left(z_{1 i t}\right)-P\left(z_{0 i t}\right)=\alpha_{z_{0}}+\alpha_{t}+\alpha_{I}+\beta_{w} P\left(w_{i t} ; z_{0 i t}\right)+\mathbf{X}_{i t}+\varepsilon_{i t},
$$

where $P\left(z_{1 i t}\right)$ is the percentile of the origin municipality in the separation year, $P\left(z_{0 i t}\right)$ is the percentile of the destination municipality in the job finding year, $\alpha_{z_{0}}$ denotes département fixed effects, $\alpha_{t}$ denotes year 
fixed effects, $\alpha_{I}$ denotes a set of worker characteristics fixed effects (e.g. age, gender, birthplace, occupation), $P\left(w_{0 i t} ; z_{0 i t}\right)$ is individual $i$ 's income percentile in municipality $z_{0 i t}, \mathbf{X}_{i t}$ is a vector of various worker-level controls that we describe below, and $\varepsilon_{i t}$ is a mean zero error term that we assume has the standard mean independence properties. We are particularly interested in the value of $\beta_{w}$. The theory predicts that agents that are lower in the income rank of their origin municipality should downgrade relative to others as a result of the unemployment spell. So our 'location as an asset' view implies that $\beta_{w}>0$. Below, we also construct a measure of asset holdings using a perpetual inventory method and verify that our results are robust to replacing local wage percentiles $P\left(w_{i t} ; z_{0 i t}\right)$ by local asset percentiles $P\left(a_{i t} ; z_{0 i t}\right)$.

Table 1 presents the results for $\beta_{w}$ when we select the sample to agents that move as a result of (or concurrently to) the unemployment shock. As implied by our view, the estimated coefficient on the origin wage percentile is positive and significant. The magnitude varies between 0.100 and 0.148 depending on the set of fixed effects we use in the regression. All standard errors are clustered at the département level. The coefficient increases as we add a more and more complete set of individual characteristic fixed effects. The interpretation is simple, using our preferred estimate in column four, a job termination implies that agents in the bottom percentile of their location's income distribution downgrade to a location 14.8 percentile points worse than the highest-income agents in their original location. This is a large effect that indicates very different mobility patterns across individuals. The results in column four should be interpreted as the average effect (across all municipalities) for workers within the same period and departement, and with the same age, gender, birthplace, and pre-separation 2-digit occupation and industry.

Comparing columns one to three with column four, it is clear that industry and occupation fixed effects increase the magnitude of the coefficients significantly. This is probably related to the fact that occupations and industries are clustered in space. As a result, in the data individuals in the same occupation and industry with very different incomes tend to move to the same location due to the spatial concentration of labor demand in specific industries and occupations. Our focus is on the effect of financial constraints on consumption smoothing through financial and location assets, so adding these fixed effects is preferable. Similarly, life cycle effects and historical ties to certain locations might affect the choices of individuals beyond the forces in our model. Hence, adding these fixed effects is probably important as well, although in practice this addition does not change the estimates much. Independently of the specification chosen, our main hypothesis is clearly not falsified by these results.

Figure 8 presents the change in location percentile for agents at the bottom quintile, relative to all other quintiles, and $90 \%$ confidence intervals. It shows our estimates when we estimate effects separately for agents that exhibit different unemployment spell lengths. The top panel presents the effect for all individuals, including movers and non-movers, while the bottom panel presents the effects of movers. The graph shows that the main effects of unemployment on location are larger as time spent non-employed increases (we limit the non-employment spells to 3 quarters since beyond that length the number of transitions in the data is relatively small). The effects are monotone in the agent's income quintile in the original location, as can be determined by the shifting down of the curves as we compare with higher quintiles. This is exactly what we 
Table 1: Unemployment spells and location decisions

\begin{tabular}{|c|c|c|c|c|c|c|c|c|c|}
\hline Origin Wage Perc. (OWP) & $\begin{array}{l}0.100^{* * *} \\
(0.005)\end{array}$ & $\begin{array}{l}0.100^{* * *} \\
(0.005)\end{array}$ & $\begin{array}{l}0.119^{* * *} \\
(0.004)\end{array}$ & $\begin{array}{l}0.148^{* * *} \\
(0.006)\end{array}$ & $\begin{array}{l}0.354^{* * *} \\
(0.018)\end{array}$ & $\begin{array}{l}0.345^{* * *} \\
(0.018)\end{array}$ & $\begin{array}{l}0.343^{* * *} \\
(0.018)\end{array}$ & $\begin{array}{l}0.341^{* * *} \\
(0.018)\end{array}$ & $\begin{array}{l}0.730^{* * *} \\
(0.051)\end{array}$ \\
\hline \multicolumn{10}{|l|}{ Controls } \\
\hline Pre-Move Log Wage & & & & & $\begin{array}{l}-0.084^{* * *} \\
(0.004)\end{array}$ & $\begin{array}{l}-0.087^{* * *} \\
(0.004)\end{array}$ & $\begin{array}{l}-0.087^{* * *} \\
(0.004)\end{array}$ & $\begin{array}{l}-0.088^{* * *} \\
(0.004)\end{array}$ & $\begin{array}{l}-0.083^{* * *} \\
(0.004)\end{array}$ \\
\hline Post-Move Log Wage & & & & & & $\begin{array}{l}0.023^{* * *} \\
(0.002)\end{array}$ & $\begin{array}{l}0.022^{* * *} \\
(0.002)\end{array}$ & $\begin{array}{l}0.020^{* * *} \\
(0.002)\end{array}$ & $\begin{array}{l}0.024^{* * *} \\
(0.002)\end{array}$ \\
\hline Post-Move Log Comm. Dist. & & & & & & & $\begin{array}{l}0.010^{* * *} \\
(0.001)\end{array}$ & $\begin{array}{l}0.001 \\
(0.001)\end{array}$ & $\begin{array}{l}0.001 \\
(0.001)\end{array}$ \\
\hline $\begin{array}{l}\text { Post-Move Amenities Perc. } \\
\text { (First PC, other } 4 \text { unrep.) }\end{array}$ & & & & & & & & $\begin{array}{l}0.290^{* * *} \\
(0.013)\end{array}$ & $\begin{array}{l}0.289^{* * *} \\
(0.013)\end{array}$ \\
\hline $\mathrm{OWP} * \mathrm{~W} 0$ & & & & & & & & & $\begin{array}{l}-0.094^{* * *} \\
(0.010)\end{array}$ \\
\hline Constant & $\begin{array}{l}-0.044^{* * *} \\
(0.009)\end{array}$ & & & & & & & & \\
\hline \multicolumn{10}{|l|}{ Fixed effects } \\
\hline Origin Département \& Year & & $\checkmark$ & $\checkmark$ & $\checkmark$ & $\checkmark$ & $\checkmark$ & $\checkmark$ & $\checkmark$ & $\checkmark$ \\
\hline Age, Birthplace \& Gender & & & $\checkmark$ & $\checkmark$ & $\checkmark$ & $\checkmark$ & $\checkmark$ & $\checkmark$ & $\checkmark$ \\
\hline 2-Digit Origin Occ. \& Ind. & & & & $\checkmark$ & $\checkmark$ & $\checkmark$ & $\checkmark$ & $\checkmark$ & $\checkmark$ \\
\hline Obs. & 292489 & 292489 & 292431 & 292428 & 292428 & 292428 & 270351 & 269914 & 269914 \\
\hline$R^{2}$ & 0.008 & 0.060 & 0.072 & 0.075 & 0.088 & 0.090 & 0.093 & 0.154 & 0.157 \\
\hline W.- $R^{2}$ & & 0.008 & 0.009 & 0.010 & 0.024 & 0.026 & 0.029 & 0.095 & 0.098 \\
\hline
\end{tabular}

22,180 Origin Municipalities; 2002-2007. Standard errors in parenthesis.

${ }^{*} p<0.05,{ }^{* *} p<0.01,{ }^{* * *} p<0.001$. SEs clustered at the department level.

Effect of $\mathrm{OWP}$ at median $\mathrm{W} 0$ in last column $=0.730-0.094 * 3.512=0.400$. At $\mathrm{P} 10=0.496$. At $\mathrm{P} 90=0.334$

would expect if initial income percentile makes borrowing constraints more binding.

Our interpretation of the results above as evidence for the use of the location asset can be threatened by other potentially relevant mechanisms. First, the level of an individual's permanent income is not a direct motivation to borrow or save. This is why we look at the local wage percentile. However, individuals with different earning potentials sort in space. Therefore, the extent to which individuals at the same local wage percentile are financially constrained depends on these individual characteristics $\sqrt[30]{30}$ For example, in a low-ranked location individuals with a given skill can be unconstrained while these same individuals will be constrained in a better location. This form of selection tends to bias the coefficient of the origin wage percentile towards zero if we do not control for an agent's earning potential. Hence, in columns 5 to 9 of Table 1 we control for selection by adding the individual's pre-unemployment wage.

Second, although we would hypothesize that most wage changes will be related to the agent's location choice, we recognize that workers might obtain wage offers that are particularly high or low for idiosyncratic reasons, and that workers may have advance information regarding the future idiosyncratic component of wages. Because wages are mean-reverting, workers who anticipate a particularly high wage after the unemployment shock will expect to then face a downward-sloping income stream. Thus, these workers want to save using the 'location asset'. Hence, a particularly good realization of the idiosyncratic component of wages should be accompanied by location upgrading, while a particularly bad one should come with location

\footnotetext{
${ }^{30}$ Captured by the range of $s$ located in a given city in Figure 1
} 

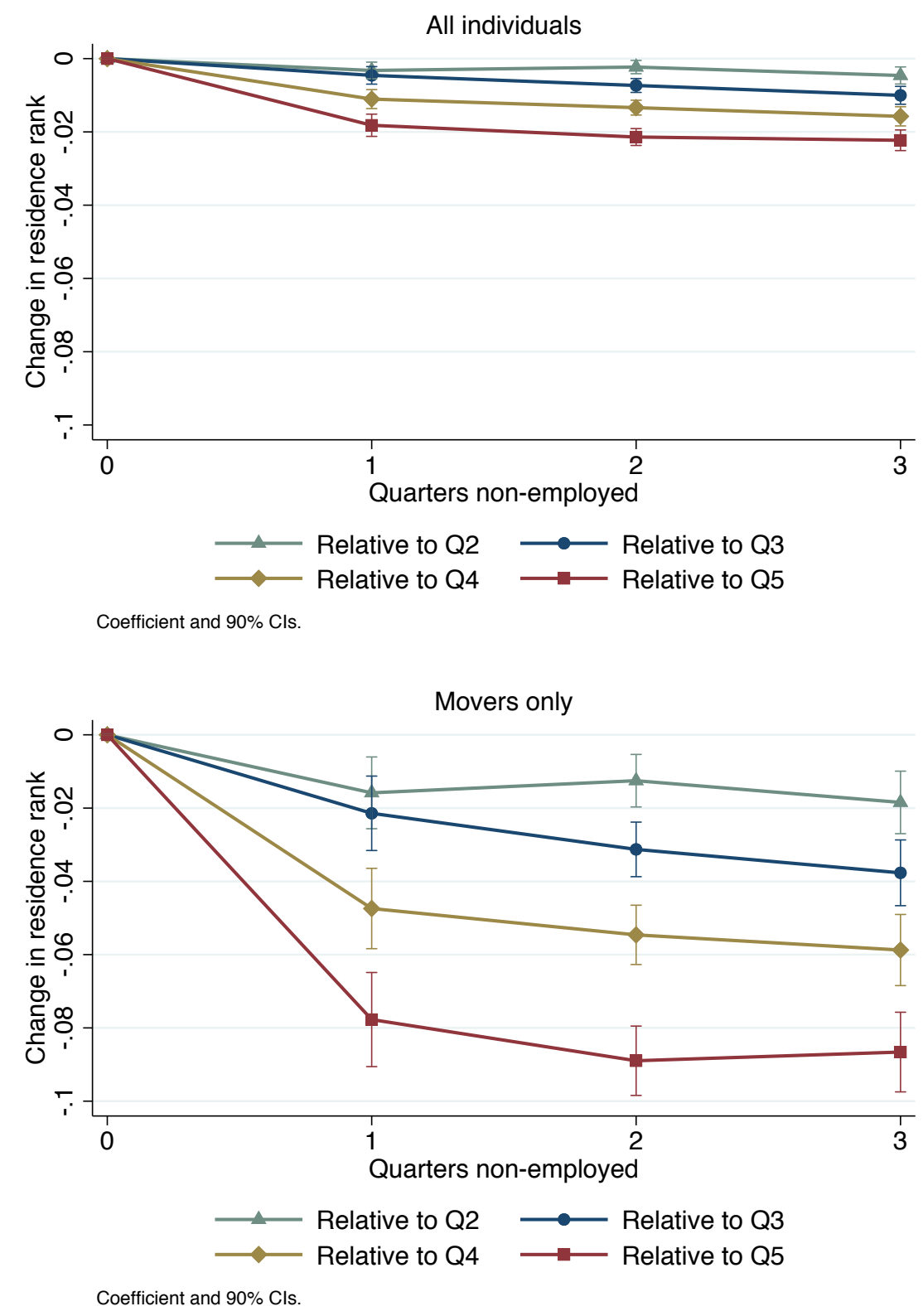

Figure 8: Change in residence percentile and unemployment spell length

downgrading. To alleviate this concern, we also control for post-unemployment wages in columns 6 to 9 of Table 1. Notice that even though post-unemployment variables are likely to be endogenous, adding them in our regressions helps us assess the robustness of our results. In Appendix D.5, we show comparable regressions where we control for wage growth instead of both wages separately. Results are similar.

Third, it could be that location decisions are the result of a static trade-off rather than a dynamic 
investment choice. In particular, one may be concerned that differences in the chosen consumption of local amenities drive our results. Note that it is difficult to rationalize our results arguing that the relative downgrading of location by movers that become non-employed and are at the bottom of a location's income distribution simply reflects their desire to consume relatively less location amenities. The reason is that the income shock associated with non-employment is in general at least as large for high earners, and these agents are the ones for whom location is more elastic. The location decisions of high earners most necessarily be more elastic than that of low earners since otherwise we would not observe them in the same location in equilibrium. Appendix B.2 formalizes this logic using a general version of our model, but without financial constraints, where location choices are the result of the amenities consumption decision only. Nonetheless, we include five measures of local amenities 31 for the destination municipality as controls in columns 8 and 9 of Table 1 to confirm our argument.

Finally, to guarantee that our results are not driven by an increase in worker's commuting time in response to unemployment shocks, we control for commuting distance ${ }^{32}$ after the unemployment spell in columns 6 to 9 of Table 1. Thus, we are comparing mobility patterns of individuals holding constant commuting distance.

The results in columns 5 to 9 of Table 1 reveal that there is a substantial amount of selection across space in the data 33 When we include pre-unemployment wages as a control, the effect of local wage rank rises more than twofold to 0.354 . This means that individuals at the bottom of the local wage distribution downgrade 35.4 percentile points more than individuals at the top in response to an unemployment shock controlling for selection in space. The coefficient on pre-unemployment wage is negative and significant: initially high-wage movers tend to move up less than low-wage earners, reflecting mean-reversion in the data due to positive sorting in space. Controlling for post-unemployment variables (wage, amenities and commuting) leaves the point estimate on OWP essentially unchanged, supporting the view that differences in amenities consumption or commuting do not challenge the 'location as an asset' hypothesis. Unsurprisingly, both post-unemployment wages and amenities are positively associated with location rank

The last column in Table 1 adds an interaction between pre-move wages and local wage ranks. We expect high-earners to react less to unemployment shocks because they are less constrained, and therefore the coefficient on the interaction to be negative. We estimate a large and significant value. To interpret its magnitude, note that it implies that individuals at the 10th percentile of the wage distribution have an OWP coefficient of 0.496 , while individuals at the 90th percentile have an OWP coefficient of 0.334 . Table

\footnotetext{
${ }^{31}$ To compute amenities at the residence municipality level, we use data from the Base Permamente des Equipements 2007 - the closest year available - on the number of 136 types of establishments in health services (e.g. hospitals), education services (e.g. pre-schools), public services (e.g. police stations), and commercial services (e.g. perfumeries). We first compute the number of these establishments per capita in each municipality. Then, we extract the first five principal components of the corresponding correlation matrix. For each municipality, we obtain the loading on each of these five principal components. We choose the sign of the principal component such that the loadings correlate positively with our measure of $z$. Finally, we rank these loadings between 0 and 1.

${ }^{32}$ To construct a measure of commuting distance, we simply compute the geodesic distance between centroids of residence and workplace municipalities.

${ }^{33}$ We expect strong selection because our measure of $z$ is constructed directly from average wages in a location.
} 
22 in Appendix D.5, we reproduce all the previous results with city ranks computed annually instead of being fixed at their 2002 values. The results are extremely similar, and, if anything, slightly larger.

So far our estimates pool observations from municipalities where most individuals are poor and hence expected to be relatively sensitive to unemployment shocks, and municipalities where most individuals are rich and thus expected to be relatively less sensitive to unemployment shocks. Similarly to the negative interaction of OWP and W0, we expect individuals in poor municipalities to use the 'location asset' more because more of them are constrained, or close to constrained, and so have a larger marginal rate of intertemporal substitution. Thus, they should have a larger OWP coefficient. We can estimate this heterogenous effects non-parametrically by decile of the pre-unemployment municipality rank. We include decile fixed effects in our regression in order to account for other sources of differences in mobility patterns across municipalities with different ranks 34 Note that, since part of the mechanism we propose is captured by the effect on location patterns of variation in the extent to which individuals are financially constrained across municipalities, adding location rank decile fixed effects to our specification will understate the use of the location asset.

Figure 9 displays our results graphically. It shows the effect of OWP by municipality decile, using two sets of controls: a full set of fixed effects (dashed blue line) and, in addition, a full set of worker-level controls (solid red line). Consistent with the 'location as an asset' view, in both cases the effect of OWP is monotonically decreasing with the municipality rank. The point estimate is 0.077 and significant at the bottom decile with the full set of worker-level controls, while it is not statistically significant at the top decile. Individuals in the best locations do not use the 'location asset' at all because none of them are constrained, while individuals in the worst locations use it much more. As expected, the estimates are smaller than in our initial specifications because any between-decile variation has been absorbed by the decile fixed effects. Table 14 in Appendix D.5 displays the corresponding coefficients with a linear interaction.

As the results above illustrate, part of the average effect of local wage percentile on the location choices of non-employed movers is accounted for by differential effects across municipalities within a département. Although some of this variation illustrates the differential use across municipalities of the location asset that arises from spatial segregation, it naturally raises the concern that unobserved variation between municipalities could drive all of our results. To address this potential concern, we reproduce the results of Tables 1 in Table 2, when we include pre-unemployment municipality fixed effects. These fixed effects absorb any systematic differences in location decisions after an unemployment shock between municipalities. Given that there is strong spatial sorting, we expect the effect of OWP estimated off residual variation only to be smaller in magnitude. Hence, this specification constitutes the strictest test (perhaps too strict) of our theory so far. We confirm the implications of the 'location as an asset' view, with statistically significant

\footnotetext{
${ }^{34}$ For example, if moves occur for idiosyncratic reasons, workers in bottom deciles can only move up, while individuals in the top decile can only move down. If the local wage rank variable OWP happens to be correlated with some of these mobility shocks, the bias is likely to be strongest at the extremes of the municipality distribution. To circumvent this possible concern, we include decile fixed effects in our regression. They absorb any systematic mobility patterns by decile, and the coefficient on OWP is identified off within-decile variation.
} 


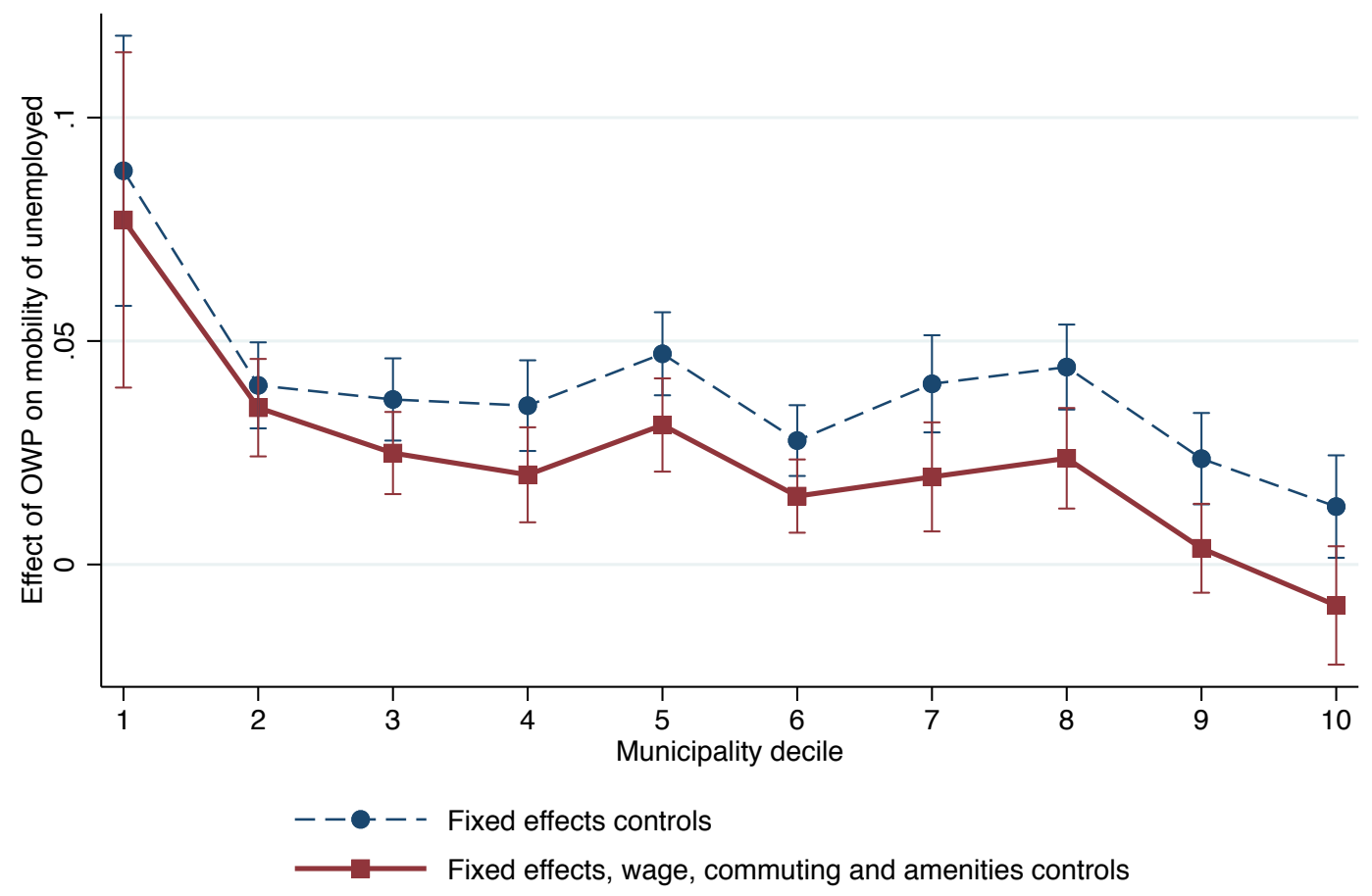

Figure 9: Non-parametric estimates and 90\% confidence intervals, of the effect of OWP by origin municipality deciles. Movers only. Controlling for département, year, age, birthplace, gender, 2-digit occupation, industry, decile fixed effects (dashed blue line), and pre- and post-move wage, commuting distance and amenities (solid red line).

point estimates of the residual OWP coefficient ranging from 0.02 to 0.06 , consistent with the magnitudes we obtained with decile fixed effects.

The reduction in the magnitude of the estimates between Table 1 and 2 could also be the result of a stronger attenuation bias when we include municipality fixed effects. Undoubtedly, in the $4 \%$ sample in Table 2, individual local wage percentiles are necessarily measured with error. To account for this possibility, we run the same specifications using repeated 2-year panels with the universe of French workers35. The results, presented in Tables 7 and 8 in Appendix D.4, indicate that the estimates are similar when we include département fixed effects. However, as expected, they are larger when we include municipality fixed effect. Using the universe of workers and municipality fixed effects the coefficient on OWP is always above 0.06 without individual-level controls and remains above 0.144 when including individual-level controls. In all specifications the coefficient on OWP is statistically significant at the $0.1 \%$ level.

One additional concern with our exercise is that transitions into non-employment might be voluntary and

\footnotetext{
${ }^{35}$ For consistency, we use the $4 \%$ sample throughout the main text given that several of our exercises require the longitudinal dimension, which is missing from the dataset with the universe of workers. The results that can be reproduced with this alternative dataset are similar and presented in Appendix D.4.
} 
Table 2: Unemployment spells and location decisions within municipalities

\begin{tabular}{|c|c|c|c|c|c|c|c|c|}
\hline Origin Wage Perc. (OWP) & $\begin{array}{l}0.100^{* * *} \\
(0.005)\end{array}$ & $\begin{array}{l}0.063^{* * *} \\
(0.003)\end{array}$ & $\begin{array}{l}0.066^{* * *} \\
(0.003)\end{array}$ & $\begin{array}{l}0.035^{* * *} \\
(0.003)\end{array}$ & $\begin{array}{l}0.044^{* * *} \\
(0.004)\end{array}$ & $\begin{array}{l}0.026^{* * *} \\
(0.005)\end{array}$ & $\begin{array}{l}0.022^{* * *} \\
(0.005)\end{array}$ & $\begin{array}{l}0.019^{* * *} \\
(0.004)\end{array}$ \\
\hline \multicolumn{9}{|l|}{ Controls } \\
\hline Pre-Move Log Wage & & & & & $\begin{array}{c}-0.003^{*} \\
(0.001)\end{array}$ & $\begin{array}{l}-0.007^{* * *} \\
(0.001)\end{array}$ & $\begin{array}{l}-0.006^{* * *} \\
(0.001)\end{array}$ & $\begin{array}{l}-0.007^{* * *} \\
(0.001)\end{array}$ \\
\hline Post-Move Log Wage & & & & & & $\begin{array}{l}0.034^{* * *} \\
(0.002)\end{array}$ & $\begin{array}{l}0.033^{* * *} \\
(0.002)\end{array}$ & $\begin{array}{l}0.032^{* * *} \\
(0.002)\end{array}$ \\
\hline Post-Move Log Comm. Dist. & & & & & & & $\begin{array}{l}0.008^{* * *} \\
(0.001)\end{array}$ & $\begin{array}{l}-0.001 \\
(0.001)\end{array}$ \\
\hline $\begin{array}{l}\text { Post-Move Amenities Perc. } \\
\text { (First PC, other } 4 \text { unrep.) }\end{array}$ & & & & & & & & $\begin{array}{l}0.308^{* * *} \\
(0.012)\end{array}$ \\
\hline Constant & $\begin{array}{l}-0.044^{* * *} \\
(0.009)\end{array}$ & & & & & & & \\
\hline \multicolumn{9}{|l|}{ Fixed effects } \\
\hline Origin Municipality \& Year & & $\checkmark$ & $\checkmark$ & $\checkmark$ & $\checkmark$ & $\checkmark$ & $\checkmark$ & $\checkmark$ \\
\hline Age, Birthplace \& Gender & & & $\checkmark$ & $\checkmark$ & $\checkmark$ & $\checkmark$ & $\checkmark$ & $\checkmark$ \\
\hline 2-Digit Origin Occ. \& Ind. & & & & $\checkmark$ & $\checkmark$ & $\checkmark$ & $\checkmark$ & $\checkmark$ \\
\hline Obs. & 292489 & 287453 & 287394 & 287391 & 287391 & 287391 & 265056 & 264604 \\
\hline$R^{2}$ & 0.008 & 0.455 & 0.463 & 0.466 & 0.466 & 0.470 & 0.474 & 0.530 \\
\hline W. $-R^{2}$ & & 0.005 & 0.005 & 0.001 & 0.001 & 0.009 & 0.012 & 0.117 \\
\hline
\end{tabular}

therefore can select the group of individuals in our empirical exercise. To address this potential concern, we restrict our sample to individuals who were initially located in municipalities where employment contracted significantly, akin to the displaced worker literature. Those individuals are thus more likely to have lost their job for exogenous reasons. As a cutoff, we chose the 10th percentile of the municipality annual employment growth distribution, which is $-5.2 \%$. Tables 9 and 10 in Appendix D.4 reproduce the results of Tables 1 and 2, and show that the coefficients all remain statistically significant and of very similar magnitudes 36 These results suggest that voluntary non-employment transitions do not select the sample in a way that noticeably affects the use of the 'location asset'.

One final potential concern with the results above is that individuals at the bottom of the income distribution in their original location tend to go to lower ranked locations relative to other individuals for reasons unrelated to the unemployment shock. For example, they could be progressively optimizing their location by correcting past location mistakes. That is, the results above could be simply capturing some form of mean reversion in the data that controlling for the variety of fixed effects and worker-level variables in Table 1 does not eliminate. To address this potential concern, ideally we would need a comparison group that moves but does not have an incentive to use the location asset to borrow. Finding such a comparison group is hard because the desire to borrow depends on the whole future expected income path.

\footnotetext{
${ }^{36}$ This strict selection criterion reduces drastically the number of observations, so Tables 9 and 10 in Appendix D.4 use data from the repeated 2-year panels with the universe of French workers. Note that, since there is less selection across municipalities in the sample restricted to contracting places, the coefficient on OWP does not increase as much after the inclusion of individual controls in the specification with municipality fixed effects.
} 
This expectation is likely affected by any job transition or move. We make an attempt to find a suitable, although not perfect, comparison by pulling all employment to employment transitions that generate moves, together with all transitions through non-employment. We use non-employment transitions that last over one year to eliminate non-employment spells that capture voluntary vacations between jobs ${ }^{37}$ We then estimate in the differential effect of origin wage percentile for workers that go through an unemployment spell.

Table 3: Location decisions of unemployed $(1$ year +$)$ relative to job switchers

\begin{tabular}{|c|c|c|c|c|c|}
\hline $1[$ Long EUE] $*$ OWP & $\begin{array}{l}0.020^{* * *} \\
(0.005)\end{array}$ & $\begin{array}{l}0.054^{* * *} \\
(0.013)\end{array}$ & $\begin{array}{l}0.065^{* * *} \\
(0.014)\end{array}$ & $\begin{array}{l}0.064^{* * *} \\
(0.015)\end{array}$ & $\begin{array}{l}0.035^{*} \\
(0.016)\end{array}$ \\
\hline OWP & $\begin{array}{l}0.136^{* * *} \\
(0.008)\end{array}$ & $\begin{array}{l}0.311^{* * *} \\
(0.021)\end{array}$ & $\begin{array}{l}0.291^{* * *} \\
(0.020)\end{array}$ & $\begin{array}{l}0.291^{* * *} \\
(0.020)\end{array}$ & $\begin{array}{l}0.316^{* * *} \\
(0.021)\end{array}$ \\
\hline \multicolumn{6}{|l|}{ Controls } \\
\hline Pre-Move Log Wage (W0) & & $\begin{array}{l}-0.080^{* * *} \\
(0.005)\end{array}$ & $\begin{array}{l}-0.074^{* * *} \\
(0.005)\end{array}$ & $\begin{array}{l}-0.075^{* * *} \\
(0.005)\end{array}$ & $\begin{array}{l}-0.085^{* * *} \\
(0.006)\end{array}$ \\
\hline $1[$ Long EUE] $*$ W0 & & $\begin{array}{l}-0.006^{* *} \\
(0.002)\end{array}$ & $\begin{array}{l}-0.016^{* * *} \\
(0.005)\end{array}$ & $\begin{array}{l}-0.014^{* *} \\
(0.005)\end{array}$ & $\begin{array}{l}-0.006 \\
(0.005)\end{array}$ \\
\hline Post-Move Log Wage (W1) & & & $\begin{array}{l}0.019^{* * *} \\
(0.004)\end{array}$ & $\begin{array}{l}0.017^{* * *} \\
(0.004)\end{array}$ & $\begin{array}{l}0.012^{* *} \\
(0.004)\end{array}$ \\
\hline $1[$ Long EUE $] * \mathrm{~W} 1$ & & & $\begin{array}{l}0.007^{*} \\
(0.004)\end{array}$ & $\begin{array}{l}0.008^{*} \\
(0.004)\end{array}$ & $\begin{array}{l}0.013^{* * *} \\
(0.004)\end{array}$ \\
\hline Post-Move Log Comm. Dist. (C1) & & & & $\begin{array}{l}0.012^{* * *} \\
(0.003)\end{array}$ & $\begin{array}{l}0.002 \\
(0.002)\end{array}$ \\
\hline $1[$ Long EUE $] * \mathrm{C} 1$ & & & & $\begin{array}{l}-0.003 \\
(0.002)\end{array}$ & $\begin{array}{l}-0.002 \\
(0.002)\end{array}$ \\
\hline $\begin{array}{l}\text { Post-Move Amenities Percentile } \\
\text { (A1, First PC, other } 4 \text { unreported) }\end{array}$ & & & & & $\begin{array}{l}0.322^{* * *} \\
(0.017)\end{array}$ \\
\hline $\begin{array}{l}1[\text { Long EUE }] * \text { A } 1 \\
\text { (other } 4 \text { interactions unreported) }\end{array}$ & & & & & $\begin{array}{l}-0.041^{* *} \\
(0.012)\end{array}$ \\
\hline \multicolumn{6}{|l|}{ Fixed Effects } \\
\hline Origin Département \& Year & $\checkmark$ & $\checkmark$ & $\checkmark$ & $\checkmark$ & $\checkmark$ \\
\hline Age, Birthplace \& Gender & $\checkmark$ & $\checkmark$ & $\checkmark$ & $\checkmark$ & $\checkmark$ \\
\hline 2-Digit Origin Occupation \& Industry & $\checkmark$ & $\checkmark$ & $\checkmark$ & $\checkmark$ & $\checkmark$ \\
\hline Obs. & 204037 & 204037 & 204037 & 188111 & 187801 \\
\hline$R^{2}$ & 0.075 & 0.088 & 0.091 & 0.093 & 0.153 \\
\hline W.- $R^{2}$ & 0.011 & 0.025 & 0.028 & 0.031 & 0.095 \\
\hline
\end{tabular}

The results are presented in Table 3. The second row indicates the overall effect of origin wage percentile, while the first row indicates the differential effect when individuals go through an unemployment spell. We expect the differential effect to be positive and significant. This is the case for all combinations of fixed effects presented in the table. In our preferred specification in column two, the differential effect is a downgrade of 5.4 percentage points for individuals at the bottom of the origin wage percentile (relative to those at the top) that go through an unemployment spell longer than a year, relative to those that go through a job-tojob transition. The finding in the first row that the effect of origin wage percentile is large and significant

\footnotetext{
${ }^{37}$ We present results with all non-employment transitions (as defined in the rest of the exercises) in Appendix D.5 The results are similar.
} 
indicates that agents in this sub-sample downgrade more if they have relatively low wages in their location. This might be the result of the cost involved in moves or job switches, or the benefit of the job switch in terms of higher wage growth in the future (which makes individuals want to borrow with the location asset even in job-to-job transitions that increase wages). Table 11 in Appendix D.4 shows that our results are very similar when using the universe of workers, except that the coefficient on the interaction in the last column remains high (0.076) and significant at the $0.1 \%$ level.

We reproduce can also reproduce this exercise restricting our sample to job switches in expanding municipalities, and non-employment spells in contracting municipalities. The rational is clear: Individuals who switch jobs in booming municipalities are less likely to do so because they were or expected to be fired, while individuals who separate in contracting municipalities are more likely to do so because they lost their job. This stricter selection criterion should improve the quality of the comparison and, therefore, the effect of non-employment on the use of the location asset. This is exactly what Table 12 in Appendix D.4 reveals. The marginal effect of OWP of going through non-employment in a contracting municipality, relative to switching jobs in an expanding municipality, increases two- to threefold (0.135) relative to our baseline exercise and is always statistically significant at the $0.1 \%$ level.

\subsection{Using Imputed Assets}

So far, following our theory, we have used the local wage percentile to proxy for the relative asset position of an individual. Of course, the map between the local wage percentile and likelihood of being financially constrained implied by the theory is unlikely to hold exactly in the data. Thus, here we propose an alternative approach to identify financially constrained individuals. We leverage the longitudinal $4 \%$ sample to construct assets from wage data using a perpetual inventory method. We then replace our measure of local wage rank, OWP, by a measure of local asset holdings percentile, OAP. The advantage of this approach is that it relaxes the underlying assumption of a strong positive correlation between relative wages rank and relative asset holdings. However, it comes at the additional cost of making another set of assumptions to construct savings. Therefore, we view both exercises as complementary.

To construct our measure of assets we first solve a standard consumption-savings model with quadratic utility and without credit constraints ${ }^{38}$ Under standard assumptions detailed in Appendix D.6, it is well known that savings, $s_{t}$, in this model have a simple expression as a function of current and expected permanent income $\left\{y_{t}\right\}$, namely,

$$
s_{t}=y_{t}-\frac{R-1}{R-R^{-T}} E_{t}\left[\sum_{s=t}^{T} R^{-(s-t)} y_{t+s}\right],
$$

\footnotetext{
${ }^{38}$ To construct assets, the ideal method would be to express savings as a function of wages in a model with credit constraints, compute savings from the data, and finally cumulate savings to obtain assets. However, models with credit constraints do not typically yield closed-form expressions of savings as a function of income. Therefore, any savings function we would obtain from a model with financial constraints would inevitably rely on the particular parameters chosen to simulate the model, an any sensitivity analysis with respect to those parameters would require to solve the model numerically again.
} 
where $E_{t}$ denotes the expectation operator and the gross interest rate, $R$, is assumed fixed. We posit that savings in this model approximate savings in a model with credit constraints. We then make two alternative assumptions regarding how individuals construct expectations of their future income stream, and report results for both cases.

First, we assume that individuals believe that wage growth follows an $\mathrm{AR}(1)$ process which we estimate in the data. Under some technical assumptions detailed in Appendix D.6, savings are given by a simple policy rule that depends only on current income and past income growth. Namely,

$$
s_{t}=\frac{y_{t}}{R}\left(1-\left(\frac{y_{t}}{y_{t-1}}\right)^{\rho}\right)
$$

where $\rho$ is the autocorrelation of the $\operatorname{AR}(1)$ process for wage growth, which we estimate to be -0.36 annually. We refer to this approach as the forecasting method.

Second, we alternatively assume that individuals have perfect foresight and thus perfectly anticipate their future wages, which we can directly read off from the data. This approach does not require us to take a stand on a particular statistical process for income but it assume that individuals can perfectly anticipate the future. We compute permanent income from wages in the 1994-2007 data 39

In both instances, we then cumulate savings starting at zero assets when we first observe individuals in the data, and rank assets in each municipality, as we did for wages, to obtain a local asset percentile, OAP. Note that, although both methods are expected to approximate assets, they are very distinct empirical measures: the forecasting method only uses current and past wages to infer savings, while the perfect foresight method only uses current and future wages. Therefore, obtaining similar results with both methods lends additional support to our methodology and hypothesis.

Table 4 first shows our results for the forecasting method, when we regress mobility decisions on our asset-based measure, OAP, instead of our wage-based measure OWP. The results are qualitatively similar to those with the OWP measure. The coefficient on the local asset percentile is always statistically significant and ranges from 0.067 to 0.09 depending on the specification, implying that the poorest individuals in a location downgrade location between 6.7 and 9 percentile points more than the wealthiest individuals in a location when going through unemployment. Table 23 in Appendix D.8, we reproduce the previous results with city ranks computed annually instead of being fixed at their 2002 values. The results are extremely similar, and, if anything, slightly larger. In all cases, the values of the coefficient on OAP are smaller than when using local wage ranks OWP. This is likely the result of classical measurement error on the righthand-side which biases our coefficient of interest towards zero. Indeed, because we impute assets from wage data, we inevitably introduce a substantial amount of noise 40 To address the potential attenuation bias, we

\footnotetext{
${ }^{39}$ Since we do not have data beyond 2007, our calculation implicitly assumes that in any given year, agents expect their income after 2007 to be constant at the average income between the current year and 2007 .

${ }^{40}$ The second reason could be a combination of static amenities demand and selection on unobserved heterogeneity that is not captured by our wage and amenities controls. If high earners in poor places expect high wages in the future, they want to upgrade location, irrespectively of the unemployment shock, in order to consume more amenities. If the coefficient on OWP captures this effect, we would expect it to be larger than the one on OAP, since accumulated assets do not determine static
} 
Table 4: Unemployment spells and location decisions using Local Asset Percentile measure: OLS

\begin{tabular}{|c|c|c|c|c|c|c|c|c|}
\hline Origin Asset Perc. (OAP) & $\begin{array}{l}0.077^{* * *} \\
(0.004)\end{array}$ & $\begin{array}{l}0.067^{* * *} \\
(0.003)\end{array}$ & $\begin{array}{l}0.071^{* * *} \\
(0.005)\end{array}$ & $\begin{array}{l}0.073^{* * *} \\
(0.006)\end{array}$ & $\begin{array}{l}0.090^{* * *} \\
(0.007)\end{array}$ & $\begin{array}{l}0.084^{* * *} \\
(0.007)\end{array}$ & $\begin{array}{l}0.084^{* * *} \\
(0.007)\end{array}$ & $\begin{array}{l}0.080^{* * *} \\
(0.008)\end{array}$ \\
\hline \multicolumn{9}{|l|}{ Controls } \\
\hline Pre-Move Log Wage & & & & & $\begin{array}{l}-0.014^{* * *} \\
(0.002)\end{array}$ & $\begin{array}{l}-0.019^{* * *} \\
(0.002)\end{array}$ & $\begin{array}{l}-0.019^{* * *} \\
(0.002)\end{array}$ & $\begin{array}{l}-0.020^{* * *} \\
(0.002)\end{array}$ \\
\hline Post-Move Log Wage & & & & & & $\begin{array}{l}0.027^{* * *} \\
(0.002)\end{array}$ & $\begin{array}{l}0.026^{* * *} \\
(0.002)\end{array}$ & $\begin{array}{l}0.024^{* * *} \\
(0.002)\end{array}$ \\
\hline Post-Move Log Comm. Dist. & & & & & & & $\begin{array}{l}0.011^{* * *} \\
(0.001)\end{array}$ & $\begin{array}{l}0.001 \\
(0.001)\end{array}$ \\
\hline $\begin{array}{l}\text { Post-Move Amenities Perc. } \\
\text { (First PC, other } 4 \text { unrep.) }\end{array}$ & & & & & & & & $\begin{array}{l}0.289^{* * *} \\
(0.013)\end{array}$ \\
\hline Constant & $\begin{array}{l}-0.041^{* * *} \\
(0.012)\end{array}$ & & & & & & & \\
\hline \multicolumn{9}{|l|}{ Fixed Effects } \\
\hline Origin Département \& Year & & $\checkmark$ & $\checkmark$ & $\checkmark$ & $\checkmark$ & $\checkmark$ & $\checkmark$ & $\checkmark$ \\
\hline Age, Birthplace \& Gender & & & $\checkmark$ & $\checkmark$ & $\checkmark$ & $\checkmark$ & $\checkmark$ & $\checkmark$ \\
\hline 2-Digit Origin Occ. \& Ind. & & & & $\checkmark$ & $\checkmark$ & $\checkmark$ & $\checkmark$ & $\checkmark$ \\
\hline Obs. & 292489 & 292489 & 292431 & 292428 & 292428 & 292428 & 270351 & 269914 \\
\hline$R^{2}$ & 0.004 & 0.055 & 0.066 & 0.068 & 0.069 & 0.072 & 0.075 & 0.136 \\
\hline W.- $R^{2}$ & & 0.003 & 0.003 & 0.003 & 0.004 & 0.007 & 0.010 & 0.075 \\
\hline
\end{tabular}

recognize that our theory identifies OWP as a valid instrument for OAP. Therefore, in Table 16 in Appendix D.7 we reproduce the exercise from Table 4, but instrumenting OAP with OWP. The coefficients on OAP increases in all specifications once we instrument using OWP ${ }^{41}$ The magnitudes become even larger than in our results using directly OWP. Put together, these patterns are consistent with statistical measurement error in OAP. Furthermore, since through the lens of the 'location as an asset' perspective, OWP contains measurement error when used to predict mobility decisions, it is natural that the instrumented coefficient on OAP is larger than the coefficient on OWP. We report the corresponding results using the perfect foresight method in Table 17 in Appendix D.7. The results are very similar, which is encouraging.

Once we adjust our estimation strategy to account for the attenuation bias using the instrumental variable approach, we can perform the stricter test of our theory where we measure the heterogenous effect of local asset percentile by decile. In Figure 10, we estimate non-parametrically the effect of OAP by municipality decile when instrumenting with OWP, as in Figure 9. We observe that the results are qualitatively similar to using OWP, although a bit larger. The effect is monotonically declining up to a statistical zero at the top. In Table 18 in Appendix D.7, we report the corresponding results with a linear interaction.

As a final test of our theory, we investigate the effect of local asset percentile on location choices after an unemployment shock controlling for municipality fixed effects. As before, these fixed effects absorb any systematic mobility patterns by origin municipality. Thus, we are now identifying the effect of OAP only from within-municipality deviations from the mean. We again instrument using OWP to correct for amenities demand. The instrumental variable results below falsify this hypothesis.

${ }^{41}$ The F-statistics of the first stage (unreported) are all well above the Stock-Yogo (2005) critical values. 


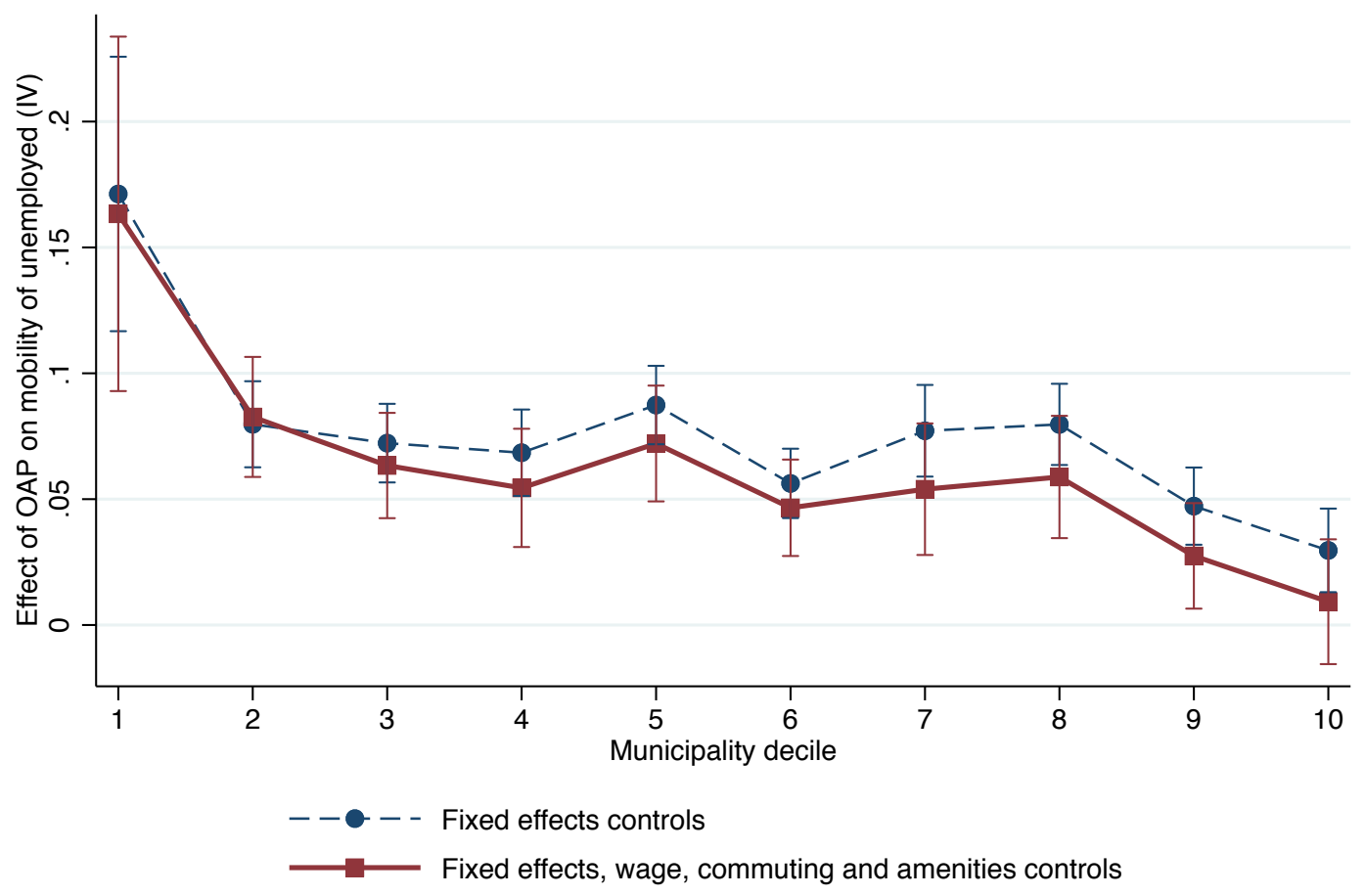

Figure 10: Non-parametric estimates and $90 \%$ confidence intervals, of the effect of OAP by origin municipality deciles. Movers only. Using OWP as instrument and controlling for département, year, age, birthplace, gender, 2-digit occupation, industry, decile fixed effects (dashed blue line), and pre- and post-move wage, commuting distance and amenities (solid red line). Forecasting method.

attenuation bias. The results are reported in Table 5. The effect of OAP is statistically significant in all specifications, ranging from 0.06 to 0.13 , thus supporting the 'location as an asset' perspective. This is perhaps the most stringent test of our theory and the effects remain quite large and significant. We report very similar results in Table 19 in Appendix D.7 when we use the perfect foresight method 42

\section{Conclusions}

This paper provides an alternative view of individual location decisions. We have argued that we can understand location decisions as an investment that allows individuals to transfer resources across periods even when they are constrained in financial markets. Individuals that are constrained to borrow in the financial markets use the location asset to borrow and live in locations that offer relatively bad work and educational opportunities but are cheap in terms of housing costs and other local expenses. Hence, our view

\footnotetext{
${ }^{42}$ We also obtain similar results in Tables 20 and 21 in Appendix D.7 where we restrict the sample to declining municipalities. However, because we can only construct assets in the $4 \%$ sample, for this exercise we restrict the sample to municipalities in which employment growth is below the 25 th percentile $(-0.4 \%)$. This allows us to maintain a large enough number of observations and include all our controls.
} 
Table 5: Unemployment spells and location decisions using Local Asset Percentile measure: IV

\begin{tabular}{|c|c|c|c|c|c|c|c|c|}
\hline Origin Asset Perc. (OAP) & $\begin{array}{l}0.160^{* * *} \\
(0.010)\end{array}$ & $\begin{array}{l}0.099^{* * *} \\
(0.005)\end{array}$ & $\begin{array}{l}0.117^{* * *} \\
(0.004)\end{array}$ & $\begin{array}{l}0.068^{* * *} \\
(0.005)\end{array}$ & $\begin{array}{l}0.131^{* * *} \\
(0.013)\end{array}$ & $\begin{array}{l}0.081^{* * *} \\
(0.015)\end{array}$ & $\begin{array}{l}0.068^{* * *} \\
(0.015)\end{array}$ & $\begin{array}{l}0.059^{* * *} \\
(0.014)\end{array}$ \\
\hline \multicolumn{9}{|l|}{ Controls } \\
\hline Pre-Move Log Wage & & & & & $\begin{array}{l}-0.013^{* * *} \\
(0.002)\end{array}$ & $\begin{array}{l}-0.012^{* * *} \\
(0.002)\end{array}$ & $\begin{array}{l}-0.011^{* * *} \\
(0.002)\end{array}$ & $\begin{array}{l}-0.011^{* * *} \\
(0.002)\end{array}$ \\
\hline Post-Move Log Wage & & & & & & $\begin{array}{l}0.033^{* * *} \\
(0.002)\end{array}$ & $\begin{array}{l}0.032^{* * *} \\
(0.002)\end{array}$ & $\begin{array}{l}0.030^{* * *} \\
(0.002)\end{array}$ \\
\hline Post-move Log Comm. Dist. & & & & & & & $\begin{array}{l}0.008^{* * *} \\
(0.001)\end{array}$ & $\begin{array}{l}-0.001 \\
(0.001)\end{array}$ \\
\hline $\begin{array}{l}\text { Post-Move Amenities Perc. } \\
\text { (First PC, other } 4 \text { unrep.) }\end{array}$ & & & & & & & & $\begin{array}{l}0.308^{* * *} \\
(0.012)\end{array}$ \\
\hline Constant & $\begin{array}{l}-0.089^{* * *} \\
(0.007)\end{array}$ & & & & & & & \\
\hline \multicolumn{9}{|l|}{ Fixed effects } \\
\hline Origin Municipality \& Year & & $\checkmark$ & $\checkmark$ & $\checkmark$ & $\checkmark$ & $\checkmark$ & $\checkmark$ & $\checkmark$ \\
\hline Age, Birthplace \& Gender & & & $\checkmark$ & $\checkmark$ & $\checkmark$ & $\checkmark$ & $\checkmark$ & $\checkmark$ \\
\hline 2-Digit Origin Occ. \& Ind. & & & & $\checkmark$ & $\checkmark$ & $\checkmark$ & $\checkmark$ & $\checkmark$ \\
\hline Obs. & 292489 & 287453 & 287394 & 287391 & 287391 & 287391 & 265056 & 264604 \\
\hline
\end{tabular}

of location choices underscores the importance of the incentives to smooth consumption and the extent to which individuals face financial constraints as essential to understand where they live.

We show that the implications of our model can rationalize the moving choices observed in France when individuals go through unemployment spells. More generally, our view can help explain why some individual locate in areas that seem so undesirable otherwise. The fact that many individuals choose to live in such locations, rather than in areas that offer more opportunities, might seem puzzling from a static perspective, but is a perfectly reasonable choice through the lens of our dynamic theory. In most cases the previous literature has relied on unobserved, and implausibly large, migration costs to explain these choices. In contrast, our view can rationalize this behavior even when migration is perfectly free. The change in perspective is relevant for policy. As we have argued, using place-based policies to improve some of the worse locations can harm some of the less skilled agents in the economy.

Of course, the 'location as an asset' view is more general than the particular model we put forward in this paper and can be contrasted more fully with the data. For example, modelling location choices in an overlapping generations model with multiple locations could help us understand the implications of our view for life-cycle patterns and investment in the skills of descendants. Modelling location choices as changing the properties of an agents income process (by, for example, affecting the likelihood of becoming unemployed) would allow us to study the value of the location asset to manage risk. In addition, in general equilibrium, the agents that decide to locate in a particular region determine, at least partly, the characteristic of the region. Incorporating this form of external effects could lead to interesting insights for policy. Finally, embedding this type of consumption-savings decision with borrowing constraints in a fully-fledged quantitative spatial 
model with skill complementarities, factor price determination, mobility and trade could help decompose the role of the location asset in determining net mobility patterns relative to other forces. It could also help us understand how the use of location as an asset affects the evaluation of global phenomena that affect factor rewards in particular locations, occupations, and industries. 


\section{References}

[1] J. M. Abowd, F. Kramarz, and D. N. Margolis. High Wage Workers and High Wage Firms. Econometrica, 67(2):251-333.

[2] T. Allen and C. Arkolakis. Trade and the Topography of the Spatial Economy. Working Paper 19181, National Bureau of Economic Research, June 2013.

[3] J. Altonji and R. Mansfield. The Role of Family, School, and Community Characteristics in Inequality in Education and Labor-Market Outcomes. Technical report, 2011.

[4] G.-M. Angeletos. Uninsured Idiosyncratic Investment Risk and Aggregate Saving. Review of Economic Dynamics, 10(1):1 - 30, 2007.

[5] N. Baum-Snow and R. Pavan. Understanding the City Size Wage Gap. The Review of Economic Studies, 79(1):88-127, 2012.

[6] S. Bonhomme, T. Lamadon, and E. Manresa. A Distributional Framework for Matched Employer Employee Data. Technical report, 2015.

[7] L. Caliendo, M. Dvorkin, and F. Parro. Trade and Labor Market Dynamics: General Equilibrium Analysis of the China Trade Shock. Working Papers 2015-9, Federal Reserve Bank of St. Louis, May 2015.

[8] L. Caliendo, L. D. Opromolla, F. Parro, and A. Sforza. Goods and Factor Market Integration: A Quantitative Assessment of the EU Enlargement. Working Paper 23695, National Bureau of Economic Research, August 2017.

[9] C. D. Carroll. The Method of Endogenous Gridpoints for Solving Dynamic Stochastic Optimization Problems. Economics Letters, 91(3):312 - 320, 2006.

[10] P. Cavalcanti-Ferreira, A. Monge-Naranjo, and L. T. de Mello Pereira. Of Cities and Slums. Technical report, 2018.

[11] R. Chetty and N. Hendren. The Impacts of Neighborhoods on Intergenerational Mobility I: Childhood Exposure Effects. Working Paper 23001, National Bureau of Economic Research, December 2016.

[12] R. Chetty, N. Hendren, and L. F. Katz. The Effects of Exposure to Better Neighborhoods on Children: New Evidence from the Moving to Opportunity Experiment. American Economic Review, 106(4):855902, April 2016.

[13] D. M. Cutler and E. L. Glaeser. Are Ghettos Good or Bad? The Quarterly Journal of Economics, 112(3):827-872, 1997. 
[14] M. A. Davis, J. Gregory, D. A. Hartley, and K. Tan. Neighborhood Choices, Neighborhood Effects and Housing Vouchers. FRB of Chicago Working Paper No. WP-2017-2, 2015.

[15] M. A. Davis and F. Ortalo-Magne. Household Expenditures, Wages, Rents. Review of Economic Dynamics, 14(2):248 - 261, 2011.

[16] J. De La Roca and D. Puga. Learning by Working in Big Cities. The Review of Economic Studies, 84(1):106-142, 2017.

[17] N. A. Denton and D. S. Massey. American Apartheid: Segregation and the Making of the Underclass. Cambridge, Mass: Harvard University Press.

[18] K. Desmet, D. Nagy, and E. Rossi-Hansberg. The Geography of Development. Journal of Political Economy, 2018.

[19] K. Desmet and E. Rossi-Hansberg. Urban Accounting and Welfare. American Economic Review, 103(6):2296-2327, October 2013.

[20] K. Desmet and E. Rossi-Hansberg. On the Spatial Economic Impact of Global Warming. Journal of Urban Economics, 88:16 - 37, 2015.

[21] R. Diamond. The Determinants and Welfare Implications of US Workers' Diverging Location Choices by Skill: 1980-2000. American Economic Review, 106(3):479-524, March 2016.

[22] R. Diamond, T. McQuade, and F. Qian. The Effects of Rent Control Expansion on Tenants, Landlords, and Inequality: Evidence from San Francisco. Working Paper 24181, National Bureau of Economic Research, January 2018.

[23] G. J. Duncan, J. Ludwig, L. A. Gennetian, L. F. Katz, R. C. Kessler, J. R. Kling, and L. Sanbonmatsu. Long-Term Neighborhood Effects on Low-Income Families: Evidence from Moving to Opportunity. American Economic Review, 103(3):226-31, May 2013.

[24] R. Fernandez and R. Rogerson. Public Education and Income Distribution: A Dynamic Quantitative Evaluation of Education-Finance Reform. The American Economic Review, 88(4):813-833, 1998.

[25] A. Fogli and V. Guerrieri. The End of the American Dream? Inequality and Segregation in US cities. Working Paper, 2018.

[26] A. Galichon. Optimal Transport Methods in Economics. Princeton University Press, 2016.

[27] E. Giannone. Skill-Biased Technical Change and Regional Convergence. 2017 Meeting Papers 190, Society for Economic Dynamics, 2017.

[28] E. L. Glaeser and D. C. Mare. Cities and Skills. Journal of Labor Economics, 19(2):316-342, 2001. 
[29] C.-T. Hsieh and E. Moretti. Housing Constraints and Spatial Misallocation. Working Paper 21154, National Bureau of Economic Research, May 2015.

[30] M. Huggett. The Risk-Free Rate in Heterogeneous-Agent Incomplete-Insurance Economies. Journal of Economic Dynamics and Control, 17(5):953 - 969, 1993.

[31] G. Kaplan and S. Schulhofer-Wohl. Understanding the Long-Run Decline in Interstate Migration. International Economic Review, 58(1):57-94, 2017.

[32] J. Kennan and J. R. Walker. The Effect of Expected Income on Individual Migration Decisions. Econometrica, 79(1):211-251, 2011.

[33] R. E. J. Lucas. Life Earnings and Rural-Urban Migration. Journal of Political Economy, 112(S1):S29S59, 2004.

[34] B. Moll. Productivity Losses from Financial Frictions: Can Self-Financing Undo Capital Misallocation? American Economic Review, 104(10):3186-3221, October 2014.

[35] M. Morten. Temporary Migration and Endogenous Risk Sharing in Village India. Working Paper 22159, National Bureau of Economic Research, April 2016.

[36] F. Postel-Vinay and J.-M. Robin. Equilibrium Wage Dispersion with Worker and Employer Heterogeneity. Econometrica, 70(6):2295-2350, 2002.

[37] S. J. Redding. Goods Trade, Factor Mobility and Welfare. Journal of International Economics, 101:148 $-167,2016$.

[38] L. A. Sjaastad. The Costs and Returns of Human Migration. Journal of Political Economy, 70(5):80-93, 1962.

[39] J. Stock and M. Yogo. Testing for Weak Instruments in Linear IV Regression. Andrews DWK Identification and Inference for Econometric Models, pages 80-108, 2005.

[40] W. J. Wilson. The Truly Disadvantaged. The Inner City, the Underclass and Public Policy. University of Chicago Press, 1987. 


\section{A Appendix: Proofs for the model in Section 2}

\section{A.1 Proof of Lemma 1}

We split the proof in three parts:

1. Location decisions of constrained and unconstrained individuals

2. Equilibrium in cities in which at least one unconstrained individual lives

3. Equilibrium in cities with only constrained individuals

\section{A.1.1 Location decisions}

Recall that for unconstrained individuals,

$$
R=\frac{s}{q^{\prime}(z)}
$$

Therefore, unconstrained individuals of skill $s$ locate in cities $\mathcal{Z}^{U}(s)$ such that

$$
R=\frac{s}{q^{\prime}\left(\mathcal{Z}^{U}(s)\right)}
$$

In addition, some constrained individuals may choose cities in which only constrained individuals locate. For those individuals, we cannot use the expression above, and we directly use the mobility Euler equation:

$$
\frac{\left(y_{1}+R \underline{a}\right)+z \mathcal{S}^{C}\left(y_{0}, y_{1}, z\right)}{\beta\left[y_{0}-\underline{a}-q(z)\right]}=\frac{\mathcal{S}^{C}\left(y_{0}, y_{1}, z\right)}{q^{\prime}(z)}
$$

which implies

$$
\mathcal{S}^{C}\left(y_{0}, y_{1}, z\right)=\frac{q^{\prime}(z)\left(y_{1}+R \underline{a}\right)}{\beta\left[y_{0}-\underline{a}-q(z)\right]-z q^{\prime}(z)}
$$

Notice that for constrained individuals $\left(y_{0}, y_{1}, \mathcal{S}^{C}\left(y_{0}, y_{1}, z\right)\right)$ who locate in a city $z$ where at least one unconstrained individual with skill $\mathcal{S}^{U}(z)$ lives, we can substitute out $q^{\prime}(z)=\mathcal{S}^{U}(z) / R$, leading to

$$
\mathcal{S}^{C}\left(y_{0}, y_{1}, z\right)=\frac{\mathcal{S}^{U}(z)\left(y_{1}+R \underline{a}\right)}{\beta R\left(y_{0}-\underline{a}-q(z)\right)-z \mathcal{S}^{U}(z)}
$$

In the sequel, it will be useful to have notation for this relationship in terms of all the endogenous objects. Therefore, we define

$$
X\left(y_{0}, y_{1}, s, \mathcal{Z}^{U}(s), q\left(\mathcal{Z}^{U}(s)\right)\right)=\frac{s\left(y_{1}+R \underline{a}\right)}{\beta R\left(y_{0}-\underline{a}-q\left(\mathcal{Z}^{U}(s)\right)\right)-\mathcal{Z}^{U}(s) s}
$$

Equation 13 describes which constrained individuals $\left(y_{0}, y_{1}, X\left(y_{0}, y_{1}, s, \mathcal{Z}^{U}(s), q\left(\mathcal{Z}^{U}(s)\right)\right)\right)$ choose to locate in city $\mathcal{Z}^{U}(s)$. 
To obtain the lowest possible income in a given city, we can re-write equation (12) as

$$
y_{0}=\underline{a}+q(z)+\frac{1}{\beta R}\left[z \mathcal{S}^{U}(z)+\frac{\left(y_{1}+R \underline{a}\right) \mathcal{S}^{U}(z)}{\mathcal{S}^{C}\left(y_{0}, y_{1}, z\right)}\right]
$$

This delivers the lower bound on initial income for constrained individuals who locate in city $z$ with at least an unconstrained individual:

$$
y_{0} \geq \underline{Y}_{0}(z)=\underline{a}+q(z)+\frac{1}{\beta R}\left[z \mathcal{S}^{U}(z)+\left(\underline{y_{1}}+R \underline{a}\right) \times \frac{\mathcal{S}^{U}(z)}{\bar{s}}\right]
$$

A similar bound involving $q^{\prime}(z)$ holds for cities in which only unconstrained individuals live.

\section{A.1.2 Equilibrium in cities with at least one unconstrained individual}

We first consider equilibrium in cities with at least one constrained individual. Because at any skill, constrained individuals locate in worse cities that unconstrained individuals, cities with unconstrained individuals have higher $z$ than those with only constrained individuals. Thus, there exists a cutoff $\hat{z}$ such that a city has at least one unconstrained individual iff $z \geq \hat{z}$.

We start by assuming that the matching function $\mathcal{Z}^{U}(s)$ is increasing at all $s$. Total population that locates in cities $\left[\mathcal{Z}^{U}(s), \mathcal{Z}^{U}(s)+\mathcal{Z}_{s}^{U}(s) d s\right)$ is the sum of the unconstrained individuals of the same skill and constrained individuals of higher skill. Before expressing total population, we denote by

$$
\tilde{A}\left(y_{0}, y_{1}, s, \mathcal{Z}^{U}(s), q\left(\mathcal{Z}^{U}(s)\right)\right)=y_{0}-q\left(\mathcal{Z}^{U}(s)\right)-\frac{y_{0}-q\left(\mathcal{Z}^{U}(s)\right)+\frac{y_{1}+s \mathcal{Z}^{U}(s)}{R}}{1+\beta}
$$

desired savings as a function of individual characteristics and the matching function. Using the notation we defined, we can express total population as:

$$
\begin{aligned}
& G\left(s, \mathcal{Z}^{U}(s), q\left(\mathcal{Z}^{U}(s)\right), \mathcal{Z}_{s}^{U}(s)\right) \\
\equiv & \iint f\left(y_{0}, y_{1}, s\right) \mathbf{1}\left[\tilde{A}\left(y_{0}, y_{1}, s, \mathcal{Z}^{U}(s), q\left(\mathcal{Z}^{U}(s)\right)\right)>\underline{a}\right] d y_{0} d y_{1} \\
+ & \iint \mathbf{1}\left[\tilde{A}\left(y_{0}, y_{1}, s, \mathcal{Z}^{U}(s), q\left(\mathcal{Z}^{U}(s)\right)\right) \leq \underline{a}\right] \\
& \quad \times f\left(y_{0}, y_{1}, X\left(y_{0}, y_{1}, s, \mathcal{Z}^{U}(s), q\left(\mathcal{Z}^{U}(s)\right)\right)\right) \times \frac{d\left[X\left(y_{0}, y_{1}, s, \mathcal{Z}^{U}(s), q\left(\mathcal{Z}^{U}(s)\right)\right)\right]}{d s} d y_{0} d y_{1}
\end{aligned}
$$

where it is understood that $\frac{d\left[X\left(y_{0}, y_{1}, s, \mathcal{Z}^{U}(s), q\left(\mathcal{Z}^{U}(s)\right)\right)\right]}{d s}$ is the total derivative of $s \mapsto X\left(y_{0}, y_{1}, s, \mathcal{Z}^{U}(s), q\left(\mathcal{Z}^{U}(s)\right)\right)$ 
with respect to $s$. We can calculate this last term explicitly:

$$
\begin{aligned}
\frac{d\left[X\left(y_{0}, y_{1}, s, \mathcal{Z}^{U}(s), q\left(\mathcal{Z}^{U}(s)\right)\right)\right]}{d s} \equiv & X_{0}\left(y_{0}, y_{1}, s, \mathcal{Z}^{U}(s), q\left(\mathcal{Z}^{U}(s)\right)\right) \\
& +\frac{X_{1}\left(y_{0}, y_{1}, s, \mathcal{Z}^{U}(s), q\left(\mathcal{Z}^{U}(s)\right)\right) \times \mathcal{Z}_{s}^{U}(s)}{1+\beta} \\
& +\frac{\beta R}{s} \frac{X_{1}\left(y_{0}, y_{1}, s, \mathcal{Z}^{U}(s), q\left(\mathcal{Z}^{U}(s)\right)\right)}{1+\beta} \times q^{\prime}\left(\mathcal{Z}^{U}(s)\right) \times \mathcal{Z}_{s}^{U}(s)
\end{aligned}
$$

where an $s$ subscript denotes a derivative w.r.t. $s$, and where we define

$$
\begin{aligned}
X_{0}\left(y_{0}, y_{1}, s, \mathcal{Z}^{U}(s), q\left(\mathcal{Z}^{U}(s)\right)\right) & =\frac{y_{1}+R \underline{a}}{\beta R\left(y_{0}-\underline{a}-q\left(\mathcal{Z}^{U}(s)\right)\right)-\mathcal{Z}^{U}(s) s}+\frac{s \mathcal{Z}^{U}(s)\left(y_{1}+R \underline{a}\right)}{\left[\beta R\left(y_{0}-\underline{a}-q\left(\mathcal{Z}^{U}(s)\right)\right)-\mathcal{Z}^{U}(s) s\right]^{2}} \\
& =\frac{\beta R\left(y_{0}-\underline{a}-q\left(\mathcal{Z}^{U}(s)\right)\right)\left(y_{1}+R \underline{a}\right)}{\left[\beta R\left(y_{0}-\underline{a}-q\left(\mathcal{Z}^{U}(s)\right)\right)-\mathcal{Z}^{U}(s) s\right]^{2}}
\end{aligned}
$$

and

$$
\frac{X_{1}\left(y_{0}, y_{1}, s, \mathcal{Z}^{U}(s), q\left(\mathcal{Z}^{U}(s)\right)\right)}{1+\beta}=\frac{s^{2} \mathcal{Z}^{U}(s)\left(y_{1}+R \underline{a}\right)}{\left[\beta R\left(y_{0}-\underline{a}-q\left(\mathcal{Z}^{U}(s)\right)\right)-\mathcal{Z}^{U}(s) s\right]^{2}}
$$

We now make use once again of the mobility Euler equation $q^{\prime}\left(\mathcal{Z}^{U}(s)\right)=R / s$ to re-write

$$
\begin{aligned}
\frac{d\left[X\left(y_{0}, y_{1}, s, \mathcal{Z}^{U}(s), q\left(\mathcal{Z}^{U}(s)\right)\right)\right]}{d s}= & X_{0}\left(y_{0}, y_{1}, s, \mathcal{Z}^{U}(s), q\left(\mathcal{Z}^{U}(s)\right)\right) \\
& +X_{1}\left(y_{0}, y_{1}, s, \mathcal{Z}^{U}(s), q\left(\mathcal{Z}^{U}(s)\right)\right) \times \mathcal{Z}_{s}^{U}(s)
\end{aligned}
$$

Substituting these expressions into our expression for the supply of individuals in cities $\left[\mathcal{Z}^{U}(s), \mathcal{Z}^{U}(s)+\right.$ $\left.\mathcal{Z}_{s}^{U}(s) d s\right)$, we obtain

$$
G\left(s, \mathcal{Z}^{U}(s), q\left(\mathcal{Z}^{U}(s)\right), \mathcal{Z}_{s}^{U}(s)\right)=A\left(s, \mathcal{Z}^{U}(s), q\left(\mathcal{Z}^{U}(s)\right)\right)+B\left(s, \mathcal{Z}^{U}(s), q\left(\mathcal{Z}^{U}(s)\right)\right) \times \mathcal{Z}_{s}^{U}(s)
$$

where we defined

$$
\begin{aligned}
A\left(s, \mathcal{Z}^{U}(s), q\left(\mathcal{Z}^{U}(s)\right)\right)=\iint f & \left(y_{0}, y_{1}, s\right) \mathbf{1}\left[\tilde{A}\left(y_{0}, y_{1}, s, \mathcal{Z}^{U}(s), q\left(\mathcal{Z}^{U}(s)\right)\right)>\underline{a}\right] d y_{0} d y_{1} \\
+\iint \mathbf{1} & {\left[\tilde{A}\left(y_{0}, y_{1}, s, \mathcal{Z}^{U}(s), q\left(\mathcal{Z}^{U}(s)\right)\right) \leq \underline{a}\right] } \\
\times & f\left(y_{0}, y_{1}, X\left(y_{0}, y_{1}, s, \mathcal{Z}^{U}(s), q\left(\mathcal{Z}^{U}(s)\right)\right)\right) \\
& \times X_{0}\left(y_{0}, y_{1}, s, \mathcal{Z}^{U}(s), q\left(\mathcal{Z}^{U}(s)\right)\right) d y_{0} d y_{1} \\
B\left(s, \mathcal{Z}^{U}(s), q\left(\mathcal{Z}^{U}(s)\right)\right)=\iint \mathbf{1} & {\left[\tilde{A}\left(y_{0}, y_{1}, s, \mathcal{Z}^{U}(s), q\left(\mathcal{Z}^{U}(s)\right)\right) \leq \underline{a}\right] } \\
& \times f\left(y_{0}, y_{1}, X\left(y_{0}, y_{1}, s, \mathcal{Z}^{U}(s), q\left(\mathcal{Z}^{U}(s)\right)\right)\right) \\
& \times X_{1}\left(y_{0}, y_{1}, s, \mathcal{Z}^{U}(s), q\left(\mathcal{Z}^{U}(s)\right)\right) d y_{0} d y_{1}
\end{aligned}
$$


Now, equating total population supply to total housing supply:

$$
h\left(\mathcal{Z}^{U}(s)\right) L\left(\mathcal{Z}^{U}(s)\right) \mathcal{Z}_{s}^{U}(s)=G\left(s, \mathcal{Z}^{U}(s), q\left(\mathcal{Z}^{U}(s)\right), \mathcal{Z}_{s}^{U}(s)\right)
$$

where recall that $h(z)$ is the density of cities with income $z$. Re-arranging,

$$
\mathcal{Z}_{s}^{U}(s)=\frac{A\left(s, q\left(\mathcal{Z}^{U}(s)\right), \mathcal{Z}^{U}(s)\right)}{h\left(\mathcal{Z}^{U}(s)\right) L\left(\mathcal{Z}^{U}(s)\right)-B\left(s, q\left(\mathcal{Z}^{U}(s)\right), \mathcal{Z}^{U}(s)\right)}
$$

It is easier at this stage to write the system in terms of the inverse matching function for unconstrained individuals $\mathcal{S}^{U}(z)$ for the range of cities in which unconstrained individuals live. Using the mobility Euler equation again, we finally obtain a nonlinear system of coupled Ordinary Differential Equations (ODEs):

$$
\begin{aligned}
\mathcal{S}_{z}^{U}(z) & =\frac{h(z) L(z)-B\left(\mathcal{S}^{U}(z), Q(L(z)), z\right)}{A\left(\mathcal{S}^{U}(z), Q(L(z)), z\right)} \\
L_{z}(z) & =\frac{R}{\mathcal{S}^{U}(z) Q^{\prime}(L(z))}
\end{aligned}
$$

where recall that house prices are given by $q(z)=Q(L(z))$. The boundary conditions of this system are $\mathcal{S}^{U}(\bar{z})=\bar{s}$, and $\mathcal{S}^{U}(\hat{z})$ given by total population supply, as defined below. When $\underline{s}>0$ and $f$ is bounded, inspection of this system reveals that it is uniformly Lipschitz continuous. In addition, the solution, if it exists, must be bounded. Indeed, diverging $\mathcal{S}^{U}$ or $L(z)$ are ruled out by our compact support assumptions and by the fact that house prices cannot exceed income which is bounded above. Thus, conditional on boundary conditions, standard results ensure existence and uniqueness of a global solution to this system..

Recall that we assumed that the matching function $\mathcal{Z}^{U}(s)$ was locally increasing. We now show that the matching function $\mathcal{Z}^{U}(s)$ cannot be decreasing. The ODE without assuming that the matching function is increasing would be $\left|\mathcal{S}_{z}^{U}(z)\right|=\frac{h(z) L(z)-B(\mathcal{S}(z), Q(L(z)), z)}{A(\mathcal{S}(z), Q(L(z)), z)}$. Then, if the matching function has negative slope negative at some $z_{0}$, since the right-hand-side is of constant sign and the matching function $\mathcal{Z}^{U}(s)$ cannot be flat (otherwise we would have a mass point, ruled out through the price function), the matching function $\mathcal{S}(z)$ cannot have a zero and hence is decreasing everywhere. Thus, house prices are concave throughout the support (from the no-arbitrage condition). Then we have $q^{\prime}(z)=\mathcal{S}(z) / R<\bar{s} / R$, and hence $q(z)<q\left(S^{U}(\hat{z})\right)+\bar{s} z / R$. Substituting back into the budget constraint of the individuals with skill in $(\bar{s}-d s, \bar{s}]$, they would have an incentive to increase their city choice, since this would yield a higher return on housing. This violates the Second Order Condition for optimality, and hence cannot hold in equilibrium.

\section{A.1.3 Equilibrium in cities with only constrained individuals}

We now turn to cities in which only constrained individuals live. We will apply the exact same logic as in the case for cities with at least one unconstrained individuals. We first define notation that is the counterpart 
of $\mathcal{S}^{C}\left(y_{0}, y_{1}, z\right)$, but makes explicit the dependence on all endogenous objects:

$$
C\left(y_{0}, y_{1}, q(z), q^{\prime}(z)\right)=\frac{q^{\prime}(z)\left(y_{1}+R \underline{a}\right)}{\beta\left[y_{0}-\underline{a}-q(z)\right]-z q^{\prime}(z)}
$$

and notice that $\mathcal{S}^{C}\left(y_{0}, y_{1}, z\right)=C\left(y_{0}, y_{1}, q(z), q^{\prime}(z)\right)$ at the equilibrium house rent schedule.

Total population in location $z$ must satisfy

$$
\begin{aligned}
h(z) L(z)= & \iint \mathbf{1}\left[\tilde{A}\left(y_{0}, y_{1}, C\left(y_{0}, y_{1}, q(z), q^{\prime}(z)\right)\right) \leq \underline{a}\right] \\
& \times f\left(y_{0}, y_{1}, C\left(y_{0}, y_{1}, q(z), q^{\prime}(z)\right)\right) \times \frac{d\left[C\left(y_{0}, y_{1}, q(z), q^{\prime}(z)\right)\right]}{d z} \times d y_{0} d y_{1}
\end{aligned}
$$

We can compute

$$
\frac{d\left[C\left(y_{0}, y_{1}, q(z), q^{\prime}(z)\right)\right]}{d z}=C_{0}\left(y_{0}, y_{1}, z, q(z), q^{\prime}(z)\right)+C_{1}\left(y_{0}, y_{1}, z, q(z), q^{\prime}(z)\right) \times q^{\prime \prime}(z)
$$

where we define

$$
\begin{aligned}
C_{0}\left(y_{0}, y_{1}, z, q(z), q^{\prime}(z)\right) & =\frac{(1+\beta)\left[q^{2}\left[y_{1}+R \underline{a}\right]\right.}{\left\{\beta\left[y_{0}-\underline{a}-q(z)\right]-z q^{\prime 2}\right.} \\
C_{1}\left(y_{0}, y_{1}, z, q(z), q^{\prime}(z)\right) & =\frac{y_{1}+R \underline{a}}{\beta\left[y_{0}-\underline{a}-q(z)\right]-z q^{\prime}(z)}+
\end{aligned}
$$

and hence

$$
h(z) L(z)=D\left(z, q(z), q^{\prime}(z)\right)+E\left(z, q(z), q^{\prime}(z)\right) \times q^{\prime \prime}(z)
$$

where

$$
\begin{aligned}
D\left(z, q(z), q^{\prime}(z)\right)= & \iint \mathbf{1}\left[\tilde{A}\left(y_{0}, y_{1}, C\left(y_{0}, y_{1}, q(z), q^{\prime}(z)\right)\right) \leq \underline{a}\right] \\
& \times f\left(y_{0}, y_{1}, C\left(y_{0}, y_{1}, q(z), q^{\prime}(z)\right)\right) \times C_{0}\left(y_{0}, y_{1}, z, q(z), q^{\prime}(z)\right) \times d y_{0} d y_{1} \\
E\left(z, q(z), q^{\prime}(z)\right)= & \iint \mathbf{1}\left[\tilde{A}\left(y_{0}, y_{1}, C\left(y_{0}, y_{1}, q(z), q^{\prime}(z)\right)\right) \leq \underline{a}\right] \\
& \times f\left(y_{0}, y_{1}, C\left(y_{0}, y_{1}, q(z), q^{\prime}(z)\right)\right) \times C_{1}\left(y_{0}, y_{1}, z, q(z), q^{\prime}(z)\right) \times d y_{0} d y_{1}
\end{aligned}
$$

which defines the nonlinear second-order ODE:

$$
q^{\prime \prime}(z)=\frac{h(z) Q^{-1}(q(z))-D\left(z, q(z), q^{\prime}(z)\right)}{E\left(z, q(z), q^{\prime}(z)\right)}
$$

with boundary conditions $q\left(\hat{z}^{-}\right)=q\left(\hat{z}^{+}\right), q\left(z_{\text {min }}\right)=0$ that pins down $z_{\text {min }}$. In addition, $q^{\prime}$ must be continuous at the limiting point, otherwise there would be scope for arbitrage: $q^{\prime}\left(\hat{z}^{-}\right)=q^{\prime}\left(\hat{z}^{+}\right)=R / \mathcal{S}^{U}(\hat{z})$. The same argument as before ensures existence and uniqueness of the global solution conditional on boundary 
conditions. Finally, $\mathcal{S}^{U}(\hat{z})$ is determined by the requirement that $\int h(z) L(z) d z=1$, total population. Thus, an equilibrium exists.

\section{A.2 Proof of Lemma 3}

Suppose that $\underline{s}=\bar{s}=s$. Unconstrained individuals are indifferent between any of the locations in which there is at least one unconstrained individual. Because constrained individuals always locate in worst cities than any unconstrained individual of the same skill and we have only one skill type, it must be that constrained individuals all locate below $\hat{z}$. In other words, there is perfect segregation.

In this case, for unconstrained individuals,

$$
R=\frac{s}{q^{\prime}(z)}
$$

This implies that for all cities $z \geq \hat{z}$,

$$
\frac{d\left[q^{\prime}(z)\right]}{d R}=-\frac{s}{R^{2}}<0
$$

By continuity, this result extends to the case in which $\bar{s}-\underline{s}$ is strictly positive but small enough.

\section{A.3 Proof of Lemma 4}

First, we need to specify the production technology of housing. Suppose housing a produced using the final good $k$ as sole input, according to $H=x k^{\theta}$, where $\eta=\frac{1-\theta}{\theta}$ and $q_{0}=\frac{1}{\theta x^{1 / \theta}}$. Under perfect competition in the housing sector, this production function results in the house rent prices used in the competitive equilibrium. The planner's problem can then be split into two stages: (1) allocate individuals over space to maximize second period output net of discounted housing creation, and (2) redistribute output for consumption. So if the planner can produce more output net of housing production than the competitive equilibrium, he can achieve any utilitarian or Pareto improvements over the competitive equilibrium. The planner chooses the joint distribution of $(s, z), g(s, z)$, to solve

$$
\begin{array}{ll} 
& \max _{g, k} \int s z g(s, z) d s d z-R \int k(z) d z \\
\text { s.t. } & \int g(s, z) d z=f(s) \\
& \int g(s, z) d s=x k(z)^{\theta} \\
& \int g(s, z) d s d z=1
\end{array}
$$

where $f$ is the given marginal skill distribution. Note that the planner discounts house production at the market interest rate, since if it did not use second period output to pay for housing today, it could save those resources which would deliver a gross return of $R$ tomorrow. 
First, we re-write this in terms of the shadow price of land that would prevail in the planner's allocation. We have after some algebra

$$
k(z)=\left(\frac{L(z)}{x}\right)^{\frac{1}{\theta}}=(\theta x)^{\frac{1}{1-\theta}} q(z)^{\frac{1}{1-\theta}}
$$

and hence

$$
\begin{aligned}
& \max _{g, q} \int s z g(s, z) d z d z-R(\theta x)^{\frac{1}{1-\theta}} \int q(z)^{1+\frac{1}{\eta}} d z \\
\text { s.t. } & \int g(s, z) d z=f(s) \\
& \int g(s, z) d s=q_{0}^{-1 / \eta} q(z)^{1 / \eta}
\end{aligned}
$$

By construction, the planner's solution must yield weakly higher output than the competitive equilibrium.

Now, conditional on a shadow housing price schedule $q(z)$, this is a standard optimal transport problem, and given the supermodularity of the surplus $s z$, the solution is perfect Positive Assortative Matching (PAM): there exists an increasing matching function $S(z)$ such that

$$
\int_{S(z)}^{\bar{s}} f(x) d x=q_{0}^{-1 / \eta} \int_{z}^{\bar{z}} q\left(z^{\prime}\right)^{1 / \eta} d z^{\prime}
$$

i.e.

$$
\begin{aligned}
S(z) & =\bar{F}^{-1}\left(\int_{z}^{\bar{z}} q\left(z^{\prime}\right)^{1 / \eta} d z^{\prime}\right) \\
f(S(z)) S^{\prime}(z) & =Q_{0}^{-1 / \eta} q(z)^{1 / \eta}
\end{aligned}
$$

where $\bar{F}(s)=1-F(s)$ is the skill tail cdf. In addition, from Theorem 4.7 p. 39 in Galichon (2016), we know that the solution is unique.

Now, the planner also chooses $q$. Clearly the house rent schedule from the competitive equilibrium is in the planner's choice set. Yet, we know that conditional on the competitive equilibrium's house rent schedule, the unique maximizer of the planner's problem features perfect PAM. Since the competitive equilibrium delivers imperfect PAM (the positive mass of constrained individuals do not satisfy strict PAM), the planner's solution must yield strictly higher gross output than the competitive equilibrium given the same house rent schedule.

In addition, since the planner can always choose the same house rent schedule as the competitive equilibrium, and the sorting of individuals differ strictly between both cases, it must be that output net of housing 
costs is strictly higher in the planner's solution. In sum, the planner's solution yields strictly higher gross and net output compared to the competitive equilibrium.

\section{A.4 Proof of Lemma 5}

The proof is structured in three steps.

1. Show that city income net of rents is a sufficient statistic to capture welfare losses from the policy

2. Show that city income net of rents declines for all unconstrained individuals below the announced skill threshold

3. Show that this implies that it declines also for constrained individuals below the same skill threshold.

\section{A.4.1 Indirect utility}

We first go back to the problem of the individual and define indirect utility. For the unconstrained, consumption is

$$
\begin{aligned}
& c_{0}=\frac{1}{1+\beta}\left[y_{0}-q^{*}+\frac{y_{1}+z^{*} s}{R}\right] \\
& c_{1}=\beta R c_{0}
\end{aligned}
$$

where we denote optimal choices with asterisks $(*)$, and omit dependence on individual characteristics for notational simplicity. Indirect utility of unconstrained individuals is

$$
\begin{aligned}
V^{U} & :=\beta \log \beta R+(1+\beta) \log c_{0} \\
& =\log \frac{(\beta R)^{\beta}}{(1+\beta)^{1+\beta}}+(1+\beta) \log \left(y_{0}+\frac{y_{1}}{R}+\frac{s z^{*}}{R}-q^{*}\right)
\end{aligned}
$$

For the constrained, consumption is

$$
\begin{aligned}
& c_{0}=y_{0}-q^{*}-\underline{a} \\
& c_{1}=y_{1}+z^{*} s+R \underline{a}
\end{aligned}
$$

and their indirect utility is

$$
V^{C}=\log \left(y_{0}-q^{*}-\underline{a}\right)+\beta \log \left(y_{1}+z^{*} s+R \underline{a}\right)
$$

Consider a small change in $q(d q)$ and $z s(d(z s))$. Then indirect utility changes according to

$$
d V^{C}=-\frac{1}{c_{0}} d q+\frac{c_{1}}{\beta} d(z s)
$$


Therefore, using the financial Euler equation,

$$
c_{0} \times d V^{C}<d\left[\frac{z^{*} s}{R}-q^{*}\right]
$$

Therefore, if the right-hand-side is negative for the policy change (even though the change may be large, we can integrate the inequality across a sequence of infinitesimal changes), constrained individuals lose. In

sum, for both constrained and unconstrained individuals, a decline in $\frac{z^{*} s}{R}-q^{*}$ entails a decline in indirect utility.

\section{A.4.2 Income net of rent for unconstrained individuals}

Define net income before the policy change as

$$
I\left(y_{0}, y_{1}, s\right)=\frac{s z^{*}\left(y_{0}, y_{1}, s\right)}{R}-q\left(z^{*}\left(y_{0}, y_{1}, s\right)\right)
$$

and net income after the policy change as

$$
\bar{I}(s)=\frac{z_{0} s}{R}-\bar{q}_{0}
$$

where $\bar{q}_{0}$ is unique the rent after the policy change. For unconstrained individuals, we simplify notation to

$$
I\left(y_{0}, y_{1}, s\right) \equiv I^{U}(s)=\frac{s \mathcal{Z}^{U}(s)}{R}-q\left(\mathcal{Z}^{U}(s)\right)
$$

because location choice does not depend on $\left(y_{0}, y_{1}\right)$ conditional upon being unconstrained. For them, net income is an increasing and convex function of skill $s$. Indeed, differentiating it w.r.t. $s$ :

$$
\frac{d}{d s}\left(\frac{s \mathcal{Z}^{U}(s)}{R}-q\left(\mathcal{Z}^{U}(s)\right)\right)=\frac{\mathcal{Z}^{U}(s)}{R}+\left(\frac{s}{R}-q^{\prime}\left(\mathcal{Z}^{U}(s)\right)\right) \cdot Z_{s}^{U}(s)=\frac{Z^{U}(s)}{R}>0
$$

where the last equality comes from the mobility Euler equation.

After the policy change, matching still holds (even though it is degenerate) and hence the same formula applies. In this case the slope calculated in the previous equation is constant in $s$, and takes the unique value $z_{0} / R$.

We now turn to the rent after the policy change, $\bar{q}_{0}$. Using the assumption $\eta<1$, we can easily make 
comparisons:

$$
\begin{array}{rlrl}
\bar{q}_{0} & =q_{0} L_{0}^{\eta} & & \\
& =q_{0} E[L]^{\eta} & & \text { (where } L \text { is the equilibrium population before policy change) } \\
& >q_{0} E\left[L^{\eta}\right] & & \text { (Jensen's inequality on the concave function } \left.L \mapsto L^{\eta}\right) \\
& =E[q] & & \text { (Jensen's inequality on the convex function } z \mapsto q(z)) \\
& >q(E[z]) &
\end{array}
$$

Now, define $s_{1}<s_{0}$ such that $Z^{U}\left(s_{1}\right)=E[z]<z_{0}=Z^{U}\left(s_{0}\right)$. For unconstrained individuals with $s_{1} \leq s \leq$ $s_{0}$, since $I_{s}^{U}(s)=Z^{U}(s) \in\left[E[z], z_{0}\right]$, we can integrate to obtain

$$
\frac{E[z]\left(s_{0}-s_{1}\right)}{R}<I^{U}\left(s_{0}\right)-I^{U}\left(s_{1}\right)<\frac{z_{0}\left(s_{0}-s_{1}\right)}{R}
$$

Therefore,

$$
\begin{aligned}
I^{U}\left(s_{1}\right) & >I^{U}\left(s_{0}\right)-\frac{z_{0}\left(s_{0}-s_{1}\right)}{R} \\
& =\frac{s_{1} z_{0}}{R}-q(E[z]) \\
& >\frac{s_{1} z_{0}}{R}-\bar{q}_{0}=\bar{I}\left(s_{1}\right)
\end{aligned}
$$

Hence, we know that at skill $s_{1}$, net income for unconstrained individuals pre-reform is above net income post-reform. In addition, the slope of net income is lower pre-reform for $s \leq s_{1}$ : it is $Z^{U}(s) \leq E[z]$ pre-reform, compared to $z_{0}>E[z]$ post-reform.

The convexity of $I^{U}(s)$ then implies that

$$
I^{U}(s)>\bar{I}(s), \forall s \leq s_{1}
$$

i.e. that all unconstrained individuals with lower skill than $s_{1}$ lose net income form the reform. Since net income is a sufficient statistic for indirect utility, unconstrained individuals with $s \leq S^{U}(E[z])$ lose from the policy.

\section{A.4.3 Constrained individuals.}

We can repeat exactly the same argument as for unconstrained individuals. We simply need to allow for dependence on $\left(y_{0}, y_{1}\right)$ and leverage the monotonicity property of $Z^{C}$ in skill. Define $s_{0}\left(y_{0}, y_{1}\right)<s_{1}\left(y_{0}, y_{1}\right)$ such that $\mathcal{Z}^{C}\left(y_{0}, y_{1}, s_{1}\left(y_{0}, y_{1}\right)\right)=E[z]<z_{0}=\mathcal{Z}^{C}\left(y_{0}, y_{1}, s_{0}\left(y_{0}, y_{1}\right)\right)$. Then the argument carries through, holding $\left(y_{0}, y_{1}\right)$ fixed: the range is now for all constrained individuals with skill in $\left[\underline{s}, \mathcal{S}^{C}\left(y_{0}, y_{1}, E[z]\right)\right]$. Since $\mathcal{S}^{C}\left(y_{0}, y_{1}, z\right)>\mathcal{S}^{U}(z)$, the range of skills for which constrained individuals lose is larger. 


\section{B Appendix: Extensions with Amenities and Variable Housing Choice}

This section develops extensions to our baseline model. We add amenities and a variable housing choice. We start by deriving the optimality conditions for location choice in that extended model. With an eye towards our empirical exercise, we then proceed to showing comparative statics with respect to income shocks in the absence of credit constraints. In particular, we show that without credit constraints two individuals who start in the same location and both receive the same negative income shock would downgrade location, but the initially high-income individual would downgrade more. This is inconsistent with the empirical evidence we present. Therefore, our results are unlikely to be driven by a simple static amenities choice. In fact, it suggests that if we do not control for wage growth, or amenities in the new location, our estimates are a lower bound on the causal effect of the consumption-smoothing motive alone, net of the contribution of amenity consumption to mobility. This lends additional support to the intertemporal consumptionsmoothing mechanism we highlight in the main text.

The key observation is that for two individuals to be in the same location, the initially high-income individual must have lower returns to mobility. Thus, following the income shocks, the initially high-income individual would downgrade more. To formally prove this result, we rely on the central insight that in the absence of credit constraint, a dynamic model is essentially isomorphic to a static model because it can be cast in present value terms. We rely on it to show our comparative statics in the two-period model. We then show that the logic is robust to adding more time periods, and extend our results to an infinite-horizon model.

\section{B.1 Generalized two-period model}

We first consider a version of our two-period model with variable housing choice, amenities, and city income in both periods. Namely, suppose that individuals indexed by $(y, s)$ solve the following problem:

$$
\begin{aligned}
& V\left(y_{0}, y_{1}, s\right)=\max _{c_{0}, c_{1}, h_{0}, h_{1}, a, z} \log \left(A(z) \cdot \ell_{0}^{\alpha} c_{0}^{1-\alpha}\right)+\beta \log \left(A(z) \cdot \ell_{1}^{\alpha} c_{1}^{1-\alpha}\right) \\
& \text { s.t. } c_{0}+a+q(z)+p(z) \ell_{0}=y_{0}+\tau \Phi(s, z) \\
& c_{1}+\theta\left[q(z)+p(z) \ell_{1}\right]=y_{1}+R a+\Phi(s, z) \\
& a \geq \underline{a}
\end{aligned}
$$

where, relative to the model in the main text, $\tau$ governs how much of the mobility returns individual receive immediately, and $\theta$ governs how much housing costs must be paid in the second period. When $\Phi(s, z)=s z$, $\tau=\theta=p(z)=0, A(z)=1$, and $\alpha=0$, we obtain the model in the main text.

Cobb-Douglas utility in consumption and variable housing implies constant expenditure shares on consumption and housing, so that the individual's problem can equivalently be written in terms of consumption 
only. Namely,

$$
\begin{aligned}
& V\left(y_{0}, y_{1}, s\right)=\max _{c_{0}, c_{1}, a, z} \log \left(B(z) \cdot c_{0}\right)+\beta \log \left(B(z) \cdot c_{1}\right) \\
& \text { s.t. } \frac{c_{0}}{1-\alpha}+a+q(z)=y_{0}+\tau \Phi(s, z) \\
& \frac{c_{1}}{1-\alpha}+\theta q(z)=y_{1}+R a+\Phi(s, z) \\
& a \geq \underline{a}
\end{aligned}
$$

where $B(z)=\frac{A(z)}{p(z)^{\alpha}}$ are perceived amenities after variable housing consumption has been internalized.

The financial Euler equation is then

$$
\frac{c_{1}}{\beta c_{0}} \geq R
$$

which holds with equality if and only if the individual is financially unconstrained, i.e. $a^{*}>\underline{a}$,

The mobility Euler equation becomes

$$
\frac{c_{1}}{\beta c_{0}}=\frac{\Phi_{z}(s, z)-\theta q^{\prime}(z)}{q^{\prime}(z)-\tau \Phi_{z}(s, z)}
$$

where the period- 1 return has to be netted out from housing costs at that period, and the period- 0 cost has to be netted our from the current return of mobility.

\section{B.2 Comparative statics in the generalized two-period model without credit con- straints}

When we remove credit constraints, we can compare the location decisions of individuals who initially locate in the same place, but have different income. The goal is to verify that incentives to change amenities consumption in response to an income shock cannot explain our empirical findings. We show that when two individuals who start in the same location receive a negative income shock, the initially high-income individual should downgrade more. This supports the view that our empirical findings are not driven by amenity or variable housing choice, but rather by consumption-smoothing incentives in the presence of credit constraints. More formally, we show the following result.

Lemma 6 Suppose the following assumptions hold:

1. A(z) is continuously differentiable and nondecreasing in $z$

2. $p(z) \equiv p_{0}$ is constant across locations (materials for construction)

3. The housing production technology results in land prices $q(z)=Q(L(z))$ where $L(z)$ is total population in $z$, and $Q$ is an increasing function such that $Q(0)=0$ and $\lim _{L \rightarrow+\infty} Q(L)=+\infty$ 
4. The supply of land exceeds population: $\int h(z) d z \geq 1$, where $h(z)$ is the density of land of quality $z \geq 0$

5. Individual income is of the form $I(y, s, z)=y+\Phi(s, z)$, where $\Phi$ is continuously differentiable and $\Phi(s, z)>0, \Phi_{z}(s, z)>0, \Phi_{s z}(s, z)>0$

6. There are no credit constraints: $\underline{a}=-\infty$

Consider two individuals $A$ and $B$ who solve Problem (16), with the same future income and location choice. Namely, they have:

- The same period-1 income: $y_{1}^{A}=y_{1}^{B}$

- Different period-0 incomes: $y_{0}^{A}<y_{0}^{B}$. A is initially lower-income than $B$

- The same location choice: $z^{A}=z^{B}=z^{*}$

Suppose that they both receive a negative income shock in period 0, such that both individuals loose income down to $y_{0}^{\prime}{ }^{A}=y_{0}^{\prime B}<y_{0}^{A}$. Then the initially high-income individual (B) downgrades location more than the initially low-income $(A)$ :

$$
z^{B}<z^{\prime A}<z^{*}
$$

The logic for this result is simple. Without credit constraints, the dynamic problem above can be reduced to a static present-value problem. As we explain in the proof, we can boil it down to the following maximization:

$$
\max _{z} B(z)[\mathbf{y}+\mathbf{\Phi}(s, z)-\mathbf{q}(z)]
$$

where $\mathbf{y}$ is permanent income, and $\mathbf{\Phi}, \mathbf{q}$ are proportional to $\Phi, q$. In that static problem, for two individuals to locate in the same place, it must be that the high- $y$ individuals is low- $s$. Therefore, the initially highincome individual is more location-elastic because she cares less about downgrading location. Thus, after the income shock, she downgrade more.

We structure the proof of this result in several steps. First, we study the static problem and show the comparative statics there. Second, we reduce the dynamic two-period problem to the static problem and deduce the comparative statics.

To assess the robustness of this result, we prove it under several variants. First, as mentioned already, we show it in a static case. Second, we extend it in a similar infinite-horizon model without credit constraints. Third, we show that the result does not depend on the particular assumptions 1 to 6 in Lemma 6 , as long as there is strict positive sorting in the economy. We state this last point as follows:

Corollary 7 Suppose only:

7. Primitives are such that individuals choose location according to a matching function $Z(\mathbf{y}, s)$, where $\mathbf{y}$ is permanent income, and such that $Z_{y}(y, s)>0$ and $Z_{s}(y, s)>0$, 
instead of Assumptions 1-6. Then the implications of Lemma 6 continue to hold: consider two individuals $A$ and $B$ who solve Problem (16), with the same future income and location choice. Namely, they have:

- The same period-1 income $y_{1}^{A}=y_{1}^{B}$

- Different period-0 income $y_{0}^{A}<y_{0}^{B}: A$ is initially lower-income than $B$

- The same location choice $z^{A}=z^{B}=z^{*}$

Suppose that they both receive a negative income shock in period 0, such that both individuals loose $y_{0}^{\prime}{ }^{A}=y_{0}^{\prime B}<y_{0}^{A}$. Then the initially high-income individual (B) downgrades location more than the initially low-income $(A)$ :

$$
z^{B}<z^{A}<z^{*}
$$

\section{B.2.1 Proof of Lemma 6 and Corollary 7; Part 1, Static Problem}

We study the following static problem:

$$
\begin{array}{ll} 
& \max _{c, h, z} A(z) c^{1-\alpha} \ell^{\alpha} \\
\text { s.t. } & c+q(z)+p(z) \ell=I(y, s, z)
\end{array}
$$

The consumption-housing choice implies that expenditure shares on consumption and housing are constant fraction of income:

$$
\begin{aligned}
c & =(1-\alpha) I(y, s, z) \\
p(z) h & =\alpha I(y, s, z)
\end{aligned}
$$

Substituting housing and consumption decisions into the maximization problem, we obtain a problem in terms of choosing location alone:

$$
\max _{z} B(z) I(y, s, z)
$$

where we defined

$$
B(z)=\frac{A(z)}{p(z)^{\alpha}}
$$

the perceived amenities of location $z$, after variable housing choice. The FOC is

$$
\nu(z)+\frac{s z-z q^{\prime}(z)}{y+s z-q(z)}=0
$$

where $\nu(z)=\frac{z B^{\prime}(z)}{B(z)}$ is the elasticity of perceived amenities. Re-arrange it as

$$
y=\frac{(\nu(z)+\eta(z)) q(z)-(\phi(s, z)+\nu(z)) \Phi(s, z)}{\nu(z)}
$$


where $\phi(s, z)=\frac{z \Phi_{z}(s, z)}{\Phi(s, z)}$ is the elasticity of city-income elasticity. Define

$$
G(z, s)=\frac{(\nu(z)+\eta(z)) q(z)-(\phi(s, z)+\nu(z)) \Phi(s, z)}{\nu(z)}
$$

First, suppose that there is positive sorting in equilibrium on both $y$ and $s$. Namely, we assume that there exists a unique solution $Z(y, s)$ to the FOC

$$
y=G(Z(y, s), s)
$$

and in addition we assume $Z_{y}(y, s), Z_{s}(y, s)>0$. Use of the implicit function theorem implies that $G_{z}>0$ and $G_{s}<0$. In particular, $\nu(z)>0$. Now consider individuals $\mathrm{A}$ and B, before and after the shock. Then

$$
G\left(z^{\prime A}, s^{A}\right)=G\left(z^{B}, s^{B}\right)
$$

Because $G_{s}<0<G_{z}$, it must be that $z^{\prime A}>z^{\prime B}$. Thus, the initially high-income individual downgrades more. This proves Corollary 7 .

Second, we show that positive sorting obtains in equilibrium under Assumptions 1-6. First, the assumptions that $A(z)$ is increasing and that $p(z)=p_{0}$ ensure that $\nu(z)=\frac{z B^{\prime}(z)}{B(z)} \geq 0$. Denote

$$
u(z ; y, s)=B(z)[y+\Phi(s, z)-q(z)]
$$

the utility function. Then

$$
\frac{z u_{z}(z ; y, s)}{u} \cdot[y+\Phi(s, z)-q(z)]=\nu(z) y+\nu(z) \Phi(s, z)+z \Phi_{z}(s, z)-\nu(z) q(z)-z q^{\prime}(z)
$$

Second, the assumption of excess land together with $Q(0)=0$ ensures that there is always a worst city which is empty with zero land price. Thus, in equilibrium,

$$
y+\Phi(s, z)-q(z) \geq 0
$$

Finally, denote again the optimal location choice $Z(y, s)$ (the matching function). Notice that if $u_{z}(Z(y, s) ; y, s)=$ 0 , then $u_{z}\left(Z(y, s) ; y, s^{\prime}\right)>0$ for $s^{\prime}>s$. Therefore, it must be that the optimal choice $Z(y, s)$ is weakly increasing in $s: Z_{s}(y, s) \geq 0$. If the matching function is locally flat (i.e. the derivative is zero), then the assumption that $\lim _{L \rightarrow+\infty} Q(L)=+\infty$ implies that prices are locally infinite. This cannot be an equilibrium, and hence the matching function is strictly increasing. The same logic applies for $Z_{y}(y, s)>0$. Therefore, strict positive assortative matching must hold in equilibrium. Thus, the comparative statics proven above follow. 


\section{B.2.2 Proof of Lemma 6] and Corollary 7: Part 2. Two-Period Problem}

First, maximizing out the variable housing choice that attributes constant expenditure shares in Problem (16), we obtain the equivalent problem

$$
\begin{gathered}
V\left(y_{0}, y_{1}, s\right)=\max _{C_{0}, C_{1}, a, z} \log \left(B(z) \cdot C_{0}\right)+\beta \log \left(B(z) \cdot C_{1}\right) \\
\text { s.t. } C_{0}+a+q(z)=y_{0}+\tau \Phi(s, z) \\
C_{1}+\theta q(z)=y_{1}+R a+\Phi(s, z)
\end{gathered}
$$

where $B(z)=A(z) / p(z)^{\alpha}$. Second, using the Euler equation $C_{1}=\beta R C_{0}$ to express consumption in period 1 as a function of consumption in period 0 , and combining both budget constraints into the intertemporal budget constraint, we obtain the equivalent problem

$$
\begin{aligned}
V\left(y_{0}, y_{1}, s\right) & =\max _{C_{0}, z}(1+\beta) \log \left[B(z) C_{0}\right] \\
\text { s.t. }(1+\beta) C_{0}+\left(1+\theta R^{-1}\right) q(z) & =y_{0}+R^{-1} y_{1}+\left[\tau+R^{-1}\right] \Phi(s, z)
\end{aligned}
$$

Using the budget constraint to expression period-0 consumption as a function of location, we obtain the equivalent problem

$$
V\left(y_{0}, y_{1}, s\right)=\max _{z} B(z)[\mathbf{y}+\mathbf{\Phi}(s, z)-\mathbf{q}(z)]
$$

where we defined

$$
\begin{aligned}
\mathbf{\Phi}(s, z) & =\left(\tau+R^{-1}\right) \Phi(s, z) \\
\mathbf{y} & =y_{0}+R^{-1} y_{1} \\
\mathbf{q}(z) & =\left(1+\theta R^{-1}\right) q(z)
\end{aligned}
$$

The result follows from Part 1 of the proof.

\section{B.3 Comparative statics in the generalized infinite-horizon extension without credit constraints}

We now extend the previous results in our two-period model to an infinite-horizon model without credit constraints. We assume no risk for simplicity. Individuals solve 


$$
\begin{aligned}
V\left(a_{0}, y_{0}, z_{-1}, s\right) & =\max _{c, a, h, z} \sum_{t=o}^{\infty} \beta^{t} \log \left(A\left(z_{t}\right) c_{t}^{1-\alpha} \ell_{t}^{\alpha}\right) \\
\text { s.t. } & c_{t}+q\left(z_{t}\right)+p\left(z_{t}\right) \ell_{t}+a_{t+1}=R a_{t}+s\left(z_{t-1}+\tau z_{t}\right)+y_{t}
\end{aligned}
$$

where $a_{t}$ are assets, $z_{t}$ is location, $c_{t}$ is consumption of a perishable good, $h_{t}$ is housing consumption. $s$ is a permanent skill that governs returns to location. $\tau$ governs the fraction of location-specific income that accrues upon arrival in a location. $y_{t}$ is an exogenous income stream. $R \geq 1$ is an exogenous interest rate on financial assets. $A(z)$ are amenities, $p(z)$ is the price of variable housing, and $q(z)$ is the price of the fixed component of housing. Relative to the two-period model in which we spread our rents for a unique location choice across the two periods, we effectively set $\theta=0$ because the natural assumption with many periods is to have rents paid in the current period. Lemma 6 extends in the following way.

Corollary 8 Impose either (i) assumptions 1-6 of Lemma 6, or (ii) assumption 7 of Corollary 7 for period0 location choice. Consider two individuals $A$ and B solving Problem (17) in a stationary equilibrium, with the same initial assets, past location and future income and location choice. Namely, they have:

- The same income after period 1: $y_{t}^{A}=y_{t}^{B}$ for all $t \geq 1$; the same asset holdings $a_{0}^{A}<a_{0}^{B}$; the same past location $z_{-1}^{A}=z_{-1}^{B}$

- Different period-0 income $y_{0}^{A}<y_{0}^{B}: A$ is initially lower-income than $B$

- The same location choice in period 0: $z_{0}^{A}=z_{0}^{B}=z_{0}^{*}$

Suppose that they both receive a negative income shock in period 0, such that both individuals loose $y_{0}^{\prime}{ }^{A}=y_{0}^{\prime B}<y_{0}^{A}$. Then the initially high-income individual $(B)$ downgrades location more than the initially low-income $(A)$ :

$$
z_{0}^{B}<z_{0}^{\prime A}<z_{0}^{*}
$$

Proof. Using the same logic as in the two-period model, we can (i) maximize out variable housing choice, (ii) use the Euler equation to link consumption across time periods, (iii) iterate forward on the budget constraints and use the transversality condition to re-write Problem (17) as an equivalent presentvalue problem:

$$
V\left(a_{0},\left\{y_{t}\right\}_{t}, z_{-1}, s\right)=\max _{\left\{z_{t}\right\}_{t \geq 0}} B\left(\left\{z_{t}\right\}_{t}\right)\left[Y\left(a_{0},\left\{y_{t}\right\}_{t}\right)+\Psi\left(s,\left\{z_{t}\right\}_{t}\right)-Q\left(\left\{z_{t}\right\}_{t}\right)\right]
$$


where we defined

$$
\begin{aligned}
B\left(\left\{z_{t}\right\}_{t}\right) & =\exp \left[\sum_{t=0}^{\infty} \beta^{t} \log \frac{A\left(z_{t}\right)}{p\left(z_{t}\right)^{\alpha}}\right] \\
Y\left(a_{0},\left\{y_{t}\right\}_{t}\right) & =R\left[a_{0}+\sum_{t-0}^{\infty} R^{-t} y_{t}+\Phi\left(s, z_{-1}\right)\right] \\
\Psi\left(s,\left\{z_{t}\right\}_{t}\right) & =\sum_{t-0}^{\infty} R^{-t}\left(\Phi\left(s, z_{t}\right)+\tau \Phi\left(s, z_{t+1}\right)\right) \\
Q\left(\left\{z_{t}\right\}_{t}\right) & =\sum_{t-0}^{\infty} R^{-t} q\left(z_{t}\right)
\end{aligned}
$$

$\beta R=1$ must hold in a stationary equilibrium. Then the utility value of amenities decays at the same rate as income. Taking the FOC with respect to. $z_{t}$, we obtain:

$$
\nu\left(z_{t}\right)+\frac{\left(\tau+R^{-1}\right) \Phi_{z}\left(s, z_{t}\right)-q^{\prime}\left(z_{t}\right)}{Y_{0}+\Psi\left(s,\left\{z_{t}\right\}_{t}\right)-Q\left(\left\{z_{t}\right\}_{t}\right)}=0
$$

where $\nu$ is the elasticity of $\frac{A(z)}{p(z)^{\alpha}}$. Then it is straightforward to show that:

$$
z_{0}^{*}=Z\left(Y_{0},\left\{y_{t}\right\}_{t \geq 1}, s\right)
$$

and depends on $y_{0}$ only through the denominator (first express it as a function of $Y_{0}+\Psi\left(s,\left\{z_{t}\right\}_{t}\right)-Q\left(\left\{z_{t}\right\}_{t}\right)$ ). Denote

$$
\begin{aligned}
B(z)= & \frac{A(z)}{p(z)^{\alpha}} \\
\mathbf{\Phi}(s, z)= & \left(\tau+R^{-1}\right) \Phi(s, z) \\
\mathbf{Y}\left(a_{0},\left\{y_{t}\right\}_{\left.t \geq 1, z_{-1}\right)=}\right. & R\left[a_{0}+\sum_{t-1}^{\infty} R^{-t} y_{t}+\Phi\left(s, z_{-1}\right)\right] \\
& +\sum_{t-1}^{\infty} R^{-t}\left(\Phi\left(s, Z\left(Y_{t},\left\{y_{r}\right\}_{r \geq t}, s\right)\right)+\tau \Phi\left(s, Z\left(Y_{t},\left\{y_{r}\right\}_{r \geq t+1}, s\right)\right)\right) \\
& -\sum_{t-1}^{\infty} R^{-t} q\left(Z\left(Y_{t},\left\{y_{r}\right\}_{r \geq t}, s\right)\right)
\end{aligned}
$$

The problem for solving for $z_{0}$ as a function of $\left(y_{0}, s\right)$ given $\left(a_{0},\left\{y_{t}\right\}_{t \geq 1}, z_{-1}\right)$ is now equivalent to solving

$$
V\left(y_{0}, s ; a_{0},\left\{y_{t}\right\}_{t \geq 1}, z_{-1}\right)=\max _{z} B(z)\left[y_{0}+\mathbf{Y}\left(a_{0},\left\{y_{t}\right\}_{t \geq 1, z_{-1}}\right)+\mathbf{\Phi}(s, z)-q(z)\right]
$$

The result the follows from the proof in the static case (Part 1 of the proof in the two-period case). 


\section{Appendix: Calibration}

We calibrate our infinite horizon economy to an annual level with two income states $N=2$ for CRRA utility $u(c)=\frac{c^{1-\frac{1}{\sigma}}-1}{1-\frac{1}{\sigma}}$. We choose the parameter values in Table 6

Table 6: Calibration Parameters

\begin{tabular}{lcr}
\hline \hline & & \\
Parameter & Notation & Value \\
& & \\
\hline Preferences & $\beta$ & 0.95 \\
$\quad$ Discount Factor & $\sigma$ & 0.2 \\
Intertemporal Elasticity of Substitution & & \\
& & \\
Idiosyncratic Income & $s$ & 0.5 \\
Skill & $y_{1}$ & 0.2 \\
Low Income State & $y_{2}$ & 0.6 \\
High Income State & $\Lambda_{12}$ & 0.1 \\
Transition Probability From Low to High & $\Lambda_{21}$ & \\
Transition Probability From High to Low & & 1.03 \\
& & 0.00 \\
Financial Markets & $R$ & \\
Risk-Free Rate & $\underline{a}$ & 1.00 \\
Credit Constraint & & 0.00 \\
& $\bar{z}$ & $\int_{z}^{z} q^{\prime}(x) d x$ \\
Cities & $\underline{z}$ & \\
Best City & $q(z)$ & $0.18+0.44$ \\
Worst City & & $z^{1.05}$ \\
House Rents Slope & & \\
House Rents & & \\
& & \\
\hline \hline
\end{tabular}

Most of those values are standard. For instance, if we interpret the low income state $y_{1}$ as unemployment and the high income state $y_{2}$ as employment, we can compute the stationary unemployment rate in this economy through the invariant distribution of the Markov chain transition matrix $\Lambda^{\prime}$. At our current values, we obtain a stationary unemployment rate of $14 \%$.

Our value of the Intertemporal Elasticity of Substitution $\sigma$ (IES) is within the accepted range. The value of skill we use is $s=0.5$. Given our house rent schedule and the equilibrium city choice, this implies that the idiosyncratic component of income $y_{t}$ represents between $15 \%$ and $30 \%$ of total labor income $y_{t}+s z_{t}$ depending on where individuals are in the state space. City income $s z_{t}$ thus represents between $70 \%$ and $85 \%$. This reflects the large observed differences in wages across cities. The differences in location between 
the best city 0.99 and the lowest city 0.43 individuals locate in, imply an income change of 0.28 , which is of the order of magnitude of the high idiosyncratic income state.

Finally, our house rents schedule is constructed in such a way that unconstrained individuals of skill $s=0.5$ locate towards $99 \%$ of the best available city, and are free to downgrade as much as they like. It also implies housing expenses of about one third of total labor income, consistent with its empirical counterpart reported in Davis and Ortalo-Magne (2011).

To solve the model numerically, we adapt the method of endogenous grid points of Caroll (2006).

\section{Appendix: Data Description and Robustness Exercises}

\section{D.1 Data Description and Sample Selection}

Our main data sources are the DADS Panel and Postes. Both are administrative tax data from the French statistical institute (INSEE). The DADS are matched empoyer-employee datasets with rich information on the universe of workers who receive taxable labor income in France. The DADS Panel is a panel of all workers in France born in October of even years (approximately 4\%). In this dataset we can track the same individual throughout her employment spells for the period 1994-2007. The DADS Postes have a different structure, although they come from the same original ax returns. One DADS Postes dataset is a 2-year panel with the universe of workers in France. Each worker is uniquely identified in that 2-year panel. For both the DADS Panel and Postes, for each worker, we use the following variables:

- the start and end day of all of her employment spells

- for each employment spell:

- total net wage earnings

- age and gender

- municipality of residence and workplace

- district (département) of birth

- their employer's unique firm identifier

- occupation and industry 4-digit codes

As is common with matched employer-employee datasets, because the underlying data is reported by employers, we have no information on individuals when they are not employed. Therefore, for simplicity, we label any individual who is not in the dataset as 'Unemployed', even though we acknowledge that the labor force participation margin may be active for some individuals.

The French mainland territory is partitioned in about 96 districts ('Départements') and 36,552 municipalities ('Communes'). Départements are fairly large areas (median area is 8,763 km2 and median population 
is 531,380 inhabitants), while municipalities are much smaller (median area is slightly above $10 \mathrm{~km} 2$, and median population is 432 inhabitants). To measure house prices and calculate real wages we use a house price index at the département-year level computed by INSEE.

Individual identifiers are reset in each of the 2-year panels of the DADS Postes, so that we cannot link individuals across datasets. However, the time coverage of the panels overlap. For instance, the first panel we use has years 2002 and 2003, and the second has years 2003 and 2004. For this reason, we apply all our data selection criteria separately to each of those datasets and merge them at the end. Because we observe start and end dates of each spell, we can make sure that a given spell for a given individual is not duplicated in our final sample. For each of the DADS Postes and for the for the DADS Panel. We use the Postes and the Panel for different empirical exercises, so we apply slightly different sample selection rules. Namely, we do the following:

- We first compute a measure of how desirable a municipality is. To do so, we compute log nominal daily wages for each individual and each municipality. We then compute the average log nominal daily wage in each municipality. We then rank mean log nominal daily wages across municipalities in each year, and compute the corresponding percentile for each municipality. This is our measure of $z$. We do this computation in the DADS Postes to obtain the most accurate information, and use the ranks from the Postes in the exercises with the Panel.

- Second, we restrict the sample of individuals and employment spells in the following way:

- (Only for DADS Postes) Because the data comes at the annual level, we first combine any employment spells that end in the last day of the first year with a corresponding employment spell that starts in the first day of the second year, with the same individual and firm identifier, as one employment spell. We do not do the same in the Panel because we wish to track individuals at the annual frequency, even if they keep the same employer.

- Second, we remove minor employment spell to ensure that each individual has only one employment spell at any given point in time. To do so, we keep only the highest paying employment spell in any given month for each individual and remove spells less than one month..

- Third, we define Employment-to-Employment (EE) and Employment-to-Unemployment-to- Employment (EUE) transitions as follows. An EE transition happens if an individual switches firms with less than forty days non-employed (the start day of the second employment spell minus the end day of the first employment spell is less than forty). We define an EUE transition if an individual switches firms with more than forty days non-employed.

- (Only for DADS Postes) Fourth, we restrict our sample to individuals who have exactly one EE transition or one EUE transition. Within 2 years:

* $1.7 \%$ of individuals experience at least one EUE transition. Of those individuals, $98 \%$ experience exactly one EUE transition. 
* $0.9 \%$ of individuals experience at least one EE transition. Of those individuals, $98 \%$ experience exactly one EE transition.

Thus, our restriction keeps the vast majority of individuals who experience a transition. At this stage, we obtain a sample of individuals who make exactly one EE transition or one EUE transition. We thus observe exactly two employment spells per individual.

- Fifth, we keep only transitions for which each employment spell before and after the transition exceeds three months.

- Sixth, we keep only transitions for which the origin municipality has more than 100 inhabitants throughout the year, to limit measurement error issues in our right-hand-side variables.

- (Only for DADS Postes) We then combine those samples for each of the years between 2002-2003 and 2006-2007. We do so because of a major classification revision in 2008 and more minor one in 2002. We end up with a sample of over 7 million transitions in the Postes, and over 300,000 transitions individuals in the Panel.

\section{D.2 Appendix: Initial Verifications for $z$}

Here we verify that our measure of $z$ is positively associated with wages after controlling for cost of life and selection on observables and selection on unobservables. We use the long $4 \%$ panel. The solid blue line in Figure 11 shows mean log daily real wages by deciles of $z$. They are monotonically increasing, with a difference of $40 \%$ between the best municipality and the worst. To construct the dashed red line, we first run a standard Mincer regression

$$
\log w_{i, t}=\alpha_{G(i)}+\alpha_{A(i, t)}+\alpha_{Y(t)}+\alpha_{O(i, t)}+\alpha_{I(i, t)}+\varepsilon_{i, t}
$$

where $w_{i, t}$ are log daily wages divided by the house price index in $i$ 's residence location at time $t$. We include fixed effects for gender $\left(\alpha_{G(i)}\right)$, each age $\left(\alpha_{A(i, t)}\right)$, year $\left(\alpha_{Y(t)}\right)$, 2-digit occupation $\left(\alpha_{O(i, t)}\right)$ and industry $\left(\alpha_{I(i, t)}\right)$ of worker $i$ at time $t$. We then compute the average of the estimated residual $\widehat{\varepsilon_{i, t}}$ by decile of $z$, which we plot as the dashed red line. Mean residual wages remain monotonically increasing in $z$, with about half of the real wage gap between the extremes begin absorbed by selection on observables. To confirm that $z$ is positively associated with wages when controlling for selection on unobservables, we include worker fixed effects in the above Mincer regression, and plot the residuals as the dashed green line. The gap between the best and the worst location shrinks to $2.5 \%$, but the relationship with $z$ remains positive. In addition, because we have typically few observations for a given worker, the worker fixed effect would absorb a large part of the causal effect of location on wages, explaining the relatively smaller pay gap. 


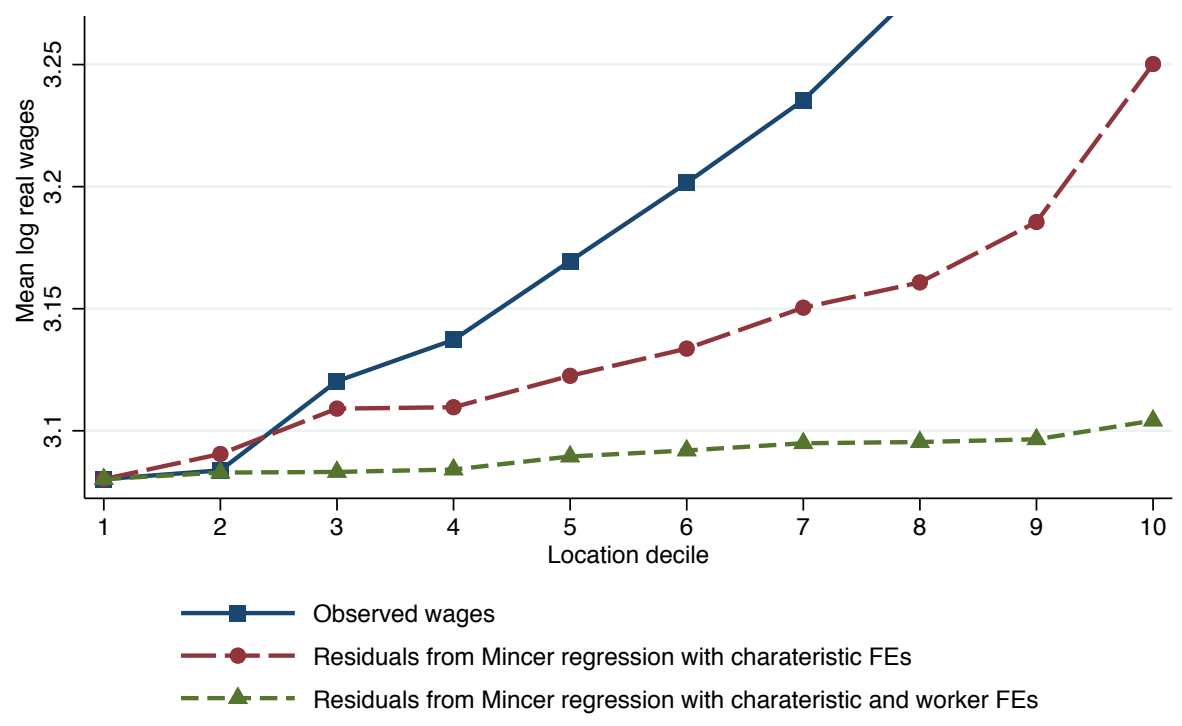

Figure 11: Plot of mean log real daily wages across deciles of $z$. The solid blue line (circles) displays mean observed wages. The dashed red line (squares) displays mean residual wages from a Mincer regression that includes a full set of gender, age, 2-digit occupation and 2-digit industry fixed effects. The dashed green line (triangles) shows mean residual wages when including worker fixed effects in the Mincer regressions.

\section{D.3 Appendix: Robustness of Return to Location}

Here we show two robustness exercises to support the results in Figure 6. First, Figure 12 shows the simple mean log daily nominal wage, for movers to municipalities in the top quintile, and movers to the municipalities in the bottom quintile. The means are plotted for each year before and after the move. The pre-period shows some noise, but after the move a gap of $10 \%$ opens upon impact, and widens over time up to $20 \%$. Notice that the difference in the simple means is very similar to the magnitude of the effect estimated in equation (9) that controls for unobserved fixed worker heterogeneity and group trends. Second, Figure 13 displays the coefficients $\beta_{t}-\beta_{-1}$ in a regression similar to equation (9), but that does not include the non-parametric trends $\alpha_{i, t}$ Controlling for lagged wage increases the direct mobility gain to $20 \%$, but the incremental return over 7 years is still about $10 \%$.

\section{D.4 Appendix: Robustness: Universe of Workers}

See Tables 7, 8, 9, 10, 11 and 12 .

\section{D.5 Appendix: Robustness of Wage Regressions}

See Tables 13, 14, and 15 . 


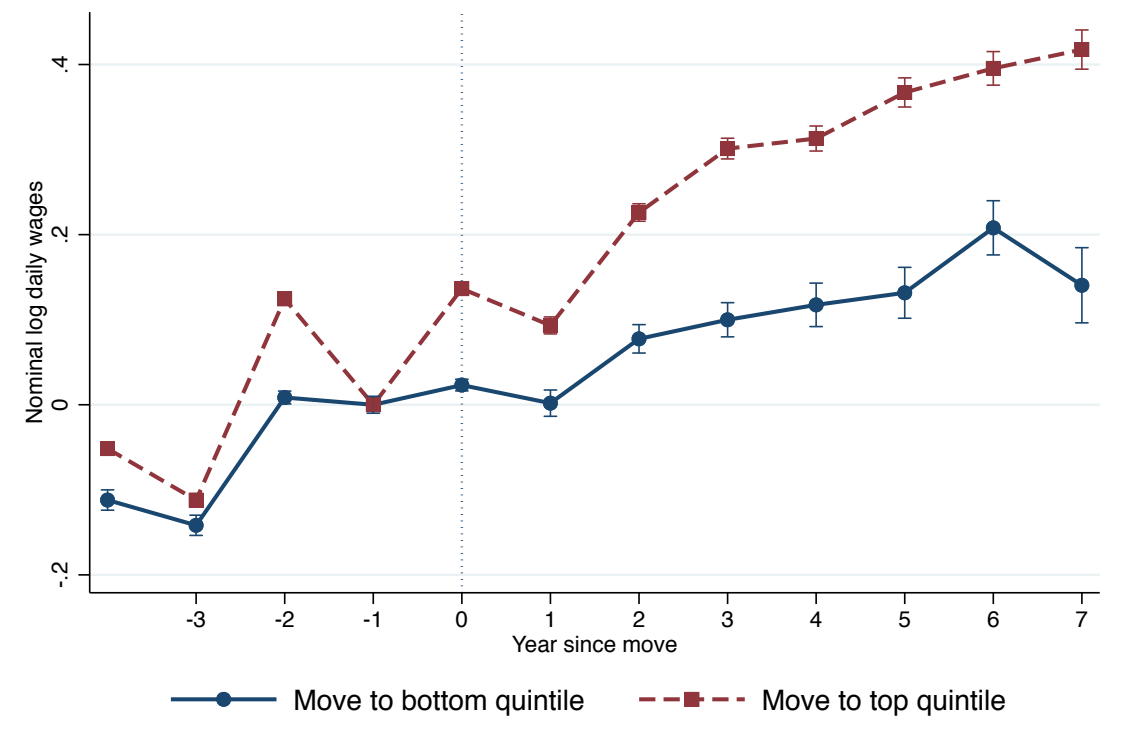

Figure 12: Plot of nominal nominal log daily wages. Movers to top quintile and movers to bottom quintile of $z$. Normalized 1 year before move. $t=0$ is the first move of a worker and is the instantaneous effect of location. Group means and $90 \%$ confidence intervals.

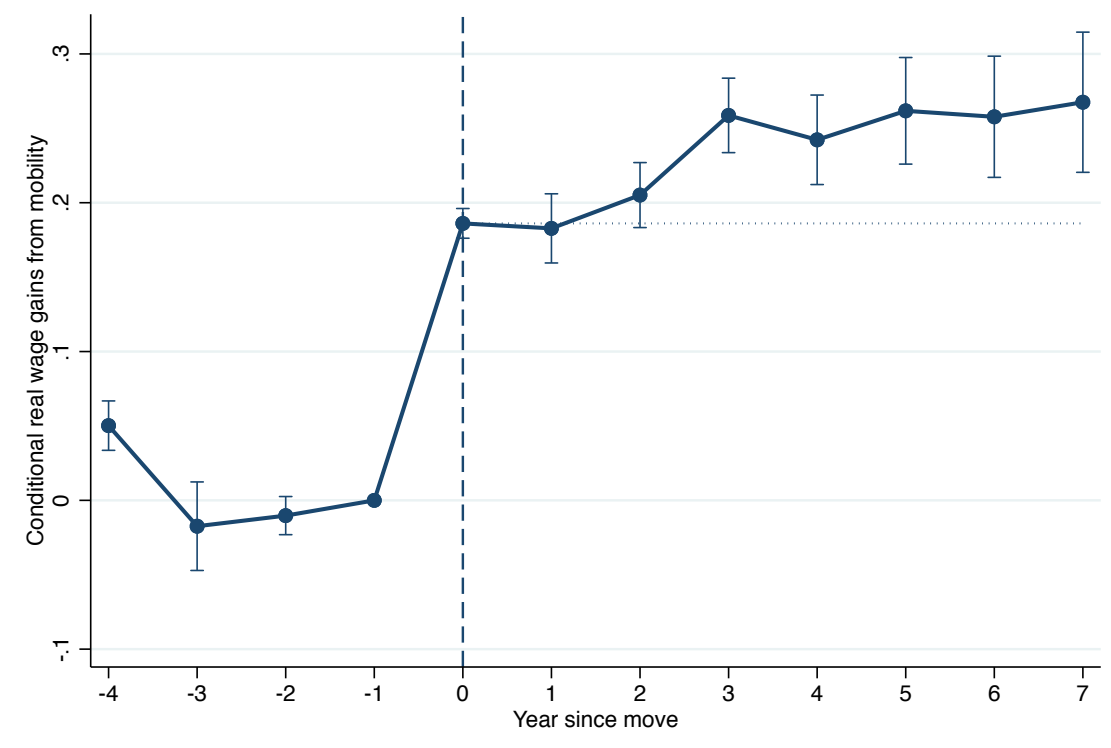

Figure 13: Plot of the $\beta_{t}-\beta_{-1}$ coefficients, for $t=-4 \ldots 7$, and observed daily real wages. $t=0$ is the first move of a worker and is the instantaneous effect of location. Standard errors clustered at the origin municipality level. Using the $4 \%$ long panel. Point estimates and $90 \%$ confidence intervals. 
Table 7: Unemployment spells and location decisions: Universe of workers with département fixed effects

\begin{tabular}{|c|c|c|c|c|c|c|c|c|c|}
\hline Origin Wage Perc. (OWP) & $\begin{array}{l}0.089^{* * *} \\
(0.007)\end{array}$ & $\begin{array}{l}0.088^{* * *} \\
(0.006)\end{array}$ & $\begin{array}{l}0.101^{* * *} \\
(0.004)\end{array}$ & $\begin{array}{l}0.124^{* * *} \\
(0.004)\end{array}$ & $\begin{array}{l}0.333^{* * *} \\
(0.012)\end{array}$ & $\begin{array}{l}0.324^{* * *} \\
(0.012)\end{array}$ & $\begin{array}{l}0.321^{* * *} \\
(0.012)\end{array}$ & $\begin{array}{l}0.321^{* * *} \\
(0.012)\end{array}$ & $\begin{array}{l}0.499^{* * *} \\
(0.019)\end{array}$ \\
\hline \multicolumn{10}{|l|}{ Controls } \\
\hline Pre-Move Log Wage & & & & & $\begin{array}{l}-0.084^{* * *} \\
(0.002)\end{array}$ & $\begin{array}{l}-0.069^{* * *} \\
(0.002)\end{array}$ & $\begin{array}{l}-0.070^{* * *} \\
(0.002)\end{array}$ & $\begin{array}{l}-0.070^{* * *} \\
(0.002)\end{array}$ & $\begin{array}{l}-0.071^{* * *} \\
(0.002)\end{array}$ \\
\hline Post-Move Log Wage & & & & & & $\begin{array}{l}0.015^{* * *} \\
(0.001)\end{array}$ & $\begin{array}{l}0.016^{* * *} \\
(0.001)\end{array}$ & $\begin{array}{l}0.013^{* * *} \\
(0.001)\end{array}$ & $\begin{array}{l}0.014^{* * *} \\
(0.001)\end{array}$ \\
\hline Post-Move Log Comm. Dist. & & & & & & & $\begin{array}{l}0.008^{* * *} \\
(0.002)\end{array}$ & $\begin{array}{l}-0.001 \\
(0.001)\end{array}$ & $\begin{array}{l}-0.001 \\
(0.001)\end{array}$ \\
\hline $\begin{array}{l}\text { Post-Move Amenities Perc. } \\
\text { (First PC, other } 4 \text { unrep.) }\end{array}$ & & & & & & & & $\begin{array}{l}0.290^{* * *} \\
(0.013)\end{array}$ & $\begin{array}{l}0.290^{* * *} \\
(0.013)\end{array}$ \\
\hline OWP * W0 & & & & & & & & & $\begin{array}{l}-0.045^{* * *} \\
(0.002)\end{array}$ \\
\hline Constant & $\begin{array}{l}-0.044^{* * *} \\
(0.009)\end{array}$ & & & & & & & & \\
\hline \multicolumn{10}{|l|}{ Fixed effects } \\
\hline Origin Département \& Year & & $\checkmark$ & $\checkmark$ & $\checkmark$ & $\checkmark$ & $\checkmark$ & $\checkmark$ & $\checkmark$ & $\checkmark$ \\
\hline Age, Birthplace \& Gender & & & $\checkmark$ & $\checkmark$ & $\checkmark$ & $\checkmark$ & $\checkmark$ & $\checkmark$ & $\checkmark$ \\
\hline 2-Digit Origin Occ. \& Ind. & & & & $\checkmark$ & $\checkmark$ & $\checkmark$ & $\checkmark$ & $\checkmark$ & $\checkmark$ \\
\hline Obs. & $2,302,146$ & $2,302,146$ & $2,285,408$ & $2,052,150$ & $2,052,150$ & $2,052,150$ & $1,866,967$ & $1,840,675$ & $1,840,675$ \\
\hline$R^{2}$ & 0.005 & 0.059 & 0.069 & 0.073 & 0.087 & 0.088 & 0.089 & 0.155 & 0.157 \\
\hline W.- $R^{2}$ & & 0.005 & 0.006 & 0.008 & 0.022 & 0.023 & 0.025 & 0.095 & 0.097 \\
\hline
\end{tabular}

Table 8: Unemployment spells and location decisions: Universe of workers with municipality fixed effects

Movers only. Fixed city ranks.

\begin{tabular}{|c|c|c|c|c|c|c|c|c|}
\hline Origin Wage Perc. (OWP) & $\begin{array}{l}0.089^{* * *} \\
(0.007)\end{array}$ & $\begin{array}{l}0.055^{* * *} \\
(0.005)\end{array}$ & $\begin{array}{l}0.062^{* * *} \\
(0.003)\end{array}$ & $\begin{array}{l}0.067^{* * *} \\
(0.003)\end{array}$ & $\begin{array}{l}0.162^{* * *} \\
(0.007)\end{array}$ & $\begin{array}{l}0.149^{* * *} \\
(0.007)\end{array}$ & $\begin{array}{l}0.144^{* * *} \\
(0.007)\end{array}$ & $\begin{array}{l}0.144^{* * *} \\
(0.007)\end{array}$ \\
\hline \multicolumn{9}{|l|}{ Controls } \\
\hline Pre-Move Log Wage & & & & & $\begin{array}{c}-0.031^{*} \\
(0.002)\end{array}$ & $\begin{array}{l}-0.032^{* * *} \\
(0.002)\end{array}$ & $\begin{array}{l}-0.031^{* * *} \\
(0.002)\end{array}$ & $\begin{array}{l}-0.033^{* * *} \\
(0.002)\end{array}$ \\
\hline Post-Move Log Wage & & & & & & $\begin{array}{l}0.020^{* * *} \\
(0.001)\end{array}$ & $\begin{array}{l}0.021^{* * *} \\
(0.001)\end{array}$ & $\begin{array}{l}0.019^{* * *} \\
(0.001)\end{array}$ \\
\hline Post-Move Log Comm. Dist. & & & & & & & $\begin{array}{l}0.007^{* * *} \\
(0.001)\end{array}$ & $\begin{array}{l}-0.002^{*} \\
(0.001)\end{array}$ \\
\hline $\begin{array}{l}\text { Post-Move Amenities Perc. } \\
\text { (First PC, other } 4 \text { unrep.) }\end{array}$ & & & & & & & & $\begin{array}{l}0.292^{* * *} \\
(0.013)\end{array}$ \\
\hline Constant & $\begin{array}{l}-0.043^{* * *} \\
(0.009)\end{array}$ & & & & & & & \\
\hline \multicolumn{9}{|l|}{ Fixed effects } \\
\hline Origin Municipality \& Year & & $\checkmark$ & $\checkmark$ & $\checkmark$ & $\checkmark$ & $\checkmark$ & $\checkmark$ & $\checkmark$ \\
\hline Age, Birthplace \& Gender & & & $\checkmark$ & $\checkmark$ & $\checkmark$ & $\checkmark$ & $\checkmark$ & $\checkmark$ \\
\hline 2-Digit Origin Occ. \& Ind. & & & & $\checkmark$ & $\checkmark$ & $\checkmark$ & $\checkmark$ & $\checkmark$ \\
\hline Obs. & $2,302,146$ & $2,302,146$ & $2,285,408$ & $2,052,150$ & $2,052,150$ & $2,052,150$ & $1,866,967$ & $1,840,675$ \\
\hline$R^{2}$ & 0.005 & 0.302 & 0.307 & 0.311 & 0.314 & 0.316 & 0.319 & 0.384 \\
\hline $\mathrm{W} .-R^{2}$ & & 0.003 & 0.003 & 0.003 & 0.007 & 0.009 & 0.011 & 0.102 \\
\hline
\end{tabular}

\section{D.6 Appendix: Construction of Assets}

To construct assets, we assume that individuals solve the following maximization problem

$$
\begin{array}{ll} 
& \max E_{0}\left[\sum_{t=0}^{T} \beta^{t}\left(c_{t}-\alpha c_{t}^{2}\right)\right] \\
\text { s.t.. } & c_{t}+a_{t+1} \stackrel{70}{=} R a_{t}+y_{t}
\end{array}
$$


Table 9: Unemployment spells and location decisions: Universe of workers with département fixed effects, in declining municipalities only.

Movers only. Fixed City Rank. Declining municipalities only $(<\mathrm{P} 10=-5.2 \%)$.

\begin{tabular}{|c|c|c|c|c|c|c|c|c|c|}
\hline Origin Wage Perc. (OWP) & $\begin{array}{l}0.078^{* * *} \\
(0.013)\end{array}$ & $\begin{array}{l}0.077^{* * *} \\
(0.011)\end{array}$ & $\begin{array}{l}0.092^{* * *} \\
(0.008)\end{array}$ & $\begin{array}{l}0.129^{* * *} \\
(0.009)\end{array}$ & $\begin{array}{l}0.315^{* * *} \\
(0.027)\end{array}$ & $\begin{array}{l}0.313^{* * *} \\
(0.028)\end{array}$ & $\begin{array}{l}0.307^{* * *} \\
(0.031)\end{array}$ & $\begin{array}{l}0.305^{* * *} \\
(0.032)\end{array}$ & $\begin{array}{l}0.526^{* * *} \\
(0.060)\end{array}$ \\
\hline \multicolumn{10}{|l|}{ Controls } \\
\hline Pre-Move Log Wage (W0) & & & & & $\begin{array}{l}-0.064^{* * *} \\
(0.007)\end{array}$ & $\begin{array}{l}-0.065^{* * *} \\
(0.007)\end{array}$ & $\begin{array}{l}-0.064^{* * *} \\
(0.007)\end{array}$ & $\begin{array}{l}-0.064^{* * *} \\
(0.007)\end{array}$ & $\begin{array}{l}-0.055^{* * *} \\
(0.007)\end{array}$ \\
\hline Post-Move Log Wage & & & & & & $\begin{array}{l}0.005 \\
(0.003)\end{array}$ & $\begin{array}{l}0.009^{* *} \\
(0.003)\end{array}$ & $\begin{array}{l}0.005 \\
(0.003)\end{array}$ & $\begin{array}{l}0.006^{*} \\
(0.003)\end{array}$ \\
\hline Post-Move Log Comm. Dist. & & & & & & & $\begin{array}{l}0.007^{* * * *} \\
(0.002)\end{array}$ & $\begin{array}{l}-0.002 \\
(0.001)\end{array}$ & $\begin{array}{l}-0.002 \\
(0.001)\end{array}$ \\
\hline $\begin{array}{l}\text { Post-Move Amenities Perc. } \\
\text { (First PC, other } 4 \text { unrep.) }\end{array}$ & & & & & & & & $\begin{array}{l}0.235^{* * *} \\
(0.018)\end{array}$ & $\begin{array}{l}0.235^{* * *} \\
(0.018)\end{array}$ \\
\hline $\mathrm{OWP} * \mathrm{~W} 0$ & & & & & & & & & $\begin{array}{l}-0.055^{* * *} \\
(0.010)\end{array}$ \\
\hline Constant & $\begin{array}{l}-0.038 \\
(0.021)\end{array}$ & & & & & & & & \\
\hline \multicolumn{10}{|l|}{ Fixed Effects } \\
\hline Origin Département \& Year & & $\checkmark$ & $\checkmark$ & $\checkmark$ & $\checkmark$ & $\checkmark$ & $\checkmark$ & $\checkmark$ & $\checkmark$ \\
\hline Age, Birthplace \& Gender & & & $\checkmark$ & $\checkmark$ & $\checkmark$ & $\checkmark$ & $\checkmark$ & $\checkmark$ & $\checkmark$ \\
\hline 2-Digit Origin Occ. \& Ind. & & & & $\checkmark$ & $\checkmark$ & $\checkmark$ & $\checkmark$ & $\checkmark$ & $\checkmark$ \\
\hline Obs. & 49455 & 49454 & 49235 & 42001 & 42001 & 42001 & 36865 & 35737 & 35737 \\
\hline$R^{2}$ & 0.004 & 0.115 & 0.128 & 0.134 & 0.144 & 0.144 & 0.137 & 0.192 & 0.193 \\
\hline W.- $R^{2}$ & & 0.004 & 0.005 & 0.008 & 0.019 & 0.019 & 0.020 & 0.078 & 0.080 \\
\hline
\end{tabular}

Table 10: Unemployment spells and location decisions: Universe of workers with municipality fixed effects, in declining municipalities only.

Movers only. Fixed City Rank. Declining municipalities only $(<\mathrm{P} 10=-5.2 \%)$.

\begin{tabular}{|c|c|c|c|c|c|c|c|c|}
\hline Origin Wage Perc. (OWP) & $\begin{array}{l}0.078^{* * *} \\
(0.013)\end{array}$ & $\begin{array}{l}0.046^{* * *} \\
(0.006)\end{array}$ & $\begin{array}{l}0.048^{* * *} \\
(0.005)\end{array}$ & $\begin{array}{l}0.039^{* * *} \\
(0.007)\end{array}$ & $\begin{array}{l}0.057^{* * *} \\
(0.013)\end{array}$ & $\begin{array}{l}0.046^{* * *} \\
(0.013)\end{array}$ & $\begin{array}{l}0.039^{* *} \\
(0.015)\end{array}$ & $\begin{array}{l}0.040^{* *} \\
(0.014)\end{array}$ \\
\hline \multicolumn{9}{|l|}{ Controls } \\
\hline Pre-Move Log Wage (W0) & & & & & $\begin{array}{l}-0.006 \\
(0.004)\end{array}$ & $\begin{array}{c}-0.007^{*} \\
(0.004)\end{array}$ & $\begin{array}{l}-0.006 \\
(0.004)\end{array}$ & $\begin{array}{l}-0.007 \\
(0.004)\end{array}$ \\
\hline Post-Move Log Wage & & & & & & $\begin{array}{l}0.019^{* * *} \\
(0.002)\end{array}$ & $\begin{array}{l}0.022^{* * *} \\
(0.002)\end{array}$ & $\begin{array}{l}0.020^{* * *} \\
(0.002)\end{array}$ \\
\hline Post-Move Log Comm. Dist. & & & & & & & $\begin{array}{l}0.008^{* * *} \\
(0.002)\end{array}$ & $\begin{array}{l}-0.001 \\
(0.001)\end{array}$ \\
\hline $\begin{array}{l}\text { Post-Move Amenities Perc. } \\
\text { (First PC, other } 4 \text { unrep.) }\end{array}$ & & & & & & & & $\begin{array}{l}0.257^{* * *} \\
(0.015)\end{array}$ \\
\hline Constant & $\begin{array}{l}-0.038 \\
(0.021)\end{array}$ & & & & & & & \\
\hline \multicolumn{9}{|l|}{ Fixed Effects } \\
\hline Origin Municipality \& Year & & $\checkmark$ & $\checkmark$ & $\checkmark$ & $\checkmark$ & $\checkmark$ & $\checkmark$ & $\checkmark$ \\
\hline Age, Birthplace \& Gender & & & $\checkmark$ & $\checkmark$ & $\checkmark$ & $\checkmark$ & $\checkmark$ & $\checkmark$ \\
\hline 2-Digit Origin Occ. \& Ind. & & & & $\checkmark$ & $\checkmark$ & $\checkmark$ & $\checkmark$ & $\checkmark$ \\
\hline Obs. & 49455 & 46278 & 46058 & 38703 & 38703 & 38703 & 33539 & 32390 \\
\hline$R^{2}$ & 0.004 & 0.564 & 0.570 & 0.571 & 0.571 & 0.573 & 0.575 & 0.624 \\
\hline W.- $R^{2}$ & & 0.003 & 0.002 & 0.001 & 0.001 & 0.005 & 0.008 & 0.106 \\
\hline
\end{tabular}

where $\alpha>0$ is such that consumption is always increasing in the equilibrium range, $T$ is time to retirement. We assume $\beta R=1$, which must hold in any stationary equilibrium when there are no credit constraints. It 
Table 11: Unemployment spells and location decisions: Universe of workers unemployed (1 year+) relative to job switchers

\begin{tabular}{|c|c|c|c|c|c|}
\hline $1[$ Long EUE] $*$ OWP & $\begin{array}{l}0.005 \\
(0.006)\end{array}$ & $\begin{array}{l}0.073^{* * *} \\
(0.008)\end{array}$ & $\begin{array}{l}0.073^{* * *} \\
(0.007)\end{array}$ & $\begin{array}{l}0.066^{* * *} \\
(0.007)\end{array}$ & $\begin{array}{l}0.076^{* * *} \\
(0.007)\end{array}$ \\
\hline OWP & $\begin{array}{l}0.162^{* * *} \\
(0.005)\end{array}$ & $\begin{array}{l}0.369^{* * *} \\
(0.015)\end{array}$ & $\begin{array}{l}0.364^{* * *} \\
(0.016)\end{array}$ & $\begin{array}{l}0.359^{* * *} \\
(0.016)\end{array}$ & $\begin{array}{l}0.358^{* * *} \\
(0.016)\end{array}$ \\
\hline \multicolumn{6}{|l|}{ Controls } \\
\hline Pre-Move Log Wage (W0) & & $\begin{array}{l}-0.079^{* * *} \\
(0.003)\end{array}$ & $\begin{array}{l}-0.076^{* * *} \\
(0.003)\end{array}$ & $\begin{array}{l}-0.076^{* * *} \\
(0.004)\end{array}$ & $\begin{array}{l}-0.076^{* * *} \\
(0.003)\end{array}$ \\
\hline $1[$ Long EUE $] *$ W0 & & $\begin{array}{l}-0.006^{* *} \\
(0.002)\end{array}$ & $\begin{array}{l}-0.035^{* * *} \\
(0.003)\end{array}$ & $\begin{array}{l}-0.032^{* * *} \\
(0.002)\end{array}$ & $\begin{array}{l}-0.035^{* *} \\
(0.002)\end{array}$ \\
\hline Post-Move Log Wage (W1) & & & $\begin{array}{l}0.002 \\
(0.002)\end{array}$ & $\begin{array}{l}0.004^{*} \\
(0.002)\end{array}$ & $\begin{array}{l}0.004^{*} \\
(0.002)\end{array}$ \\
\hline $1[$ Long EUE] $* \mathrm{~W} 1$ & & & $\begin{array}{l}0.023^{*} \\
(0.002)\end{array}$ & $\begin{array}{l}0.019^{* * *} \\
(0.002)\end{array}$ & $\begin{array}{l}0.016^{* * *} \\
(0.002)\end{array}$ \\
\hline Post-Move Log Comm. Dist. (C1) & & & & $\begin{array}{l}0.009^{* * *} \\
(0.001)\end{array}$ & $\begin{array}{l}0.005^{* * *} \\
(0.001)\end{array}$ \\
\hline $1[$ Long EUE $] * \mathrm{C} 1$ & & & & $\begin{array}{l}0.003^{* * *} \\
(0.001)\end{array}$ & $\begin{array}{l}0.004^{* * *} \\
(0.001)\end{array}$ \\
\hline $\begin{array}{l}\text { Post-Move Amenities perc. (A1) } \\
\text { (First PC, other } 4 \text { unrep,) }\end{array}$ & & & & & $\begin{array}{l}-0.010^{* * *} \\
(0.002)\end{array}$ \\
\hline $\begin{array}{l}1[\text { Long EUE] } * \text { A } 1 \\
\text { (other } 4 \text { interactions unreported) }\end{array}$ & & & & & $\begin{array}{l}0.014^{* * *} \\
(0.002)\end{array}$ \\
\hline \multicolumn{6}{|l|}{ Fixed Effects } \\
\hline Origin Département \& Year & $\checkmark$ & $\checkmark$ & $\checkmark$ & $\checkmark$ & $\checkmark$ \\
\hline Age, Birthplace \& Gender & $\checkmark$ & $\checkmark$ & $\checkmark$ & $\checkmark$ & $\checkmark$ \\
\hline 2-Digit Origin Occupation \& Industry & $\checkmark$ & $\checkmark$ & $\checkmark$ & $\checkmark$ & $\checkmark$ \\
\hline Obs. & $1,156,191$ & $1,156,191$ & $1,156,191$ & $1,050,533$ & $1,035,741$ \\
\hline$R^{2}$ & 0.067 & 0.082 & 0.083 & 0.085 & 0.114 \\
\hline W.- $R^{2}$ & 0.012 & 0.028 & 0.028 & 0.031 & 0.061 \\
\hline
\end{tabular}

is well-known that savings have a closed-form expression in this model. When $T$ is large, savings are, to a first order,

$$
a_{1}-a_{0}=y_{0}-\frac{R-1}{R-R^{-T}} E_{0}\left[\sum_{t=0}^{T} R^{-t} y_{t}\right] \longrightarrow_{R \downarrow 1} y_{0}-\frac{1}{T+1} E_{0}\left[\sum_{t=0}^{T} y_{t}\right]
$$

The next step is to define how individuals form their expectation of future income $E_{0}\left[\sum_{t=0}^{T} R^{-t} y_{t}\right]$. In the forecasting approach, we assume that individuals predict their future annual income wages based on an $\operatorname{AR}(1)$ process for annual income growth 43 .

$$
\log \frac{y_{t+1}}{y_{t}}=\rho \log \frac{y_{t}}{y_{t-1}}+\varepsilon_{t+1}
$$

We estimate $\hat{\rho}=-0.36$ annually. To avoid having to construct forecast many years ahead which would

\footnotetext{
${ }^{43}$ We do not include a constant in the regression so that savings take the most transparent expression possible. When we include a constant, we estimate it to be 0.24 , and so a factor 1.27 would pre-multiply wage growth in the expression for savings. The autocorrelation is then -0.39 . Results in both cases are virtually identical.
} 
Table 12: Unemployment spells and location decisions: Universe of workers unemployed (1 year+) in declining municipalities relative to job switchers in expanding municipalities.

\begin{tabular}{|c|c|c|c|c|}
\hline $1[$ Long EUE] $*$ OWP & $\begin{array}{l}0.105^{* * *} \\
(0.013)\end{array}$ & $\begin{array}{l}0.126^{* * *} \\
(0.015)\end{array}$ & $\begin{array}{l}0.124^{* * *} \\
(0.015)\end{array}$ & $\begin{array}{l}0.135^{* * *} \\
(0.017)\end{array}$ \\
\hline OWP & $\begin{array}{l}0.306^{* * *} \\
(0.024)\end{array}$ & $\begin{array}{l}0.290^{* * *} \\
(0.022)\end{array}$ & $\begin{array}{l}0.289^{* * *} \\
(0.024)\end{array}$ & $\begin{array}{l}0.285^{* * *} \\
(0.025)\end{array}$ \\
\hline \multicolumn{5}{|l|}{ Controls } \\
\hline Pre-Move Log Wage (W0) & $\begin{array}{l}-0.064^{* * *} \\
(0.004)\end{array}$ & $\begin{array}{l}-0.055^{* * *} \\
(0.006)\end{array}$ & $\begin{array}{l}-0.055^{* * *} \\
(0.007)\end{array}$ & $\begin{array}{l}-0.055^{* * *} \\
(0.007)\end{array}$ \\
\hline $1[$ Long EUE] $*$ W0 & $\begin{array}{l}-0.026^{* * *} \\
(0.003)\end{array}$ & $\begin{array}{l}-0.045^{* * *} \\
(0.005)\end{array}$ & $\begin{array}{l}-0.044^{* * *} \\
(0.005)\end{array}$ & $\begin{array}{l}-0.047^{* * *} \\
(0.006)\end{array}$ \\
\hline Post-Move Log Wage (W1) & & $\begin{array}{l}0.013^{*} \\
(0.006)\end{array}$ & $\begin{array}{l}0.012^{*} \\
(0.006)\end{array}$ & $\begin{array}{l}0.016^{* *} \\
(0.005)\end{array}$ \\
\hline $1[$ Long EUE $] * \mathrm{~W} 1$ & & $\begin{array}{l}0.019^{* *} \\
(0.006)\end{array}$ & $\begin{array}{l}0.017^{* *} \\
(0.006)\end{array}$ & $\begin{array}{l}0.008 \\
(0.005)\end{array}$ \\
\hline Post-Move Log Comm. Dist. (C1) & & & $\begin{array}{l}0.011^{* * *} \\
(0.002)\end{array}$ & $\begin{array}{l}0.003^{*} \\
(0.001)\end{array}$ \\
\hline $1[$ Long EUE] $* \mathrm{C} 1$ & & & $\begin{array}{l}0.003^{*} \\
(0.001)\end{array}$ & $\begin{array}{l}0.001 \\
(0.001)\end{array}$ \\
\hline $\begin{array}{l}\text { Post-Move Amenities Perc. (A1) } \\
\text { (First PC, other } 4 \text { unrep.) } \\
1[\text { Long EUE] * A } 1\end{array}$ & & & & $\begin{array}{l}0.256^{* * *} \\
(0.019) \\
0.036^{*} \\
(0.014)\end{array}$ \\
\hline \multicolumn{5}{|l|}{ Fixed Effects } \\
\hline Origin Département \& Year & $\checkmark$ & $\checkmark$ & $\checkmark$ & $\checkmark$ \\
\hline $\begin{array}{l}\text { Age, Birthplace \& Gender } \\
\text { 2-Digit Origin Occ. \& Ind. }\end{array}$ & $\begin{array}{l}\checkmark \\
\checkmark\end{array}$ & $\begin{array}{l}\checkmark \\
\checkmark\end{array}$ & $\begin{array}{l}\checkmark \\
\checkmark\end{array}$ & $\begin{array}{l}\checkmark \\
\checkmark\end{array}$ \\
\hline Obs. & 117188 & 117188 & 106415 & 105050 \\
\hline$R^{2}$ & 0.099 & 0.102 & 0.105 & 0.165 \\
\hline W.- $R^{2}$ & 0.023 & 0.027 & 0.031 & 0.095 \\
\hline
\end{tabular}

necessarily be inaccurate given the simplicity of the specified income process, we further assume that individuals predict next year's income from the $\mathrm{AR}(1)$ process, and subsequently expect their income to remain constant. Under this additional assumption, and with residuals of small variance, savings are

$$
a_{1}-a_{0}=\frac{y_{0}}{R}\left(1-\left(\frac{y_{0}}{y_{-1}}\right)^{\rho}\right)
$$

Finally, we set $R=1.00$, although results with $R=1.04$ are virtually identical. In the perfect foresight approach, we simply read off future income from the data.

\section{D.7 Appendix: Robustness of Assets Regressions}

See Tables 16, 17, 18, 19, 20 and 21. 
Table 13: Unemployment spells and location decisions: Wage growth controls

\begin{tabular}{|c|c|c|c|c|c|c|}
\hline Origin Wage Percentile (OWP) & $\begin{array}{l}0.156^{* * *} \\
(0.010)\end{array}$ & $\begin{array}{l}0.151^{* * *} \\
(0.010)\end{array}$ & $\begin{array}{l}0.179^{* * *} \\
(0.009)\end{array}$ & $\begin{array}{l}0.225^{* * *} \\
(0.010)\end{array}$ & $\begin{array}{l}0.222^{* * *} \\
(0.010)\end{array}$ & $\begin{array}{l}0.212^{* * *} \\
(0.010)\end{array}$ \\
\hline \multicolumn{7}{|l|}{ Controls } \\
\hline Wage Growth Percentile (WGP) & $\begin{array}{l}0.124^{* * *} \\
(0.007)\end{array}$ & $\begin{array}{l}0.112^{* * *} \\
(0.006)\end{array}$ & $\begin{array}{l}0.119^{* * *} \\
(0.006)\end{array}$ & $\begin{array}{l}0.127^{* * *} \\
(0.006)\end{array}$ & $\begin{array}{l}0.123^{* * *} \\
(0.006)\end{array}$ & $\begin{array}{l}0.110^{* * *} \\
(0.005)\end{array}$ \\
\hline OWP * WGP & $\begin{array}{l}-0.001 \\
(0.012)\end{array}$ & $\begin{array}{l}-0.000 \\
(0.012)\end{array}$ & $\begin{array}{l}-0.003 \\
(0.012)\end{array}$ & $\begin{array}{l}-0.003 \\
(0.011)\end{array}$ & $\begin{array}{l}-0.001 \\
(0.011)\end{array}$ & $\begin{array}{l}-0.019 \\
(0.011)\end{array}$ \\
\hline Post-Move Log Commuting Distance & & & & & $\begin{array}{l}0.009^{* * *} \\
(0.001)\end{array}$ & $\begin{array}{l}0.001 \\
(0.001)\end{array}$ \\
\hline $\begin{array}{l}\text { Post-Move Amenities Percentile } \\
\text { (First PC, other } 4 \text { unreported) }\end{array}$ & & & & & & $\begin{array}{l}0.279^{* * *} \\
(0.013)\end{array}$ \\
\hline Constant & $\begin{array}{l}-0.141^{* * *} \\
(0.011)\end{array}$ & & & & & \\
\hline \multicolumn{7}{|l|}{ Fixed Effects } \\
\hline Origin Département \& Year & & $\checkmark$ & $\checkmark$ & $\checkmark$ & $\checkmark$ & $\checkmark$ \\
\hline Age, Birthplace \& Gender & & & $\checkmark$ & $\checkmark$ & $\checkmark$ & $\checkmark$ \\
\hline 2-Digit Origin Occupation \& Industry & & & & $\checkmark$ & $\checkmark$ & $\checkmark$ \\
\hline Obs. & 292486 & 292486 & 292428 & 292425 & 270348 & 269911 \\
\hline$R^{2}$ & 0.019 & 0.069 & 0.082 & 0.086 & 0.088 & 0.146 \\
\hline $\mathrm{W} \cdot-R^{2}$ & & 0.018 & 0.020 & 0.022 & 0.024 & 0.086 \\
\hline
\end{tabular}

Table 14: Unemployment spells and location decisions: Heterogeneity across municipality deciles

Movers only. Fixed city ranks.

\begin{tabular}{|c|c|c|c|c|c|c|c|c|}
\hline Origin Wage Perc. (OWP) & $\begin{array}{l}0.075^{* * *} \\
(0.008)\end{array}$ & $\begin{array}{l}0.070^{* * *} \\
(0.006)\end{array}$ & $\begin{array}{l}0.063^{* * *} \\
(0.006)\end{array}$ & $\begin{array}{l}0.048^{* * *} \\
(0.006)\end{array}$ & $\begin{array}{l}0.044^{* * *} \\
(0.006)\end{array}$ & $\begin{array}{l}0.034^{* * *} \\
(0.006)\end{array}$ & $\begin{array}{l}0.032^{* * *} \\
(0.006)\end{array}$ & $\begin{array}{l}0.032^{* * *} \\
(0.006)\end{array}$ \\
\hline Origin Municip. Perc. (OMP) & $\begin{array}{l}-0.682^{* * *} \\
(0.032)\end{array}$ & $\begin{array}{l}-0.919^{* * *} \\
(0.011)\end{array}$ & $\begin{array}{l}-0.930^{* * *} \\
(0.010)\end{array}$ & $\begin{array}{l}-0.924^{* * *} \\
(0.010)\end{array}$ & $\begin{array}{l}-0.924^{* * *} \\
(0.010)\end{array}$ & $\begin{array}{l}-0.924^{* * *} \\
(0.010)\end{array}$ & $\begin{array}{l}-0.924^{* * *} \\
(0.010)\end{array}$ & $\begin{array}{l}-0.923^{* * *} \\
(0.009)\end{array}$ \\
\hline $\mathrm{OWP} * \mathrm{OMP}$ & $\begin{array}{l}-0.004 \\
(0.019)\end{array}$ & $\begin{array}{l}-0.013 \\
(0.013)\end{array}$ & $\begin{array}{l}0.004 \\
(0.011)\end{array}$ & $\begin{array}{l}-0.033^{* * *} \\
(0.009)\end{array}$ & $\begin{array}{l}-0.034^{* * *} \\
(0.009)\end{array}$ & $\begin{array}{l}-0.045^{* * *} \\
(0.009)\end{array}$ & $\begin{array}{l}-0.047^{* * *} \\
(0.009)\end{array}$ & $\begin{array}{l}-0.052^{* * *} \\
(0.010)\end{array}$ \\
\hline \multicolumn{9}{|l|}{ Controls } \\
\hline Pre-Move Log Wage & & & & & $\begin{array}{l}0.001 \\
(0.001)\end{array}$ & $\begin{array}{l}-0.003^{*} \\
(0.001)\end{array}$ & $\begin{array}{l}-0.002 \\
(0.001)\end{array}$ & $\begin{array}{l}-0.003^{*} \\
(0.001)\end{array}$ \\
\hline Post-Move Log Wage & & & & & & $\begin{array}{l}0.035^{* * *} \\
(0.002)\end{array}$ & $\begin{array}{l}0.035^{* * *} \\
(0.002)\end{array}$ & $\begin{array}{l}0.033^{* * *} \\
(0.002)\end{array}$ \\
\hline Post-Move Log Comm. Dist. & & & & & & & $\begin{array}{l}0.009^{* * *} \\
(0.001)\end{array}$ & $\begin{array}{l}-0.000 \\
(0.001)\end{array}$ \\
\hline $\begin{array}{l}\text { Post-Move Amenities Perc. } \\
\text { (First PC, other } 4 \text { unrep.) }\end{array}$ & & & & & & & & $\begin{array}{l}0.304^{* * *} \\
(0.012)\end{array}$ \\
\hline Constant & $\begin{array}{l}0.352^{* * *} \\
(0.014)\end{array}$ & & & & & & & \\
\hline \multicolumn{9}{|l|}{ Fixed effects } \\
\hline Origi Département \& Year & & $\checkmark$ & $\checkmark$ & $\checkmark$ & $\checkmark$ & $\checkmark$ & $\checkmark$ & $\checkmark$ \\
\hline Age, Birthplace \& Gender & & & $\checkmark$ & $\checkmark$ & $\checkmark$ & $\checkmark$ & $\checkmark$ & $\checkmark$ \\
\hline 2-Digit Origin Occ. \& Ind. & & & & $\checkmark$ & $\checkmark$ & $\checkmark$ & $\checkmark$ & $\checkmark$ \\
\hline Obs. & 292489 & 292489 & 292431 & 292428 & 292428 & 292428 & 270351 & 269914 \\
\hline$R^{2}$ & 0.349 & 0.409 & 0.417 & 0.422 & 0.422 & 0.427 & 0.431 & 0.493 \\
\hline W. $-R^{2}$ & & 0.376 & 0.378 & 0.382 & 0.382 & 0.387 & 0.391 & 0.457 \\
\hline
\end{tabular}

\section{D.8 Appendix: Robustness to Yearly City Ranks}

See Tables 22 and 23 , 
Table 15: Location decisions of the unemployed (40 days+) relative to job switchers

\begin{tabular}{|c|c|c|c|c|c|}
\hline $1[\mathrm{EUE}] * \mathrm{OWP}$ & $\begin{array}{l}0.011^{*} \\
(0.005)\end{array}$ & $\begin{array}{l}0.044^{* * *} \\
(0.013)\end{array}$ & $\begin{array}{l}0.050^{* * *} \\
(0.013)\end{array}$ & $\begin{array}{l}0.050^{* * *} \\
(0.014)\end{array}$ & $\begin{array}{l}0.023 \\
(0.015)\end{array}$ \\
\hline OWP & $\begin{array}{l}0.137^{* * *} \\
(0.007)\end{array}$ & $\begin{array}{l}0.310^{* * *} \\
(0.020)\end{array}$ & $\begin{array}{l}0.295^{* * *} \\
(0.019)\end{array}$ & $\begin{array}{l}0.294^{* * *} \\
(0.019)\end{array}$ & $\begin{array}{l}0.318^{* * *} \\
(0.021)\end{array}$ \\
\hline \multicolumn{6}{|l|}{ Controls } \\
\hline Pre-Move Log Wage (W0) & & $\begin{array}{l}-0.079^{* * *} \\
(0.004)\end{array}$ & $\begin{array}{l}-0.076^{* * *} \\
(0.005)\end{array}$ & $\begin{array}{l}-0.077^{* * *} \\
(0.005)\end{array}$ & $\begin{array}{l}-0.086^{* * *} \\
(0.005)\end{array}$ \\
\hline $1[\mathrm{EUE}] * \mathrm{~W} 0$ & & $\begin{array}{l}-0.005^{* *} \\
(0.002)\end{array}$ & $\begin{array}{l}-0.012^{* *} \\
(0.004)\end{array}$ & $\begin{array}{l}-0.010^{*} \\
(0.004)\end{array}$ & $\begin{array}{l}-0.002 \\
(0.005)\end{array}$ \\
\hline Post-Move Log Wage (W1) & & & $\begin{array}{l}0.018^{* * *} \\
(0.004)\end{array}$ & $\begin{array}{l}0.016^{* * *} \\
(0.004)\end{array}$ & $\begin{array}{l}0.011^{* *} \\
(0.004)\end{array}$ \\
\hline $1[\mathrm{EUE}] * \mathrm{~W} 1$ & & & $\begin{array}{l}0.005 \\
(0.004)\end{array}$ & $\begin{array}{l}0.005 \\
(0.003)\end{array}$ & $\begin{array}{l}0.009^{*} \\
(0.004)\end{array}$ \\
\hline Post-Move Log Comm. Dist. (C1) & & & & $\begin{array}{l}0.012^{* * *} \\
(0.003)\end{array}$ & $\begin{array}{l}0.002 \\
(0.002)\end{array}$ \\
\hline $1[\mathrm{EUE}] * \mathrm{C} 1$ & & & & $\begin{array}{l}-0.002 \\
(0.002)\end{array}$ & $\begin{array}{l}-0.002 \\
(0.002)\end{array}$ \\
\hline $\begin{array}{l}\text { Post-Move Amenities Percentile } \\
\text { (A1, First PC, other } 4 \text { unreported) }\end{array}$ & & & & & $\begin{array}{l}0.320^{* * *} \\
(0.017)\end{array}$ \\
\hline $\begin{array}{l}1[\mathrm{EUE}] * \mathrm{~A} 1 \\
\text { (other } 4 \text { interactions unreported) }\end{array}$ & & & & & $\begin{array}{l}-0.030^{*} \\
(0.013)\end{array}$ \\
\hline \multicolumn{6}{|l|}{ Fixed Effects } \\
\hline Origin Département \& Year & $\checkmark$ & $\checkmark$ & $\checkmark$ & $\checkmark$ & $\checkmark$ \\
\hline Age, Birthplace \& Gender & $\checkmark$ & $\checkmark$ & $\checkmark$ & $\checkmark$ & $\checkmark$ \\
\hline 2-Digit Origin Occupation \& Industry & $\checkmark$ & $\checkmark$ & $\checkmark$ & $\checkmark$ & $\checkmark$ \\
\hline Obs. & 308123 & 308123 & 308123 & 284827 & 284369 \\
\hline$R^{2}$ & 0.075 & 0.088 & 0.090 & 0.093 & 0.154 \\
\hline W.- $R^{2}$ & 0.010 & 0.024 & 0.026 & 0.029 & 0.095 \\
\hline
\end{tabular}

Table 16: Unemployment spells and location decisions using Forecasting Method assets: IV

\begin{tabular}{|c|c|c|c|c|c|c|c|c|}
\hline Origin Asset Perc. (OAP) & $\begin{array}{l}0.160^{* * *} \\
(0.010)\end{array}$ & $\begin{array}{l}0.160^{* * *} \\
(0.009)\end{array}$ & $\begin{array}{l}0.212^{* * *} \\
(0.008)\end{array}$ & $\begin{array}{l}0.281^{* * *} \\
(0.011)\end{array}$ & $\begin{array}{l}0.913^{* * *} \\
(0.044)\end{array}$ & $\begin{array}{l}0.907^{* * *} \\
(0.045)\end{array}$ & $\begin{array}{l}0.908^{* * *} \\
(0.045)\end{array}$ & $\begin{array}{l}0.903^{* * *} \\
(0.046)\end{array}$ \\
\hline \multicolumn{9}{|l|}{ Controls } \\
\hline Pre-Move Log Wage & & & & & $\begin{array}{l}-0.136^{* * *} \\
(0.007)\end{array}$ & $\begin{array}{l}-0.136^{* * *} \\
(0.007)\end{array}$ & $\begin{array}{l}-0.136^{* * *} \\
(0.007)\end{array}$ & $\begin{array}{l}-0.137^{* * *} \\
(0.007)\end{array}$ \\
\hline Post-Move Log Wage & & & & & & $\begin{array}{l}0.006^{* *} \\
(0.002)\end{array}$ & $\begin{array}{l}0.006^{*} \\
(0.002)\end{array}$ & $\begin{array}{l}0.004 \\
(0.002)\end{array}$ \\
\hline Post-Move Log Comm. Dist. & & & & & & & $\begin{array}{l}0.008^{* * *} \\
(0.001)\end{array}$ & $\begin{array}{l}-0.000 \\
(0.001)\end{array}$ \\
\hline $\begin{array}{l}\text { Post-Move Amenities Perc. } \\
\text { (First PC, other } 4 \text { unrep.) }\end{array}$ & & & & & & & & $\begin{array}{l}0.286^{* * *} \\
(0.013)\end{array}$ \\
\hline Constant & $\begin{array}{l}-0.089^{* * *} \\
(0.007)\end{array}$ & & & & & & & \\
\hline \multicolumn{9}{|l|}{ Fixed effects } \\
\hline Origin Département \& Year & & $\checkmark$ & $\checkmark$ & $\checkmark$ & $\checkmark$ & $\checkmark$ & $\checkmark$ & $\checkmark$ \\
\hline Age, Birthplace \& Gender & & & $\checkmark$ & $\checkmark$ & $\checkmark$ & $\checkmark$ & $\checkmark$ & $\checkmark$ \\
\hline 2-Digit Origin Occ. \& Ind. & & & & $\checkmark$ & $\checkmark$ & $\checkmark$ & $\checkmark$ & $\checkmark$ \\
\hline Obs. & 292489 & 292489 & 292431 & 292428 & 292428 & 292428 & 270351 & 269914 \\
\hline
\end{tabular}


Table 17: Unemployment spells and location decisions using Perfect Foresight Method assets: IV

Mobility of the unemployed. Movers only. Fixed city rank. Perfect foresight method. Instrumental variables.

\begin{tabular}{|c|c|c|c|c|c|c|c|c|}
\hline Origin Asset Perc. (OAP) & $\begin{array}{l}0.171^{* * *} \\
(0.010)\end{array}$ & $\begin{array}{l}0.171^{* * *} \\
(0.009)\end{array}$ & $\begin{array}{l}0.274^{* * *} \\
(0.010)\end{array}$ & $\begin{array}{l}0.333^{* * *} \\
(0.012)\end{array}$ & $\begin{array}{l}1.105^{* * *} \\
(0.051)\end{array}$ & $\begin{array}{l}1.016^{* * *} \\
(0.048)\end{array}$ & $\begin{array}{l}1.010^{* * *} \\
(0.048)\end{array}$ & $\begin{array}{l}1.006^{* * *} \\
(0.048)\end{array}$ \\
\hline \multicolumn{9}{|l|}{ Controls } \\
\hline Pre-Move Log Wage & & & & & $\begin{array}{l}-0.140^{* * *} \\
(0.007)\end{array}$ & $\begin{array}{l}-0.146^{* * *} \\
(0.007)\end{array}$ & $\begin{array}{l}-0.145^{* * *} \\
(0.007)\end{array}$ & $\begin{array}{l}-0.146^{* * *} \\
(0.007)\end{array}$ \\
\hline Post-Move Log Wage & & & & & & $\begin{array}{l}0.073^{* * *} \\
(0.003)\end{array}$ & $\begin{array}{l}0.072^{* * *} \\
(0.003)\end{array}$ & $\begin{array}{l}0.070^{* * *} \\
(0.003)\end{array}$ \\
\hline Post-Move Log Comm. Dist. & & & & & & & $\begin{array}{l}0.010^{* * *} \\
(0.002)\end{array}$ & $\begin{array}{l}0.003^{* *} \\
(0.001)\end{array}$ \\
\hline $\begin{array}{l}\text { Post-Move Amenities Perc. } \\
\text { (First PC, other } 4 \text { unrep.) }\end{array}$ & & & & & & & & $\begin{array}{l}0.270^{* * *} \\
(0.013)\end{array}$ \\
\hline Constant & $\begin{array}{l}-0.088^{* * *} \\
(0.007)\end{array}$ & & & & & & & \\
\hline \multicolumn{9}{|l|}{ Fixed effects } \\
\hline Origin Département \& Year & & $\checkmark$ & $\checkmark$ & $\checkmark$ & $\checkmark$ & $\checkmark$ & $\checkmark$ & $\checkmark$ \\
\hline Age, Birthplace \& Gender & & & $\checkmark$ & $\checkmark$ & $\checkmark$ & $\checkmark$ & $\checkmark$ & $\checkmark$ \\
\hline 2-Digit Origin Occ. \& Ind. & & & & $\checkmark$ & $\checkmark$ & $\checkmark$ & $\checkmark$ & $\checkmark$ \\
\hline Obs. & 292489 & 292489 & 292431 & 292428 & 292428 & 292428 & 270351 & 269914 \\
\hline
\end{tabular}

Table 18: Unemployment spells and location decisions using Forecasting Method assets: IV and heterogenous effects across municipalities

Movers only. Fixed city rank. Instrumental variables.

\begin{tabular}{|c|c|c|c|c|c|c|c|c|}
\hline Origin Asset Perc. (OAP) & $\begin{array}{l}0.133^{* * *} \\
(0.013)\end{array}$ & $\begin{array}{l}0.122^{* * *} \\
(0.009)\end{array}$ & $\begin{array}{l}0.124^{* * *} \\
(0.009)\end{array}$ & $\begin{array}{l}0.090^{* * *} \\
(0.010)\end{array}$ & $\begin{array}{l}0.102^{* * *} \\
(0.014)\end{array}$ & $\begin{array}{l}0.068^{* * *} \\
(0.013)\end{array}$ & $\begin{array}{l}0.060^{* * *} \\
(0.014)\end{array}$ & $\begin{array}{l}0.057^{* * *} \\
(0.014)\end{array}$ \\
\hline $\mathrm{OAP} * \mathrm{OMP}$ & $\begin{array}{l}-0.027 \\
(0.028)\end{array}$ & $\begin{array}{l}-0.039^{*} \\
(0.019)\end{array}$ & $\begin{array}{l}-0.015 \\
(0.015)\end{array}$ & $\begin{array}{l}-0.060^{* * *} \\
(0.014)\end{array}$ & $\begin{array}{l}-0.060^{* * *} \\
(0.015)\end{array}$ & $\begin{array}{l}-0.073^{* * *} \\
(0.014)\end{array}$ & $\begin{array}{l}-0.075^{* * *} \\
(0.014)\end{array}$ & $\begin{array}{l}-0.082^{* * *} \\
(0.015)\end{array}$ \\
\hline Origin Municipality Perc. (OMP) & $\begin{array}{l}-0.666^{* * *} \\
(0.038)\end{array}$ & $\begin{array}{l}-0.904^{* * *} \\
(0.015)\end{array}$ & $\begin{array}{l}-0.920^{* * *} \\
(0.014)\end{array}$ & $\begin{array}{l}-0.904^{* * *} \\
(0.013)\end{array}$ & $\begin{array}{l}-0.903^{* * *} \\
(0.013)\end{array}$ & $\begin{array}{l}-0.902^{* * *} \\
(0.013)\end{array}$ & $\begin{array}{l}-0.902^{* * *} \\
(0.013)\end{array}$ & $\begin{array}{l}-0.900^{* * *} \\
(0.012)\end{array}$ \\
\hline \multicolumn{9}{|l|}{ Controls } \\
\hline Pre-Move Log Wage & & & & & $\begin{array}{l}-0.003 \\
(0.002)\end{array}$ & $\begin{array}{l}-0.004^{*} \\
(0.002)\end{array}$ & $\begin{array}{l}-0.003 \\
(0.002)\end{array}$ & $\begin{array}{l}-0.004 \\
(0.002)\end{array}$ \\
\hline Post-Move Log Wage & & & & & & $\begin{array}{l}0.035^{* * *} \\
(0.002)\end{array}$ & $\begin{array}{l}0.034^{* * *} \\
(0.002)\end{array}$ & $\begin{array}{l}0.032^{* * *} \\
(0.002)\end{array}$ \\
\hline Post-Move Log Com. Dist. & & & & & & & $\begin{array}{l}0.009^{* * *} \\
(0.001)\end{array}$ & $\begin{array}{l}-0.000 \\
(0.001)\end{array}$ \\
\hline $\begin{array}{l}\text { Post-Move Amenities Perc. } \\
\text { (First PC, next } 4 \text { unrep.) }\end{array}$ & & & & & & & & $\begin{array}{l}0.304^{* * *} \\
(0.012)\end{array}$ \\
\hline Constant & $\begin{array}{l}0.309^{* * *} \\
(0.016)\end{array}$ & & & & & & & \\
\hline \multicolumn{9}{|l|}{ Fixed effects } \\
\hline Origin Département \& Year & & $\checkmark$ & $\checkmark$ & $\checkmark$ & $\checkmark$ & $\checkmark$ & $\checkmark$ & $\checkmark$ \\
\hline Age, Birthplace \& Gender & & & $\checkmark$ & $\checkmark$ & $\checkmark$ & $\checkmark$ & $\checkmark$ & $\checkmark$ \\
\hline 2-Digit Origin Occ. \& Ind. & & & & $\checkmark$ & $\checkmark$ & $\checkmark$ & $\checkmark$ & $\checkmark$ \\
\hline Obs. & 292489 & 292489 & 292431 & 292428 & 292428 & 292428 & 270351 & 269914 \\
\hline
\end{tabular}


Table 19: Unemployment spells and location decisions using Perfect Foresight Method assets: IV.

\begin{tabular}{|c|c|c|c|c|c|c|c|c|}
\hline Origin Asset Perc. (OAP) & $\begin{array}{l}0.171^{* * *} \\
(0.010)\end{array}$ & $\begin{array}{l}0.106^{* * *} \\
(0.006)\end{array}$ & $\begin{array}{l}0.154^{* * *} \\
(0.006)\end{array}$ & $\begin{array}{l}0.081^{* * *} \\
(0.006)\end{array}$ & $\begin{array}{l}0.165^{* * *} \\
(0.017)\end{array}$ & $\begin{array}{l}0.091^{* * *} \\
(0.017)\end{array}$ & $\begin{array}{l}0.076^{* * *} \\
(0.016)\end{array}$ & $\begin{array}{l}0.066^{* * *} \\
(0.016)\end{array}$ \\
\hline \multicolumn{9}{|l|}{ Controls } \\
\hline Pre-Move Log Wage & & & & & $\begin{array}{l}-0.014^{* * *} \\
(0.002)\end{array}$ & $\begin{array}{l}-0.013^{* * *} \\
(0.002)\end{array}$ & $\begin{array}{l}-0.011^{* * *} \\
(0.002)\end{array}$ & $\begin{array}{l}-0.011^{* * *} \\
(0.002)\end{array}$ \\
\hline Post-Move Log Wage & & & & & & $\begin{array}{l}0.039^{* * *} \\
(0.002)\end{array}$ & $\begin{array}{l}0.037^{* * *} \\
(0.002)\end{array}$ & $\begin{array}{l}0.035^{* * *} \\
(0.002)\end{array}$ \\
\hline Post-Move Log Comm. Dist. & & & & & & & $\begin{array}{l}0.008^{* * *} \\
(0.001)\end{array}$ & $\begin{array}{l}-0.000 \\
(0.001)\end{array}$ \\
\hline $\begin{array}{l}\text { Post-Move Amenities Perc. } \\
\text { (First PC, other } 4 \text { unrep.) }\end{array}$ & & & & & & & & $\begin{array}{l}0.307^{* * *} \\
(0.012)\end{array}$ \\
\hline Constant & $\begin{array}{l}-0.088^{* * *} \\
(0.007)\end{array}$ & & & & & & & \\
\hline \multicolumn{9}{|l|}{ Fixed effects } \\
\hline Origin Municipality \& Year & & $\checkmark$ & $\checkmark$ & $\checkmark$ & $\checkmark$ & $\checkmark$ & $\checkmark$ & $\checkmark$ \\
\hline Age, Birthplace \& Gender & & & $\checkmark$ & $\checkmark$ & $\checkmark$ & $\checkmark$ & $\checkmark$ & $\checkmark$ \\
\hline 2-Digit Origin Occ. \& Ind. & & & & $\checkmark$ & $\checkmark$ & $\checkmark$ & $\checkmark$ & $\checkmark$ \\
\hline Obs. & 292489 & 287453 & 287394 & 287391 & 287391 & 287391 & 265056 & 264604 \\
\hline
\end{tabular}

Table 20: Unemployment spells and location decisions using Forecasting Method assets in declining municipalities only: OLS.

Movers only. Fixed City Rank. Declining municipalities only $(<\mathrm{P} 25=-0.4 \%)$.

\begin{tabular}{|c|c|c|c|c|c|c|c|c|}
\hline Origin Asset Perc. (OAP) & $\begin{array}{l}0.074^{* * *} \\
(0.008)\end{array}$ & $\begin{array}{l}0.056^{* * *} \\
(0.007)\end{array}$ & $\begin{array}{l}0.056^{* * *} \\
(0.008)\end{array}$ & $\begin{array}{l}0.056^{* * *} \\
(0.008)\end{array}$ & $\begin{array}{l}0.064^{* * *} \\
(0.010)\end{array}$ & $\begin{array}{l}0.059^{* * *} \\
(0.009)\end{array}$ & $\begin{array}{l}0.059^{* * *} \\
(0.010)\end{array}$ & $\begin{array}{l}0.056^{* * *} \\
(0.010)\end{array}$ \\
\hline \multicolumn{9}{|l|}{ Controls } \\
\hline Pre-Move Log Wage & & & & & $\begin{array}{r}-0.007^{*} \\
(0.004)\end{array}$ & $\begin{array}{l}-0.013^{* * *} \\
(0.004)\end{array}$ & $\begin{array}{l}-0.013^{* * *} \\
(0.004)\end{array}$ & $\begin{array}{l}-0.016^{* * *} \\
(0.003)\end{array}$ \\
\hline Post-Move Log Wage & & & & & & $\begin{array}{l}0.026^{* * *} \\
(0.004)\end{array}$ & $\begin{array}{l}0.027^{* * *} \\
(0.004)\end{array}$ & $\begin{array}{l}0.027^{* * *} \\
(0.004)\end{array}$ \\
\hline Post-Move Log Comm. Dist. & & & & & & & $\begin{array}{l}0.012^{* * *} \\
(0.001)\end{array}$ & $\begin{array}{l}0.003^{*} \\
(0.001)\end{array}$ \\
\hline $\begin{array}{l}\text { Post-Move Amenities Perc. } \\
\text { (First PC, other } 4 \text { unrep.) }\end{array}$ & & & & & & & & $\begin{array}{l}0.245^{* * *} \\
(0.015)\end{array}$ \\
\hline Constant & $\begin{array}{l}-0.047^{* *} \\
(0.017)\end{array}$ & & & & & & & \\
\hline \multicolumn{9}{|l|}{ Fixed Effects } \\
\hline Origin Département \& Year & & $\checkmark$ & $\checkmark$ & $\checkmark$ & $\checkmark$ & $\checkmark$ & $\checkmark$ & $\checkmark$ \\
\hline Age, Birthplace \& Gender & & & $\checkmark$ & $\checkmark$ & $\checkmark$ & $\checkmark$ & $\checkmark$ & $\checkmark$ \\
\hline 2-Digit Origin Occ. \& Ind. & & & & $\checkmark$ & $\checkmark$ & $\checkmark$ & $\checkmark$ & $\checkmark$ \\
\hline Obs. & 26195 & 26195 & 26187 & 26186 & 26186 & 26186 & 24077 & 24021 \\
\hline$R^{2}$ & 0.004 & 0.097 & 0.111 & 0.115 & 0.116 & 0.118 & 0.123 & 0.185 \\
\hline W.- $R^{2}$ & & 0.003 & 0.002 & 0.002 & 0.002 & 0.005 & 0.010 & 0.079 \\
\hline
\end{tabular}


Table 21: Unemployment spells and location decisions using Forecasting Method assets in declinning municipalities only: IV.

Movers only. Fixed City Rank. IV. Declining municipalities only $(<\mathrm{P} 25=-0.4 \%)$.

\begin{tabular}{|c|c|c|c|c|c|c|c|c|}
\hline Origin Asset Perc. (OAP) & $\begin{array}{l}0.166^{* * *} \\
(0.014)\end{array}$ & $\begin{array}{l}0.092^{* * *} \\
(0.013)\end{array}$ & $\begin{array}{l}0.107^{* * *} \\
(0.014)\end{array}$ & $\begin{array}{l}0.072^{* * *} \\
(0.014)\end{array}$ & $\begin{array}{l}0.132^{* * *} \\
(0.039)\end{array}$ & $\begin{array}{l}0.095^{*} \\
(0.039)\end{array}$ & $\begin{array}{l}0.072^{+} \\
(0.041)\end{array}$ & $\begin{array}{l}0.080^{*} \\
(0.038)\end{array}$ \\
\hline \multicolumn{9}{|l|}{ Controls } \\
\hline Pre-Move Log Wage & & & & & $\begin{array}{l}-0.012 \\
(0.007)\end{array}$ & $\begin{array}{c}-0.014^{*} \\
(0.007)\end{array}$ & $\begin{array}{l}-0.010 \\
(0.007)\end{array}$ & $\begin{array}{l}-0.015^{*} \\
(0.006)\end{array}$ \\
\hline Post-Move Log Wage & & & & & & $\begin{array}{l}0.029^{* * *} \\
(0.003)\end{array}$ & $\begin{array}{l}0.030^{* * *} \\
(0.003)\end{array}$ & $\begin{array}{l}0.030^{* * *} \\
(0.003)\end{array}$ \\
\hline Post-Move Log Comm. Dist. & & & & & & & $\begin{array}{l}0.008^{* * *} \\
(0.002)\end{array}$ & $\begin{array}{l}-0.000 \\
(0.001)\end{array}$ \\
\hline $\begin{array}{l}\text { Post-Move Amenities Perc. } \\
\text { (First PC, other } 4 \text { unrep.) }\end{array}$ & & & & & & & & $\begin{array}{l}0.267^{* * *} \\
(0.015)\end{array}$ \\
\hline Constant & $\begin{array}{l}-0.100^{* * *} \\
(0.014)\end{array}$ & & & & & & & \\
\hline \multicolumn{9}{|l|}{ Fixed Effects } \\
\hline Origin Municipality \& Year & & $\checkmark$ & $\checkmark$ & $\checkmark$ & $\checkmark$ & $\checkmark$ & $\checkmark$ & $\checkmark$ \\
\hline Age, Birthplace \& Gender & & & $\checkmark$ & $\checkmark$ & $\checkmark$ & $\checkmark$ & $\checkmark$ & $\checkmark$ \\
\hline 2-Digit Origin Occ. \& Ind. & & & & $\checkmark$ & $\checkmark$ & $\checkmark$ & $\checkmark$ & $\checkmark$ \\
\hline Obs. & 26195 & 22739 & 22731 & 22729 & 22729 & 22729 & 20697 & 20645 \\
\hline
\end{tabular}

Table 22: Unemployment and location decisions using yearly city rank

\begin{tabular}{|c|c|c|c|c|c|c|c|c|}
\hline Origin Wage Perc. (OWP) & $\begin{array}{l}0.106^{* * *} \\
(0.006)\end{array}$ & $\begin{array}{l}0.107^{* * *} \\
(0.005)\end{array}$ & $\begin{array}{l}0.124^{* * *} \\
(0.004)\end{array}$ & $\begin{array}{l}0.155^{* * *} \\
(0.006)\end{array}$ & $\begin{array}{l}0.372^{* * *} \\
(0.017)\end{array}$ & $\begin{array}{l}0.362^{* * *} \\
(0.017)\end{array}$ & $\begin{array}{l}0.361^{* * *} \\
(0.017)\end{array}$ & $\begin{array}{l}0.358^{* * *} \\
(0.017)\end{array}$ \\
\hline \multicolumn{9}{|l|}{ Controls } \\
\hline Pre-Move Log Wage & & & & & $\begin{array}{l}-0.089^{* * *} \\
(0.004)\end{array}$ & $\begin{array}{l}-0.092^{* * *} \\
(0.004)\end{array}$ & $\begin{array}{l}-0.092^{* * *} \\
(0.004)\end{array}$ & $\begin{array}{l}-0.093^{* * *} \\
(0.004)\end{array}$ \\
\hline Post-Move Log Wage & & & & & & $\begin{array}{l}0.025^{* * *} \\
(0.002)\end{array}$ & $\begin{array}{l}0.024^{* * *} \\
(0.002)\end{array}$ & $\begin{array}{l}0.022^{* * *} \\
(0.002)\end{array}$ \\
\hline Post-Move Log Comm. Dist. & & & & & & & $\begin{array}{l}0.010^{* * *} \\
(0.002)\end{array}$ & $\begin{array}{l}0.001 \\
(0.001)\end{array}$ \\
\hline $\begin{array}{l}\text { Post-Move Amenities Perc. } \\
\text { (First PC, other } 4 \text { unrep.) }\end{array}$ & & & & & & & & $\begin{array}{l}0.315^{* * *} \\
(0.012)\end{array}$ \\
\hline Constant & $\begin{array}{l}-0.042^{* * *} \\
(0.009)\end{array}$ & & & & & & & \\
\hline \multicolumn{9}{|l|}{ Fixed Effects } \\
\hline Origin Département \& Year & & $\checkmark$ & $\checkmark$ & $\checkmark$ & $\checkmark$ & $\checkmark$ & $\checkmark$ & $\checkmark$ \\
\hline Age, Birthplace \& Gender & & & $\checkmark$ & $\checkmark$ & $\checkmark$ & $\checkmark$ & $\checkmark$ & $\checkmark$ \\
\hline 2-Digit Origin Occ. \& Ind. & & & & $\checkmark$ & $\checkmark$ & $\checkmark$ & $\checkmark$ & $\checkmark$ \\
\hline Obs. & 291495 & 291495 & 291437 & 291434 & 291434 & 291434 & 269496 & 269239 \\
\hline$R^{2}$ & 0.009 & 0.063 & 0.074 & 0.077 & 0.092 & 0.094 & 0.098 & 0.167 \\
\hline W.- $R^{2}$ & & 0.009 & 0.010 & 0.011 & 0.027 & 0.029 & 0.033 & 0.107 \\
\hline
\end{tabular}


Table 23: Unemployment and location decisions using the forecasting method and yearly city rank.

Yearly city rank. Movers only. Forecasting method.

\begin{tabular}{|c|c|c|c|c|c|c|c|c|}
\hline Origin Asset Perc. (OAP) & $\begin{array}{l}0.086^{* * *} \\
(0.004)\end{array}$ & $\begin{array}{l}0.076^{* * *} \\
(0.003)\end{array}$ & $\begin{array}{l}0.079^{* * *} \\
(0.004)\end{array}$ & $\begin{array}{l}0.081^{* * *} \\
(0.005)\end{array}$ & $\begin{array}{l}0.101^{* * *} \\
(0.007)\end{array}$ & $\begin{array}{l}0.094^{* * *} \\
(0.006)\end{array}$ & $\begin{array}{l}0.094^{* * *} \\
(0.006)\end{array}$ & $\begin{array}{l}0.089^{* * *} \\
(0.007)\end{array}$ \\
\hline \multicolumn{9}{|l|}{ Controls } \\
\hline Pre-Move Log Wage & & & & & $\begin{array}{l}-0.015^{* * *} \\
(0.001)\end{array}$ & $\begin{array}{l}-0.021^{* * *} \\
(0.001)\end{array}$ & $\begin{array}{l}-0.021^{* * *} \\
(0.001)\end{array}$ & $\begin{array}{l}-0.023^{* * *} \\
(0.001)\end{array}$ \\
\hline Post-Move Log Wage & & & & & & $\begin{array}{l}0.029^{* * *} \\
(0.002)\end{array}$ & $\begin{array}{l}0.028^{* * *} \\
(0.002)\end{array}$ & $\begin{array}{l}0.026^{* * *} \\
(0.002)\end{array}$ \\
\hline Post-Move Log Comm. Dist. & & & & & & & $\begin{array}{l}0.011^{* * *} \\
(0.002)\end{array}$ & $\begin{array}{l}0.001 \\
(0.001)\end{array}$ \\
\hline $\begin{array}{l}\text { Post-Move Amenities Perc. } \\
\text { (First PC, other } 4 \text { unrep.) }\end{array}$ & & & & & & & & $\begin{array}{l}0.313^{* * *} \\
(0.012)\end{array}$ \\
\hline Constant & $\begin{array}{l}-0.041^{* * *} \\
(0.012)\end{array}$ & & & & & & & \\
\hline \multicolumn{9}{|l|}{ Fixed Effects } \\
\hline Origin Département \& Year & & $\checkmark$ & $\checkmark$ & $\checkmark$ & $\checkmark$ & $\checkmark$ & $\checkmark$ & $\checkmark$ \\
\hline Age, Birthplace \& Gender & & & $\checkmark$ & $\checkmark$ & $\checkmark$ & $\checkmark$ & $\checkmark$ & $\checkmark$ \\
\hline 2-Digit Origin Occ. \& Ind. & & & & $\checkmark$ & $\checkmark$ & $\checkmark$ & $\checkmark$ & $\checkmark$ \\
\hline Obs. & 291495 & 291495 & 291437 & 291434 & 291434 & 291434 & 269496 & 269239 \\
\hline$R^{2}$ & 0.005 & 0.058 & 0.068 & 0.071 & 0.071 & 0.075 & 0.078 & 0.148 \\
\hline W.- $R^{2}$ & & 0.004 & 0.004 & 0.004 & 0.005 & 0.008 & 0.012 & 0.086 \\
\hline
\end{tabular}

22,180 Origin Municipalities; 2002-2007. Standard errors in parenthesis.

${ }^{*} p<0.05,{ }^{* *} p<0.01,{ }^{* * *} p<0.001$. SEs clustered at the department level. 